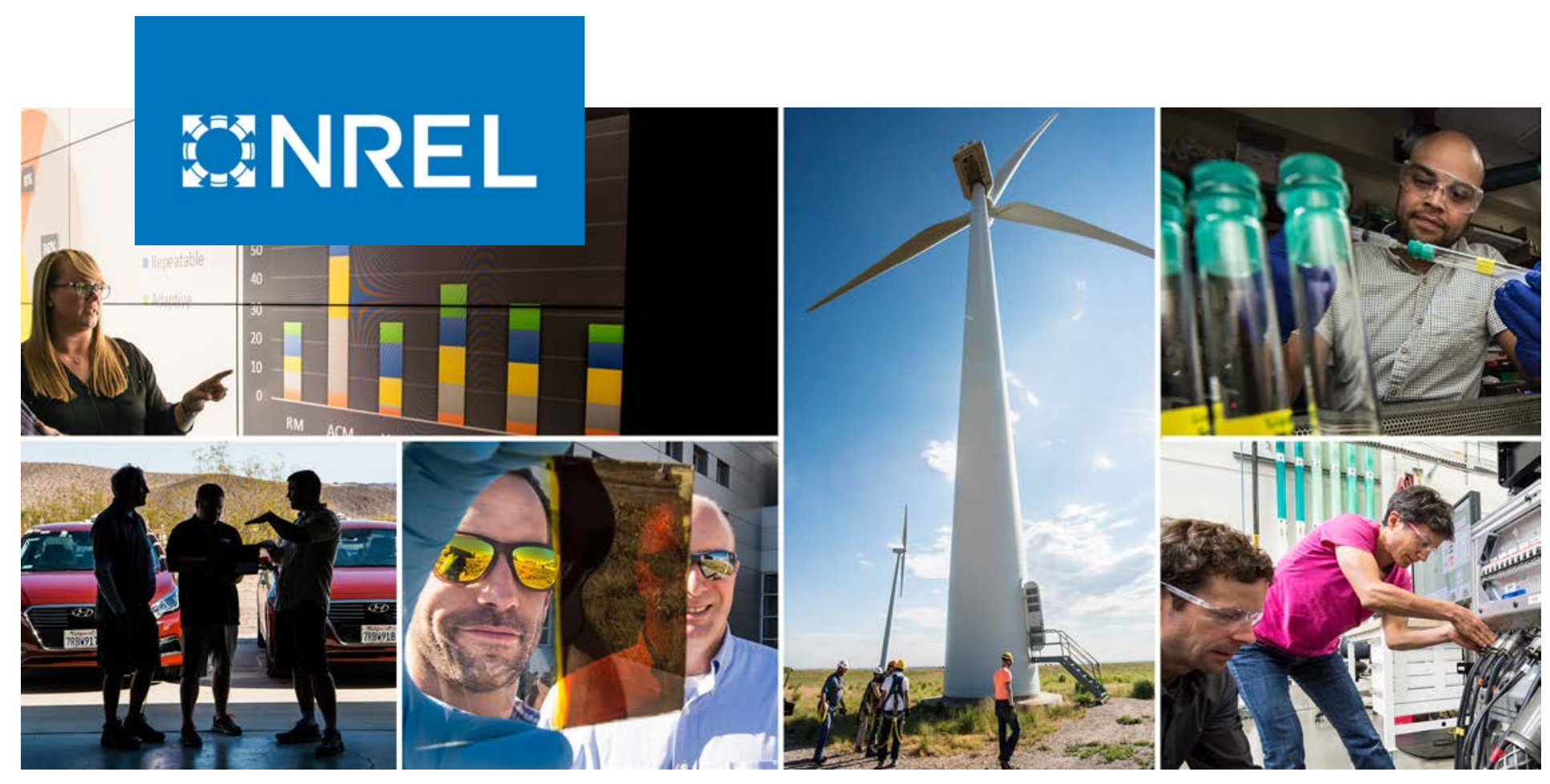

\title{
Mobility Data and Models Informing Smart Cities
}

Joshua Sperling, ${ }^{1}$ Stanley Young, ${ }^{1}$ Venu Garikapati, ${ }^{1}$ Andrew Duvall, ${ }^{1}$ and John M. Beck ${ }^{2}$

1 National Renewable Energy Laboratory

2 Idaho National Laboratory

NREL is a national laboratory of the U.S. Department of Energy

Office of Energy Efficiency \& Renewable Energy

Operated by the Alliance for Sustainable Energy, LLC

This report is available at no cost from the National Renewable Energy Laboratory (NREL) at www.nrel.gov/publications.

\section{Technical Report}

NREL/TP-5400-70734

October 2019 


\title{
GNREL
}

\section{Mobility Data and Models Informing Smart Cities}

\author{
Joshua Sperling, ${ }^{1}$ Stanley Young, ${ }^{1}$ Venu Garikapati, ${ }^{1}$ \\ Andrew Duvall, ${ }^{1}$ and John M. Beck ${ }^{2}$
}

\author{
1 National Renewable Energy Laboratory \\ 2 Idaho National Laboratory
}

\section{Suggested Citation}

Sperling, Joshua, Stanley Young, Venu Garikapati, Andrew Duvall, and John M. Beck. 2019. Mobility Data and Models Informing Smart Cities. Golden, CO: National Renewable Energy Laboratory. NREL/TP-5400-70734. https://www.nrel.gov/docs/fy20osti/70734.pdf.

NREL is a national laboratory of the U.S. Department of Energy Office of Energy Efficiency \& Renewable Energy Operated by the Alliance for Sustainable Energy, LLC

This report is available at no cost from the National Renewable Energy Laboratory (NREL) at www.nrel.gov/publications.

Contract No. DE-AC36-08GO28308
Technical Report NREL/TP-5400-70734 October 2019

National Renewable Energy Laboratory 15013 Denver West Parkway Golden, CO 80401

303-275-3000 • www.nrel.gov 


\section{NOTICE}

This work was authored in part by the National Renewable Energy Laboratory, operated by Alliance for Sustainable Energy, LLC, for the U.S. Department of Energy (DOE) under Contract No. DE-AC36-08GO28308. Funding was provided by the DOE Vehicle Technologies Office (VTO) under the Systems and Modeling for Accelerated Research in Transportation (SMART) Mobility Laboratory Consortium, an initiative of the Energy Efficient Mobility Systems (EEMS) Program. The authors would particularly like to thank David Anderson with DOE's Office of Energy Efficiency and Renewable Energy (EERE) for providing ongoing guidance and support. The views expressed in the article do not necessarily represent the views of the DOE or the U.S. Government.

This report is available at no cost from the National Renewable Energy Laboratory (NREL) at www.nrel.gov/publications.

U.S. Department of Energy (DOE) reports produced after 1991 and a growing number of pre-1991 documents are available free via www.OSTI.gov.

Cover Photos by Dennis Schroeder: (clockwise, left to right) NREL 51934, NREL 45897, NREL 42160, NREL 45891, NREL 48097, NREL 46526.

NREL prints on paper that contains recycled content. 


\section{Foreword}

The U.S. Department of Energy's Energy Efficient Mobility Systems (EEMS) Program envisions an affordable, efficient, safe, and accessible transportation future in which mobility is decoupled from energy consumption. The EEMS Program conducts early-stage research and development at the vehicle, traveler, and system levels, creating new knowledge, tools, insights, and technology solutions that increase mobility energy productivity for individuals and businesses.

The Systems and Modeling for Accelerated Research in Transportation (SMART) Mobility Consortium (Consortium) is a multi-year, multi-laboratory collaborative dedicated to further understanding the energy implications and opportunities of advanced mobility solutions. The Consortium is the EEMS Program's primary effort to create tools and generate knowledge about how future mobility systems may evolve and identify ways to reduce their energy intensity. It also identifies research and development gaps that the EEMS Program may address through its advanced research portfolio and generate insights that will be shared with mobility stakeholders.

The Consortium consists of five focused pillars of research: Connected and Automated Vehicles, Mobility Decision Science, Multi-Modal Transport, Urban Science, and Advanced Fueling Infrastructure. This report was developed as part of the Urban Science Pillar that aims to evaluate the intersection of transportation networks and the built environment in terms of energy opportunities. 


\section{Acknowledgements}

The authors would also like to acknowledge that this report was informed by ongoing exchange with the seven U.S. Department of Transportation Smart City finalists and their partners. The Kansas City Mid-America Regional Council (MARC) Summary includes material that was written and gathered by Ben Sims at Los Alamos National Laboratory. Special thanks go out to Metropolitan Planning Organization (MPO) representatives from the seven Smart Cities for their help and support in developing the material for this report.

The authors would also like to thank Joanne Wendelberger (Los Alamos National Laboratory) and Sean Qian (Carnegie Mellon University) for their independent review of the report and providing valuable comments. 


\section{List of Acronyms}

\begin{tabular}{|c|c|}
\hline ABM & activity-based model \\
\hline ACES & automated, connected, electric, and shared \\
\hline API & application programming interfaces \\
\hline AV & automated vehicle \\
\hline CAMPO & Capital Area Metropolitan Planning Organization \\
\hline CAV & connected and automated vehicle \\
\hline CDOT & Colorado Department of Transportation \\
\hline CMU & Carnegie Mellon University \\
\hline DOE & U.S. Department of Energy \\
\hline DOMI & Department of Mobility and Infrastructure \\
\hline DOT & Department of Transportation \\
\hline DRCOG & Denver Regional Council of Governments \\
\hline DTA & dynamic traffic assignment \\
\hline EDM & enterprise data management \\
\hline EEMS & Energy Efficient Mobility Systems \\
\hline EPA & U.S. Environmental Protection Agency \\
\hline $\mathrm{EV}$ & electric vehicle \\
\hline GHG & greenhouse gas \\
\hline IDE & integrated data exchange \\
\hline ITS & Intelligent Transportation System \\
\hline MARC & Mid-America Regional Council \\
\hline MCBI & Mobility Choice Blueprint Initiative \\
\hline MORPC & Mid-Ohio Regional Planning Commission \\
\hline MOVES & Motor Vehicle Emission Simulator \\
\hline MPO & Metropolitan Planning Organization \\
\hline RTD & Regional Transit District \\
\hline $\mathrm{SCF}$ & Smart City challenge finalist \\
\hline SCOS & Smart Columbus Operation System \\
\hline SFCTA & San Francisco County Transportation Authority \\
\hline SFMTA & San Francisco Municipal Transportation Agency \\
\hline SMART & Systems and Modeling for Accelerated Research in Transportation \\
\hline SMLC & SMART Mobility Laboratory Consortium \\
\hline SPC & Southern Pennsylvania Commission \\
\hline TABOR & Taxpayer's Bill of Rights \\
\hline TDM & travel demand model \\
\hline $\mathrm{TNC}$ & transportation network company \\
\hline TTI & Texas Transportation Institute \\
\hline VMT & vehicle miles traveled \\
\hline WPRDC & Western Pennsylvania Regional Data Center \\
\hline
\end{tabular}




\section{Executive Summary}

Using emerging data platforms, new mobility technologies, and travel demand models (TDMs), researchers, industry, and communities seek to improve the quality of transportation while maximizing the energy efficiency, equity, and safety of transportation services. As transportation may soon reach over 30\% of U.S. energy consumption (U.S. Energy Information Administration 2018) and with urban areas representing an increasing proportion of the U.S. population ( $>80 \%$ since 2010) (U.S. Census Bureau 2012), a critical need exists to engage in urban data scienceinformed approaches to enhancing mobility. This includes identifying, documenting, and comparing key attributes across diverse implementations of city mobility and energy data collection and modeling.

The objective of this study is therefore to explore and document how aspiring Smart Cities are using data and models to inform mobility and energy initiatives within Smart City programs and in so doing identify gaps in knowledge and processes guiding Smart City mobility investment strategies, programs, projects, and pilots. A primary focus of the Smart Cities studied was the creation of an integrated data-sharing environment approach that ranges from establishing a "Smart Columbus Operating System" in Columbus, Ohio; a "data utility" in Pittsburgh, Pennsylvania; a "PORTAL" data archive in Portland, Oregon; an enterprise data management system in Denver, Colorado; a "one data system" and "data rodeo" in Austin, Texas; an awardwinning "XAQT" platform in Kansas City, Missouri; to "DataSF" in San Francisco, California. Most of these systems are being developed in parallel with multiple new data analysis tools, while regional metropolitan planning organizations continue to slowly evolve TDMs to consider emerging mobility technologies and services. Smart City initiatives in the United States are considering the many emerging and disruptive mobility services and technologies, with keen interests to leverage knowledge and research on the mobility benefits of automated, connected, efficient/electric, and shared mobility (ACES); and understanding the related energy, environmental, economic, and societal impacts of these shifts. Building on this context and the U.S. Department of Transportation Smart City Challenge, this paper catalogs and benchmarks the evolving data ecosystems and modeling environments of the seven cities selected as Challenge finalists and their respective research and investment priorities. This effort included stakeholder interviews and data collection with the seven Smart City finalists whose initiatives track and emanate from their respective Smart City Challenge proposals. More specifically, the major focus of this paper is to characterize and benchmark current urban data, mobility models, and their evolutions. These results serve to identify key gaps in data, knowledge, and methods required to advance energy efficient urban mobility innovation, and to enable research and analysis collaboration between Smart Cities and the Systems and Modeling for Accelerated Research in Transportation (SMART) initiative, linking SMART research tasks with cities that have the requisite data resources and organization priorities and objectives as evidenced in its stated mobility goals. Key takeaways from this study include:

- Despite the emphasis placed by Smart Cities on integrated data systems, relevant data and information to guide decision making with respect to emerging ACES mobility technologies are fundamentally lacking. Efforts toward integrated data systems that encompass mobility and energy, though critical, are in their infancy. The development of centralized information resources is progressing alongside initiatives that provide new information streams with observability into the impacts of emerging modes, particularly 
those associated with mobility as a service such as ride-hailing, car sharing, and automated electric shuttles.

- As with previous challenges to transportation modeling, the ability for TDMs to reflect the impact of emerging ACES mobility technologies lags in capability. Even with methodology advances over the past decade and a half that provide more sophisticated means to reflect travel behavior choices at the individual traveler level, even the most advanced urban models, such as the 3C model being deployed in Ohio, do not reflect, predict, or anticipate impacts from ACES mobility. Traditional TDMs are perceived primarily as roadway management and capital investment tools, and cities are looking more broadly for decision guidance with respect to emerging mobility trends.

- Given the fundamental gap in data, the lagging nature of TDMs, and shortfalls in realworld automated mobility data in cities, near-term research priorities include continuous assessment and analysis of urban mobility data, specifically transportation network company uptake and utilization in cities, augmented with accessing state vehicle registration data to observe consumer behavior shirts, and coupled with advances in cross-city analyses.

Overall, this curation activity is intended to enable efficient access to the knowledge generated from Smart City peer cities, share knowledge and insights, and benchmark its progress. It also aids in continuing to identify gaps in knowledge and practice, which in turn will expose opportunities for the DOE SMART initiative to contribute and gain insight and access to valuable data emerging from Smart City programs. 


\section{Table of Contents}

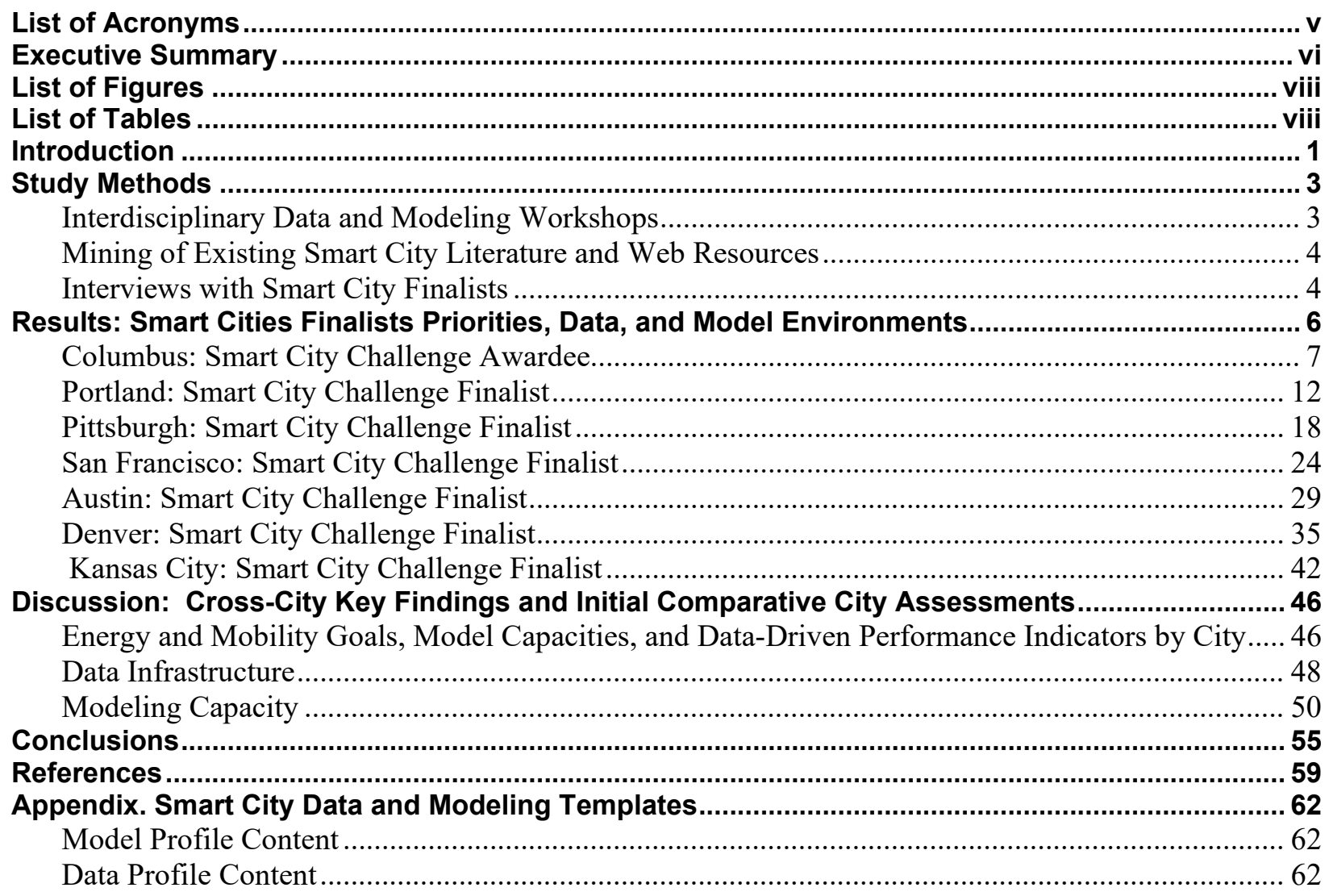

\section{List of Figures}

Figure 1. Initial framework for curating the evolving data and model environments with Smart Cities...... 2

Figure 2. Timeline of initial interaction with Smart City finalists ...................................................... 5

Figure 3. Daily VMT per person trend comparison of Portland metropolitan area to the U.S. average..... 12

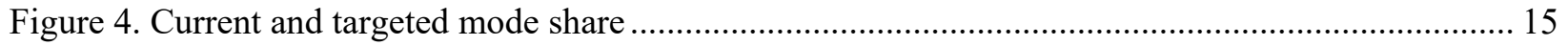

Figure 5. Average annual total per-trip delays experienced by peak-traffic commuters .......................... 20

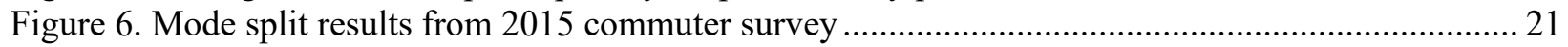

Figure 7. Sample of the TNCs Today Data Explorer - Fridays Summary Statistics ............................... 26

Figure 8. Profile of TNC activity as part of the modal split (average weekday) ......................................2 27

Figure 9. Sample view of new transportation data portals in Austin ...................................................... 31

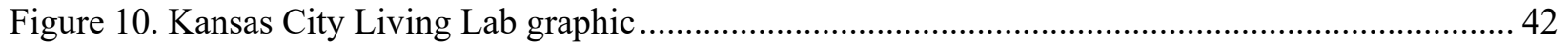

\section{List of Tables}

Table 1. Denver is Ranked Third Respectively in Population Growth among 39 Cities over 250,000

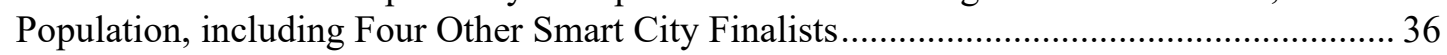

Table 2. Cross-City Model Capability Comparison Matrix ............................................................... 54 


\section{Introduction}

Many cities across the United States seek to develop, evolve, and mature by having their Smart City approaches informed by data and models to manage challenges, opportunities, and uncertainties associated with shifts in mobility technologies, human behaviors, and policy strategies. This study aims to provide a foundational baseline cross-city assessment of current data and modeling environments of the U.S. Department of Transportation (DOT) Smart City Challenge finalists (referred to as "SCFs") with respect to their ability to support critical analysis at the juncture of transportation and energy. Specifically, this effort focused on how urban and regional data environments and travel demand models (TDMs) are evolving to support and enable higher-level mobility and energy analyses, planning, and modeling, and the motivational factors driving cities to develop and enhance this analysis and modeling capacity.

Particular emphasis was placed on planning for a future of automated, connected, efficient/electric, and shared (ACES) mobility transitions through the uptake of technology and infrastructure transformations. While travel demand modeling has seen consistent progress since the 1960s (Mohammadian et al. 2009), city-based approaches to assessing and managing transportation energy and emissions remain at a nascent stage, with a need to harmonize methods similar to the recent establishment of city-scale energy and greenhouse gas (GHG) accounting protocols (e.g., Hillman and Ramaswami 2010, Mehrotra et al. 2011, Kennedy et al. 2009, Ramaswami and Chavez 2013) across cities. With ever-growing data assets and advanced mobility technologies coming to bear quickly (Sarkar and Ward 2016), especially in urban areas (Terrien et al. 2016, Shaheen 2017), there is a unique opportunity to analyze and explore the context-specific responses of cities to these disruptions to shape positive outcomes associated with ACES mobility to the greatest extent possible. Cities are still in the early stages of an evolution toward "big data" analytics, with increased interest in quality data and robust analyses that enable predictive capabilities, allow for higher-fidelity models with finer spatial and temporal resolution, and support new technology and service experimentation (e.g., on shared mobility, automated/electric vehicles, and related infrastructure). By presenting the types of data and modeling platforms emerging across Smart City ecosystems, this paper aims to enable efficient access to the knowledge generated from Smart City peer cities, share knowledge and insights, and benchmark its progress. It also aims to identify gaps in knowledge and practice, which in turn will expose opportunities for the U.S. Department of Energy's (DOE's) Systems and Modeling for Accelerated Research in Transportation (SMART) initiative to contribute and gain insight and valuable data from smart city programs.

To fill critical data-modeling-knowledge gaps, improve early understanding of urban mobility transitions and transformations, and identify best practices by cities, cross-city analysis of the seven Smart City finalists served as a critical foundation. This report builds on an initial framework for understanding city data and models (Sperling et al. 2017) for a subset of the seven SCFs (Columbus, Ohio; Denver, Colorado; Austin, Texas; and Portland, Oregon), collecting and organizing data addressing the five dimensions illustrated in Figure 1. Building on that initial study, this report characterizes and benchmarks the current data and model environments related to urban mobility systems as well as Smart City goals and critical mobility indicators with respect to emerging mobility services. The knowledge and information gained from this curation exercise are conveyed in this report. The information is also condensed and presented using template profiles for each city's data and model infrastructure in the appendix. These templates 
benchmark existing model maturity and data assets across the seven SCFs in a compact form to enable cross-city comparison. On a broader scale, these seven cities, as a result of being successful SCFs, are representative of the most advanced state of practice and analysis capabilities with respect to the use and uptake of urban data and modeling at the junction of mobility and energy in the United States.

Cross-scale

Actors \&

Institutions
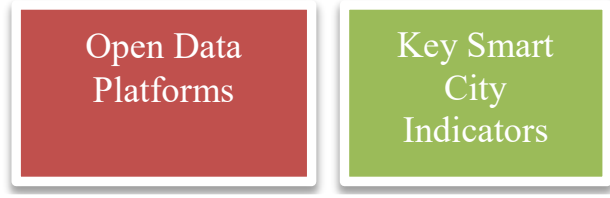

City-Based

Literature

Review

Figure 1. Initial framework for curating the evolving data and model environments with Smart Cities

In addition to providing a cross-city perspective and reference to the landscape of a city's capacity with respect to data and models, the initial findings revealed gaps in knowledge and fundamental modeling and analysis capability. Chief among those findings (as further elaborated in the Results section) suggest that few (if any) regional travel models have the capability or the base data to reflect the real-world impact of emerging services such as transportation network companies (TNCs). This is especially critical since TNCs represent the first wave of adoption of "mobility as a service," which may be accelerated by vehicle automation and digital connectivity technologies (as they mature). The ability to assess and then model "mobility as a service" is an immediate challenge to further clarify the shorter to longer term impacts of ACES vehicle technologies. This and other identified gaps in data and models are noted in the Discussion section. 


\section{Study Methods}

Initial case studies of the seven SCFs from the U.S. DOT's Smart City challenge - Columbus, Pittsburgh, Denver, Austin, Portland, San Francisco, and Kansas City-were developed to characterize the existing data and model assets. This serves as a foundation to explore the extent to which urban mobility data and models are evolving in response to Smart City action planning and with respect to the anticipated disruptions from ACES mobility technologies. The interdisciplinary methods to gather information and elicit feedback from the seven SCFs included:

- Interdisciplinary data and modeling workshops

- Mine existing literature and web resources

- Interviews with Smart City finalists.

These are described in more detail below, followed by results as the summation of these methods.

\section{Interdisciplinary Data and Modeling Workshops}

Two interdisciplinary SMART workshops were hosted by participating SMART Mobility Laboratory Consortium (SMLC) laboratories, focusing on existing capabilities and gaps in transportation modeling and the mobility data infrastructure. A main purpose was to elicit broadbased and early-stage input to the SMLC from experts on the state of transportation modeling and data. Each workshop included participants from the SMLC, the U.S. DOT, industry, academia, and state and local leading practitioners, including representatives from the majority of the SCFs.

The first of these workshops was hosted in November 2016 at Oak Ridge National Laboratory in Tennessee and focused on the mobility modeling capacity to reflect the impact of ACES technology. With roughly 75 attendees, including leading modeling consultants and premier academics, the workshop helped to open dialogues on the gaps in existing practice to move forward. The overwhelming conclusion was that although existing emerging model frameworks encompassing activity-based modeling (ABM) and dynamic traffic assignment (DTA) are likely adequate to reflect the impact of ACES, the underlying knowledge upon which to base the models was the fundamental limitation.

The second workshop focused on mobility data with an agenda of a wide-ranging array of data topics that touched on key research questions, contents, and applications of emerging big data and high-performance computing, critical knowledge gaps, data and knowledge management, and high-priority analysis opportunities for the SMLC using large data sets. Hosted in May 2017 at University of California at Berkeley with Lawrence Berkeley National Laboratory, participants represented national, state, and local perspectives as well as academic, commercial, and public agency interests while discussing the status, needs, and opportunities for advancing urban mobility data. The primary conclusions are that old data sources (e.g., fixed sensors owned by cities or periodic surveys), though critical, are inadequate on their own to reflect the impacts of ACES technology, and that new crowd-sourced, industry-owned, and internet-of-things methods offer opportunities to address critical gaps. However, these new methods will require additional skills to appropriately navigate the emerging new data economy. Interdisciplinary, 
human-centered, and systems-oriented analyses of data using emerging technologies and unique analytical methods to co-design and address key societal questions will all be important to supporting cities in maximizing mobility and minimizing energy. The national laboratories, with their high-performance computing capacity and expertise in data analysis, modeling, and management, have a role to play in partnership with traditional federal, state, and local mobility partners. Lastly, the overriding theme, mood, and conclusion of the workshop were the sense of urgency to obtain and analyze relevant data with respect to ACES mobility to address this gap in knowledge.

The combination of the two workshops helped to establish an initial baseline understanding of the state of the community with respect to data and models and set expectations with respect to interaction with the SCFs regarding their data and modeling capacities (a portion of which were represented at one or both of workshops).

\section{Mining of Existing Smart City Literature and Web Resources}

The second leg of the task relied on mining existing literature and data available from online assets, web portals, or reports by city or regional data providers. Many times, the metropolitan planning organization (MPO) fulfilled this role. Three types of data assets were reviewed to extract mobility data, including:

- Smart City websites - With the Smart City Challenge and the movement it fueled, Smart City websites that relay the city's goals and objectives and, in many cases an outline of a program to accomplish them, have become prevalent. Some even incorporate a datasharing capacity.

- Regional web data portals for open-source data - Although the Smart City Challenge has fueled data-sharing and open data systems, many urban data-sharing initiatives pre-date the Smart Cities movement. Many regional entities (often the city, the MPO for the region, or a university partner) publish substantial urban data sets, inventories, and even some application programming interfaces (APIs) for the public and third parties to access.

- City-centric mobility research publications - Recognizing that existing mobility information is lacking with respect to new mobility technologies, many public and private actors have proactively performed data collection, analysis, and research to respond to the challenge of improving understanding of current trends. Review of this literature revealed significant ongoing experimentation, data collection, and analytics for specific urban areas (yet with limited emphasis on energy efficient mobility).

\section{Interviews with Smart City Finalists}

Data gathering, particularly aspects of characterizing local data management practices and assessing the capability and maturity of their transportation modeling initiatives were best informed through face-to-face local discussions with the SCFs and their key partners. Key city participants typically included staff from their transportation operations, infrastructure, and planning units; Chief Innovation Officers; Chief Technology Officers; and city DOT directors in charge of Smart City programs. Key partner participants varied by city, but typically included 
travel demand modelers from the corresponding MPOs, local transit agency representatives, local electric utility representatives, and local research universities. Each SCF has typically involved both industry and university research partners in its transportation visioning, planning, data, or modeling aspects of its Smart City proposal. The data gathering with the SCFs, sometimes enabled by one-on-one interviews and sometimes through focus group discussion, was essential to effectively understand the key motivating factors for each city and its respective primary concerns or constraints moving forward. For example, in discussions with the City of San Francisco, the urgency and importance of understanding and measuring TNC impacts on congestion and the long-term ramifications of meeting its sustainability goals dominated the dialogue. In Pittsburgh, the city's goals to decrease dependence on privately owned vehicles is challenged by the city's reliance on parking revenue as the primary funding source for the City's retirement program.

The direct interaction with the SCFs (with the timeline shown in Figure 2) complemented other data collection activities and was instrumental in assessing research and data investment priorities for each SCF with respect to mobility and energy. The interviews and focus groups were particularly helpful in documenting self-identified gaps in data, knowledge, and methods in each city. The timeline below indicates initial interaction with each SCF; however, the dialogue is ongoing with each city. (Note that interaction with Kansas City has primarily been through email and phone conversations). The study team expects ongoing city communications to enable further insight into available and recently extended urban data and models and provide efficient access to urban data to inform and support energy-efficient mobility systems-related research.

$\begin{array}{llcc}\begin{array}{c}\text { Dec. 2016: } \\ \text { Columbus, OH }\end{array} & \begin{array}{c}\text { Apr. 2017: } \\ \text { Pittsburgh, PA }\end{array} & \begin{array}{c}\text { Jun. 2017: } \\ \text { Austin, TX }\end{array} \\ & & & \\ & & & \\ & \text { Feb. 2017: } & \text { May 2017: } & \text { July 2017: } \\ \text { Portland, OR } & \text { San Francisco, CA } & \text { Denver, CO }\end{array}$

Figure 2. Timeline of initial interaction with Smart City finalists

The synthesized results from these methods to curate the SCFs' data and models are presented city-by-city in the Results section, with initial cross-city comparative insights reserved for the Discussion section. The intended audience includes practitioners and researchers familiar with the concepts and lexicon associated with urban mobility data and modeling with insights and findings for future urban energy-efficient mobility systems analyses. 


\section{Results: Smart Cities Finalists Priorities, Data, and Model Environments}

The results are presented city by city in this section with discussion and conclusions across all cities reserved for later sections. For each city, an introduction to its respective background and approach to "Smart Cities" with an emphasis on advanced technology and energy-efficient mobility is provided. These introductions are informed by review of each city's proposals to the U.S. DOT's Smart City Challenge from 2016, city planning documents, and feedback from discussion and focus groups within the SCFs. The introductions are intended to inform the reader on each city's priorities, concerns, and visions with respect to mobility in the context of its larger Smart City initiative. This forms a backdrop from which to interpret its data and modeling environments.

After the introduction, the evolving data infrastructure and modeling capacity are documented for each city. Each is presented separately, although these two environments are highly linked and interactive for many cities. The data infrastructure material concentrates on initiatives within the city to share and collaborate in the mobility data and analysis space, highlighting any initiatives to create open-data portals and systems, as well as the content of these systems, understanding how the cities and their regional stakeholders anticipate managing a data infrastructure that can support moving forward in conjunction with Smart City plans.

The modeling capacity is typically concentrated at the MPO serving each respective city and their larger metropolitan region, though not always. The review of the modeling capacity considers the current practice for generating travel patterns representative of the population (e.g., trip generation matrices, ABMs, etc.); the sophistication of the travel network modeling software (e.g., trip assignment, DTA); and the interaction between the two. The latest trip behavior survey data upon which existing modeling is based and the modeling scenarios reflecting the impact of coming ACES technology were also explored as being of importance to assessing the evolving maturity of TDMs across the metropolitan regions in which SCFs are embedded.

Lastly, city and metro-region specific discussions are provided that concentrate on key takeaways that describe the primary concerns and motivations which drive investments in future data collection, pilot projects, analysis, and transportation modeling for each city.

In summary, the results for each city contain:

- An introduction to the city, its priorities, concerns, and goals in the mobility/energy spectrum

- Curating mobility data infrastructure as a co-evolving effort to support Smart City initiatives

- Summarizing existing transportation modeling capacity and frameworks

- Key takeaways specific to the city and its energy-efficient mobility system goals.

While the reality exists that models, data, and plans are all lagging behind what is happening in a diverse, dynamic, and disruptive mobility-as-a-service market, an overall message is that adaptive approaches are needed for future city-relevant research and analysis and to extend traditional TDMs. 


\section{Columbus: Smart City Challenge Awardee}

\section{Energy-Efficient Mobility Goals and Metrics (as stated in Smart Columbus Proposal)}

- De-carbonization of the region's electricity supply

- Success metric: 915 megawatts of solar/wind

- Fleet electrification

- Success metric: 300 electric vehicles (EVs) in public fleet, $448 \mathrm{EVs}$ in private fleet, and $30 \mathrm{EVs}$ in a car-sharing / ride-sharing fleet

- Public transportation and personal mobility de-carbonization

- Success metric: completed bus rapid transit, 3,000 Dedicated Short-Range Communication (DSRC) equipped vehicles, 6 deployed automated vehicles (AVs), and common payment platforms

- Mass consumer adoption of EVs

- 3,200 registered EVs by 2018

- Charging infrastructure installation

- 1,900 new Level II chargers

- Advanced Transportation to Improve Community Health

- Success metric: decrease the infant mortality rate in under-privileged communities (Linden neighborhood)

\section{Introduction to the Columbus Smart City}

Columbus, Ohio, was selected from 77 city applicants for the \$50-million grant award by the U.S. DOT's Smart City Challenge. In the process, Columbus attracted over $\$ 500$ million in related financial commitments (e.g., matching funds, in-kind, and other tangible investments). This number continues to grow, and Columbus' mayor announced in mid-2017 a goal to see the total financial support for the Smart Columbus initiative eclipse \$1 billion. Economic development remains a key priority, along with creating a healthy and vibrant economy that includes all and brings equitable benefits to all its citizens. A key attribute of the Smart City proposal was its level of partnership, often referred as "the Columbus Way." Smart Columbus enjoys strong support from the business community, which is led by the Columbus Partnership, an organization of the chief executive officers of the city's leading businesses and institutions and complemented with other top-tier partners (Clean Fuels Ohio, Ohio State University and other universities, American Electric Power, Ohio DOT, Mid-Ohio Regional Planning Commission [MORPC], and others). All are providing financial, political, and/or community support to the city to ensure success of the Smart Columbus program.

Columbus envisions a future transportation mobility system enabled by ACES vehicle technologies. In partnership with the U.S. DOT and the Paul G. Allen Family Foundation, the pilot implementation of mobility and energy technology in Columbus will offer useful lessons learned to other cities. The City of Columbus and its partners are currently building institutional capacity to implement and support a broad range of pilot projects. Chief among these projects is an overarching "Integrated Data Exchange (IDE)," recently branded the "Smart Columbus Operation System" (or SCOS). The SCOS is targeted to be the data exchange, not only for the grant activities, but also for city business moving forward. In addition to the SCOS, individual mobility-oriented pilot projects include more than nine U.S. DOT-funded initiatives spanning 
objectives of safety, efficiency, and equity. U.S. DOT pilot projects include: connected buses and city vehicles; an integrated multi-modal payment system for public mobility options; a trip planning mobile application; smart mobility neighborhood hubs with real-time information; new radio-frequency identification parking permit stickers; an integrated parking information system for event management; transit/pedestrian safety upgrades; a mobile device-based application for increasing mobility for all, including disabled persons and the elderly; electric automated shuttles; truck platooning: freight route optimization; real-time freight delivery management; and freight parking management. The grant also encompasses four electrification and GHG reduction initiatives funded by the Paul G. Allen Family Foundation, targeted toward accelerating Columbus' progress toward electric vehicle (EV) adoption and corresponding grid decarbonization with more renewables and EV charging infrastructure for public fleets, private fleets, and car-sharing fleets. The Paul G. Allen Family Foundation projects include adoption of EVs for public and private fleets and the associated enabling charging infrastructure. They also include consumer EV adoption programs, with public-access charging, utility-scale commercial and residential renewable energy, grid modernization efforts, consumer EV adoption programs for employees, and EV test-drives/information exchange for consumers and regional dealerships.

This quick review of Smart City initiatives underscores the intense level of effort and broad array of activities undertaken by Columbus and the requisite need for a data management system (the SCOS) to underpin, assist in management, and provide performance metrics for the various initiatives. Key factors propelling Columbus in its Smart City application are summarized:

- Leverage new technology to increase access to jobs and healthcare for under-privileged neighborhoods.

- Create an environment that encourages the use of sustainable modes and energy consumption, such as electric vehicles (EV) and smarter grids.

- Expand the use of electric and smart vehicles through changes to policy, practice and expansion toward energy and climate objectives.

Prior to receiving the grant, Columbus, in working with Clean Fuels Ohio, had already installed nearly 300 public EV charging stations throughout the metropolitan Columbus region, including at Columbus City Hall. This commitment to clean energy led the City to early adoption of bike and car sharing and ride-hailing in ways that complement regional transit systems. In addition, American Electric Power, a regional electric company, completed a major Smart Grid project in Columbus with favorable results. These formed the groundwork for Columbus to be selected for the grant award and engendered the partnership and collaboration that underscore the Smart City initiative, referred to as "the Columbus Way."

\section{Columbus Transportation Data Infrastructure}

The current capacity building at the City of Columbus to create SCOS is the standard bearer for re-aligning city operations to become a data-driven Smart City. This project is foundational to the grant efforts and will be watched closely by other cities seeking similar goals. Columbus is building on its discipline and expertise within its Division of Technology, which has served Columbus with effective and public serving web sites and geographic information systems. The transformation from a geographic information system-driven and application-centric data 
management system to that of a central data exchange utilizing open source, agile development methodologies to quickly, efficiently, and confidently go from concept to prototype to deployment and eventually towards a sustainably and broadly supported system is a major undertaking. Smart Columbus continues to work closely with the U.S. DOT and others to fully realize the SCOS as the foundation IDE for the city moving forward.

This Columbus IDE is set against a backdrop of collaborative data efforts, some of which predate the Smart Columbus initiative and some of which have sprung up because of the grant activity.

- MORPC, the regional MPO for the Columbus region, has dedicated staff for data management and sponsors a regional data-sharing portal for a wide variety of planningrelated data, much of which is mobility-oriented. MORPC works collaboratively with communities throughout the region to provide current, accurate, and comprehensive information. MORPC takes the lead for managing regional data sets critical to mobility planning. With a dedicated energy planning staff, MORPC is also looking forward to growing its data resources appropriately to support mobility-related energy analysis.

- The Columbus Partnership, in response to the Smart City challenge, created a "Smart City Sandbox" through its innovation division called the Collaboratory. This Sandbox is a development test "playground" providing participants with data, APIs, and idea fodder to spur innovative development for the betterment of Columbus.

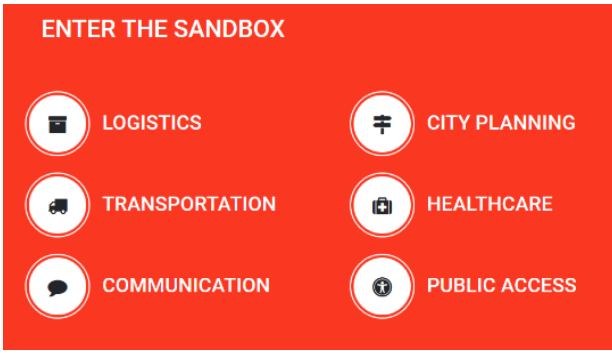
Members and partners can donate and explore data within this new sandbox, and the APIs connecting to the data span many areas (see inset), with transportation, logistics, and city planning as three of the core areas.

- Specific to transportation performance data and metrics, the Ohio DOT is a strong presence, providing not only traditional volume and traffic data, but which has also developed a track record of procuring and sharing industry probe traffic data and analytics tools. The licensing agreements for these procurements ensure that the data can be made available to local jurisdictions. Prior to the Smart City initiative, the Ohio DOT already procured travel time and speed data for the state highway system and made these data available to cities through a no-cost sub-licensing process. As part of Ohio DOT's support of the Smart Columbus initiative, this data pool was expanded to include industry cutting-edge outsourced transportation data and analytics beyond just travel time and speed, and the data and analytic tools were made available to all the public agencies within Ohio and sub-contractors working on its projects. The data set includes a sample of vehicle trajectories (endpoints and periodic waypoints of $1 \%-2 \%$ of all trips in Ohio) and analytics that provide origin-destination data plus select link analysis capability.

These major data initiatives are complemented by several other mobility data sets ranging from transit operations data to parking revenue and utilization, as examples. This underscores the collaborative partnership methods in the "Columbus Way." These data initiatives remain a core effort of Smart Columbus, with inclusive integration expected into the SCOS. 
With respect to energy and tracking electrification goals, the number of EVs adopted by consumers due to the consumer education, incentives, and charging infrastructure initiatives associated with the Paul G. Allen Family Foundation grant is one key metric being tracked. Formerly, data on the number of EV sales were available through commercial subscription to industry sources that mine the state vehicle registration archives and then relicense it to third parties. In cooperation with the Ohio Bureau of Motor Vehicles, the City is developing a means of directly accessing these data (while protecting personally identifiable information) for inclusion in the SCOS moving forward. This is an ongoing effort, and lessons learned will inform other Smart City initiatives dealing with accelerating adoption of EVs.

\section{Columbus Transportation Modeling Capacity}

Columbus is served by MORPC with respect to long-term planning and travel demand modeling scenario planning. MORPC is in the process of upgrading its existing TDM to a state-of-the-art, activity-based TDM referred to as the $3 \mathrm{C}$ model, so named because it is a joint initiative of three MPOs: Columbus (MORPC), Cleveland (Northeast Ohio Areawide Coordinating Agency), and Cincinnati, and coordinated by the Ohio DOT. Prior to the most recent upgrade, Columbus was one of the first cities to have an operational ABM (since 2004 - a tour-based approach) and continues to lead in adopting cutting edge research and scenario-planning exercises to inform transportation infrastructure modernization investments in the region. The enhanced model update will facilitate more realistic modeling and representation of travel, as the $3 \mathrm{C} \mathrm{ABM}$ explicitly considers socio-demographic characteristics (age, gender, income, vehicle ownership) of households/persons in modeling travel. Funded through the Strategic Highway Research Program 2 by the Federal Highway Administration and American Association of State Highway and Transportation Officials, the 3C model also incorporates a DTA model (DynusT), which facilitates dynamic travel response to real-time network congestion and incidents. In support of the enhanced model, the Ohio DOT is conducting a statewide household travel survey, which will inform various components of the $3 \mathrm{C}$ TDM. The model upgrade, based on six years of data from various sources, was completed in 2018 . The $3 \mathrm{C}$ model will play a key role in regional transportation planning, regional sustainability planning, and development of the metropolitan transportation plan.

The enhanced TDM considers travel by automobile, transit, walk, bike, and freight modes (with a specialized sub-model to handle freight travel) and may be able to evolve to support modeling of the impact of TNCs on travel patterns (as this trip type becomes more prevalent and based on available data). MORPC has developed a variety of scenarios related to infrastructure improvements, demographic change, and technological advancements to be tested with the TDM. The key benefit of the MORPC model is the disaggregated and realistic representation of travel patterns, and the components of the $3 \mathrm{C}$ model were estimated based on data from multiple cities in Ohio. With respect to energy and air quality, both the older and new models are linked to the U.S. Environmental Protection Agency's (EPA's) Motor Vehicle Emission Simulator (MOVES) model for standard air quality and emissions output.

Although the enhanced model does not explicitly have emerging modes of ACES mobility, the Ohio DOT has plans to incorporate some of these capabilities into the $3 \mathrm{C}$ model in the near term. In addition, the model incorporates a full activity-based trip generation phase in which realistic full-day travel itineraries are developed for synthetic representative populations, linked to a full 
dynamic traffic assignment module capable of reflecting impacts of congestion, signal operations, and other aspects of traffic flow. The ABM and DTA model will be tightly coupled to improve understanding of the congestion impacts associated with route choice and even mode choice. As the ABM and DTA gain the capability to reflect the impacts of the emerging modes at the base level, the team expects additional data and capabilities will continue to emerge through future model updates (MORPC 2017).

[See appendix for the Columbus data and modeling summary templates.]

\section{Columbus Takeaways}

With the U.S. DOT Smart City Challenge award, Columbus has become the foremost experimental test bed for Smart City mobility pilots, especially for small to mid-size cities. Columbus is deploying pilots that address the Smart City objectives in the mobility, energy, and sustainability space, thereby creating knowledge and lessons for a much broader community.

- The core IDE development (SCOS) in Columbus offers a template and lessons for other cities attempting similar transformation shifts from geographic information systems and data-sharing platforms to foundational data exchanges at the heart of city business.

- Simultaneously, Columbus has a dynamic, shared, and collaborative data infrastructure supported by various groups and partners. This data fabric is growing rapidly in response to Smart City initiatives, providing avenues for research, experimentation, and Smart City development of apps. This is a recurring theme across Smart City initiatives. Although the IDE initiative will continue to mature, the collaborative spirit to share data across organization boundaries is emerging as a prerequisite to ignite Smart City progress.

- Within Columbus, a sub-theme exists of leveraging innovative or unique commercial data. This includes non-traditional data, not gathered directly by government entities, as illustrated by Ohio traffic data procured and shared with Ohio cities. Ongoing integration of public and private data is anticipated to inform ongoing development of performance metrics with respect to mobility, energy, safety, and equity is emerging. As a consequence of using such data sets, new skills in the areas of big data, analytics, data licensing, and personal privacy protection (as in the case of the Ohio Bureau of Motor Vehicle registration records) are required at the City or through its partners.

The TDM in Columbus and the new 3C model positions Columbus to leverage the latest advances with respect to ABMs and DTAs as it co-evolves together with data to reflect the potential impacts of ACES technologies. 


\section{Portland: Smart City Challenge Finalist}

Energy-Efficient Mobility Goals and Metrics (as stated in Sustainable \& Smart City Plans)

- De-carbonization of the region's electricity supply

- Success metric: $100 \%$ clean energy by 2050

- Accessibility of key urban services

- Metric: 20-minute neighborhoods that ensure access to all key community amenities, products, and services with density of destinations within $1 / 4$ to 3 miles

- Multimodal transportation

- Success metric: double commute trips by walking, biking, and transit by 2030

- Integrating safe, active transport and transit systems with higher-density land uses

- $30 \%$ percent of new growth in downtown and $50 \%$ in centers and corridors where there is already access to transit, bike, and pedestrian infrastructure

- Shared Use Mobility

- Partner with TNCs to increase access to vehicles, including electric vehicles, to all communities (consider programs to expand in low-income areas)

- Electrification of transportation

- Continue to be a leader in this area, building on an "E-Visionary" award.

- Metrics: "top ten" city for EVs and chargers per capita, low-cost and low-carbon electric power, and EVs averaging an equivalent of 94 miles per gallon or higher.

\section{Introduction to the Portland Smart City}

Since the Smart City Challenge, Portland has continued ambitious efforts to advance energy efficient mobility systems. This includes continued progress towards the city's goal to decrease vehicle miles traveled (VMT) per person (as shown in Figure 3). The City has also continued to build on a unique political structure, with five city councils. While many cities have a Chief Innovation Officer, Chief Technology Officer, or Director of Innovation as a key touch point for Smart City-related activities, Portland aims to achieve Smart City representation in each council.

\section{Portlanders' driving has declined ahead of the national trend}

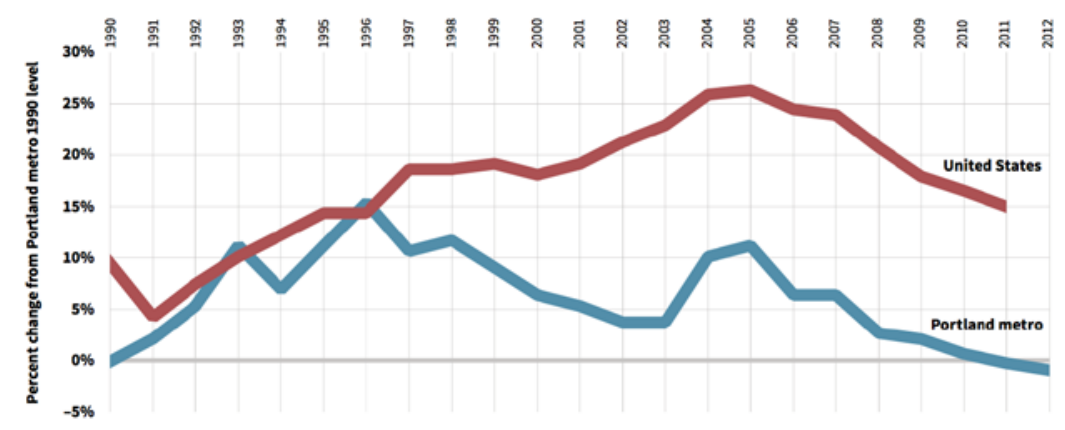

Figure 3. Daily VMT per person trend comparison of Portland metropolitan area to the U.S. average

(Metro 2016; Metro 2018) 
In the months after the Smart City Challenge, the City of Portland received an award of \$100,000 from National Institute of Standards and Technology to field-test affordable air-quality sensors near roads in terms of accuracy, durability, and price. This complements a National Science Foundation grant of \$3.5 million to Portland State University as part of the Smart and Connected Communities program, with the project focused on deploying 2,000 to 3,000 air quality sensors (with sensors that may provide other information as well). Having funding in hand to address this critical priority, the City aims to connect transportation-related air quality with affordable housing siting decisions, including focusing on pollutant exposure from factories or industrial facilities near children's daycare centers. While Portland did not win the Smart City Challenge, local and regional agencies were able to pool resources and provide an initial \$50,000 in funding to develop a regional Smart Cities action plan focused on transportation that builds on its Smart City proposal.

Portland's ongoing Smart City priorities, concerns, and goals are focused on:

- The first phases of transportation-related air quality sensor deployments on roadways

- First- and last-mile solutions for transit investments and increased connectivity

- Three hundred parking sensors for real-time parking information/enforcement.

Efforts also include mobility needs assessments, including emphasis on barriers to EV adoption among underserved populations in East Portland. The study aims to identify what shared EV mobility services may look like with new multi-family affordable housing environments. The MetroLab Partnership, West Big Data Hub, Transportation for America, Bloomberg What Works, Smart City Lab, and other national to global networks inform its ongoing Smart City action planning in the region. The City is also pursuing interests in data sharing with TNCs, but there has not been much progress to date. The City is interested in these data sets as the current perception is that TNCs such as Uber and Lyft are not decreasing single-occupancy vehicle trips, but rather are making the traffic and congestion situation worse.

By working towards an open data policy via funding from the Bloomberg What Works and Sunlight Foundation data initiatives, the City is working toward a draft data policy proposal that will go to the City Council. The proposal is expected to focus on hosting, processing, and making available any data gathered by sensors, third parties acting on behalf of the City, industry, and shared economy entities (e.g., Uber/Lyft/Airbnb), and a budget request to establish a city chief data officer. In terms of pilots on how and where automated vehicles (AVs) may emerge, General Motors and the City are expecting to pilot in areas around hospital campuses, by Portland State University, and potentially at the Nike campus.

Key City research questions include:

- Energy impacts of dropping speed limits for "Vision Zero" (zero road fatalities) goals?

- Can reviews of regional action planning/roadmaps bring in viewpoints that may have worked from other cities, such as new computational capabilities/energy perspectives (to look at co-benefits that may arise)?

- How to encourage shifts: e.g., reduce VMT, increase fuel efficiency, and enhance health/physical activity/air quality? 
- How does smart mobility improve quality of life and transform transportation behaviors?

In the mobility and energy spectrum, City goals (as included in its application) include:

- "Fossil fuel consumption will be reduced, and renewable energy will be the primary sustainable energy source ... [Portland] will explore implementation of dynamic wireless charging for EVs as well as stationary wireless charging at dedicated car-share, bus, and vehicle or truck fleet parking locations within priority demonstration zones." Portland is already home to the first solar-powered, battery-driven fast charger for EVs, developed by a local company, EV4Oregon, with support from key partner Drive Oregon.

- Collaborate to become a Zero Emission Vehicle City by 2035 through implementation of smart grid technologies. Electrify priority demonstration zone transit corridors and integrate EV charging stations into street lighting systems. Demonstrate dynamic wireless charging of EVs in key locations to enable daytime charging, thus permitting a direct path from renewable energy generation to the user.

- AV technology can improve the safety of the transportation network, energy efficiency, convenience, operating efficiency, and equity. To aid in this transition, Portland proposes to establish autonomous transportation pilot zones, beginning with academic and institutional campuses, as well as a driver-assistance and collision-avoidance bus and train line on the new car-free and multimodal Tilikum Crossing. 


\section{Portland Transportation Data Infrastructure}

Portland's Smart City institutions have come together to continue building on the success of the cross-agency data archive, called PORTAL (led by Portland State University). PORTAL includes data on bicyclists, pedestrians, connected vehicles, traffic, transit, and signal systems (Figure 4). To date, PORTAL does not yet support real-time operations, although some data come in near-real time (every 20 seconds). The online PORTAL also includes many visualizations and data applications of interest to both the City and METRO Smart City and transportation teams. Some of the relevant data include origin-destination data, city energy metrics, crashes/fatalities/injuries by mode (as a "Vision Zero" visualization/analytics platform that is currently supported by Pacific Northwest National Laboratory Advanced Computing). Portland DOT, the city transportation agency, also provides traffic volume/air quality analyses and analyses of the transportation system impacts on GHG/carbon dioxide. Currently, the METRO (as the regional MPO) travel model and enterprise services group hosts more than 150 data layers, with many maintained and published on a quarterly basis using a geospatial open data site. The METRO team contributes to and feeds off PORTAL.

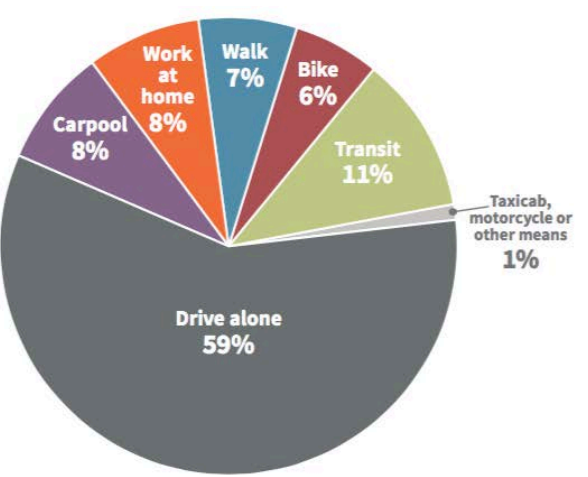

2012 current work commute mode share for Multnomah County. Source: American Community Survey (2013)

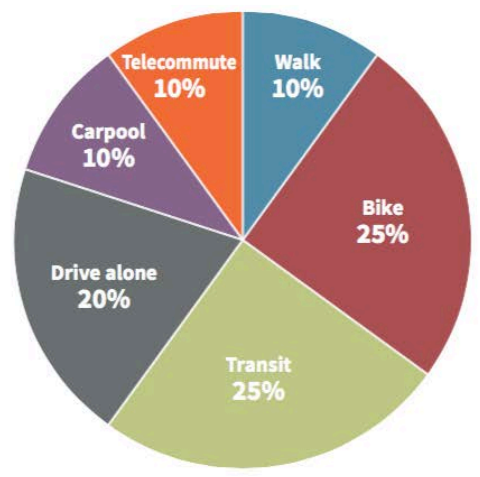

2030 target work commute mode share for Multnomah County.

Figure 4. Current and targeted mode share

Portland's open data policy, approved by the City Council in 2017, builds on an open data resolution from 2009 that focused on gathering data that would be open to the public, ranging from data gathered by sensors to third parties that are acting on behalf of the city (e.g., including those in the sharing economy such as Uber, Lyft, and Airbnb). The new open data policy leverages new data-sharing conversations as part of the framing in larger Smart Cities discussions, building on funding from the Bloomberg What Works and Sunlight Foundation (which had noted that the City of Portland was already more comprehensive and innovative in its approach to data than most others awarded by this initiative).

Together with Portland State University, the private sector, METRO, and TriMet (the transit agency), there are aspirations in Portland to create and grow a standards-based urban data economy. The $\$ 50,000$ in regional funding towards a Smart Cities action plan is emphasizing what the region wants to do in the next three to five years with data and building on the challenge grant application. 


\section{Portland Transportation Modeling Capacity}

Portland was one of the first MPOs in the United States to experiment with and implement tourbased ABMs. The Portland (METRO) TDM is an ABM developed using data collected from the 1994-1995 Household Travel Survey and updated using the more recent 2011 Household Travel Survey (Metro 2012; Geller 2013). The TDM is preceded by a land use microsimulation model developed with UrbanSim, an open-source land use planning package that provides information regarding the built environment in the city and its anticipated growth patterns. The METRO model takes this input and couples it with socio-demographic and network performance data (travel times by different modes) to generate the travel activity for every individual in the model region. The output of the METRO model goes as input to the DTA model (DynusT), which simulates the trips on the network. Finally, the output from the DTA model (link volumes/speeds, etc.) is fed into the EPA MOVES model to compute the energy and emissions footprint of travel in the model region. The METRO model is quite comprehensive in that it classifies households into 64 different categories (based on household size, income, age, and employment characteristics) for modeling purposes. The model currently covers auto, transit, walk, bike, and freight modes and houses separate sub-models for airport as well as freight travel. The model also includes a separate bicycle modeling component that aligns well with the enthusiasm for transportation by bike within the city. A comprehensive set of scenarios, from infrastructure developments to technological advancements, is being tested with the help of the TDM to better inform transportation decisions in the city. The METRO modelers identify low survey response rates (which impact the development of robust model components) and incomespecific non-response as some of the key limitations in model development.

[See the appendix for the Portland data and modeling summary template.]

\section{Portland Takeaways}

Portland's continued Smart City efforts will include evolving Smart City pilots that focus on:

- Air quality monitoring and the utilization of publicly available information kiosks that offer real-time data on air quality, transit, "wayfinding," Wi Fi, and other information.

- Exploring TNC impacts associated with parking meters and DUI citations.

- Understanding the energy impacts from uptake of the BIKETOWN bike-share system

- Transportation electrification, building on an "E-Visionary" award and a "Top Ten" city for EVs and chargers per capita. (Oregon EVs are estimated to get the equivalent of 94 miles per gallon.)

- Low-cost electric power that enables a future of semi- and fully automated EVs initially leveraged via transportation sites and academic/institutional campuses of project partners, plans for AV pilot zones at Portland's new car-free multimodal Tilikum Crossing, and with TriMet supporting Mobile-Eye transit collision-avoidance systems. 
The City is also experimenting with making equity a much larger emphasis in Smart City initiatives and drafting a city policy for connected and automated vehicles (CAVs) that begins efforts by focusing on hospitals and the regional campuses of hospitals, universities, and businesses (e.g., the Nike campus). With concerns about TNCs not decreasing single occupancy vehicle trips, yet rather potentially making the situation worse, the City views the future as moving beyond just picking up one passenger, to increased occupancy services, and identifying/shaping the synergistic futures of shared, electric, and automated vehicles, while also shifting transportation modal splits. 


\section{Pittsburgh: Smart City Challenge Finalist}

\section{Energy-Efficient Mobility Goals and Metrics (as stated in the Smart Pittsburgh Proposal)}

\section{- De-carbonization of the Region's Electricity Supply}

- One-hundred percent clean, renewable energy and a 50\% reduction in city energy use by 2035

- Enable New Synergies of Energy and Mobility, Housing and Transportation

- Metric: Performance of systems and services in terms of affordability

- Public Transit Use per Capita

- Increase use, convenience, and uptake through a new multimodal travel app

- Reduce the number of single occupancy vehicles commuting to Pittsburgh

- Alternative Fuels

- City Alternative Fuel Map (50 charging stations) and shift ratio of only a dozen EV charging stations in an area of more than 23,000 traditional parking spaces

- Dynamic Parking Management

- Real-time information and free or reduced parking for fuel efficient vehicles

- Ridesharing and Automated Shuttle

- More ride-sharing and an automated shuttle from net-zero energy site to the Oakland neighborhood

\section{Introduction to the Pittsburgh Smart City}

Since 2015, the City of Pittsburgh has instituted an urban development strategy that is defined as innovative, inclusive, and sustainable based on the Mayor's P4 framework of people, planet (sustainability), place, and performance. These principles underpin, and also predate, its Smart City initiatives. The City has created a new Department of Mobility and Infrastructure (DOMI) to engage in future planning focused on developing new technology scenarios and new residentscale metrics and analyzing ways to advance traveling in higher occupancy modes, whether that is shared AVs or more mass transit, walking, and bicycling. Key questions being considered by the City with respect to Smart City performance include: What data will be available in the future? Which technology changes may allow gathering of more data? Will the scenarios considered for modeling become outdated quickly? While aiming for a denser urban fabric with less reliance on automobiles and greater integrated used of shared mobility, the City is faced with a conundrum as parking revenue is a major source funding staff pensions (parking makes up $15 \%$ of the City's revenue). One direction the City is considering is building new impact fees into the development process (where there is a need for revenue replacement strategies). Key Smart City efforts for Pittsburgh include building a "data utility" that different public, private, and other users can build on. Examples of this include video-analytics based on Pittsburgh traffic cameras that can inform understanding of traffic patterns and use of social media and other data sets currently not leveraged in current regional transportation models and analysis.

For Pittsburgh, a few key smart mobility challenges include significant flooding-related issues and escalating congestion challenges (see Figure 5). The mayor of Pittsburgh is focused on achieving multiple benefits at the same time, noting that "we're not tearing up asphalt immediately after we just repaved (for new technologies). Utility companies, the state, and the transit authority - all those partnerships are important." Key partners include philanthropic 
institutions (e.g., Heinz endowment) and local universities (University of Pittsburgh and Carnegie Mellon University [CMU]).

One of the major projects that resulted from the U.S. DOT Smart City Challenge application is improvement of traffic flow through arterials with the deployment of an adaptive signal control system developed at CMU. Although not funded through the grant program, the Pennsylvania DOT and the Federal Highway Administration took notice of the "Smart Spines" concept, putting forth funding to the City of Pittsburgh to implement through the Advanced Transportation and Congestion Management Technologies Deployment program, or ATCMTD). Along with state and local funds, funding for the project totals over $\$ 30$ million in investment. The project deploys "Smart Spine" corridors in Pittsburgh that layer environmental, communications, energy, and transportation infrastructure technologies to improve connections between isolated neighborhoods and major centers of employment, education, and healthcare, as well as a light-emitting diode smart streetlight conversion of nearly 40,000 streetlights.

The City is considering a new policy toolkit to engage with technology companies whose business models rely on access to public trust. An example of this was the Uber pilot and experimentation, as the City learned that it is critical for cities to ensure (with emphasis on data and models) that private sector efforts are not something that will happen "to" cities rather than come "from" co-design with the cities.

Some of the key research questions being explored by the City include:

1. How does energy get prioritized for transportation modeling when not required through the normal planning process with its MPO?

2. How does the city integrate future energy supply chains, including both gas and electricity for transportation?

3. How best to make use of open data to shape key performance indicators on energy, mobility, safety, congestion, and key goals?

4. Can the federal and state government along with universities work together with cities (i.e., the MetroLab network) in supporting transitions to EVs/AVs, and address challenges at the intersection of energy and advanced mobility? With the City approaching capacity during peak hours and with time lost due to traffic delays (see Figure 5), the new Pittsburgh DOMI is considering shifts away from single-occupant travel, enabling system investments that increase inclusive accessibility to higheroccupancy mobility services and choices that take up substantially less road space and infrastructure investment for accommodating existing and new resident travel demands in the city. 


\section{Traffic Delay}

Annual traffic delay in the Pittsburgh MSA

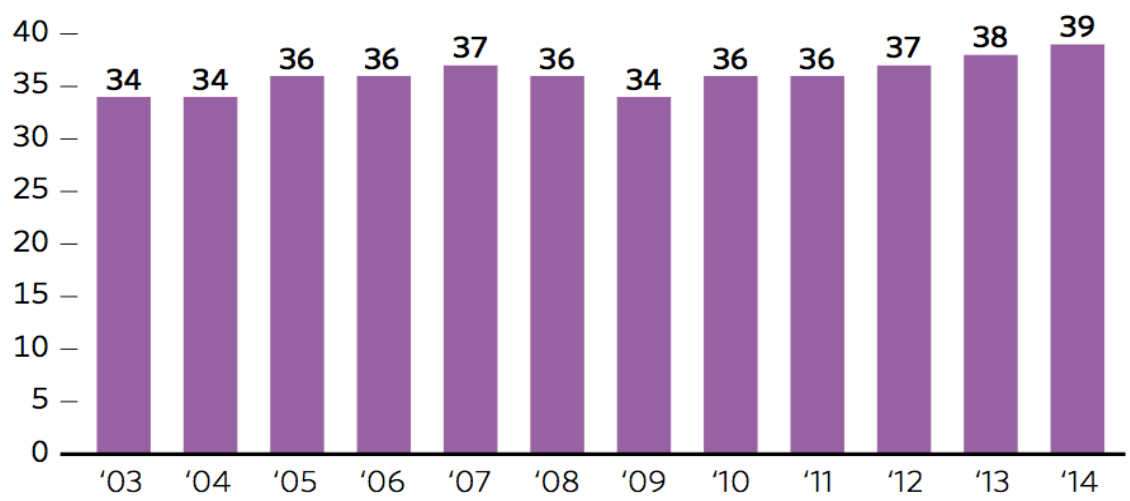

Average of total of per-trip delays experienced by peak-traffic commuters each year.

DATA SOURCE: 2015 Urban Mobility Soorecard, Texas Transportation Institute

Figure 5. Average annual total per-trip delays experienced by peak-traffic commuters

(Texas Transportation Institute 2015)

\section{Pittsburgh Transportation Data Infrastructure}

A key initiative that came to fruition from Pittsburgh's Smart City proposal is the "data utility," building on major efforts by the University of Pittsburgh, Allegheny County Port Authority, and the City bringing together over 250 data sets now available at Western Pennsylvania Regional Data Center (WPRDC). The WPRDC was initiated to bring public information to a common platform, making it easy to find and use. Data sets hosted in the WPRDC are provided by the City of Pittsburgh, Allegheny County, Pittsburgh Parking Authority, and Bike Pittsburgh and include bicycle lane use counts and parking utilization. Initial real-time parking data are available for city parking garages. A tripling in parking revenues between 2011 and 2015 (from $\$ 5.5$ million in 2011 to $\$ 17.1$ million in 2015 ) resulted from shifting from old meters and rates to new rates and "pay-by-plate" parking meter technology (paid parking is referenced to the vehicle license plate instead of the parking stall).

For measuring transportation energy, the City emphasizes use of its energy inventory efforts that include VMT (with odometer readings at city and county levels shared with CMU through a nondisclosure agreement with the Pennsylvania DOT) along with traditional national- and state-level estimates derived from VMT estimates through the U.S. DOT Highway Performance Monitoring System. As to other potential data contributing to the measurement of fuel use, the City and local researchers have not used fuel sales data or vehicle registration data; however, they do have an interest in continuing survey work with the state DOT to better understand shifting fleet composition. 
In terms of impacts of TNCs, the City is working towards a data-sharing agreement with Uber and advancing its own survey work through the City's Chief Data Officer. At the time of the interviews, the City of Pittsburgh has asked Uber and other TNCs for trip origins and destinations, trip times, time of day, number of occupants, route taken, average speeds, and incidents of crashes. The City is currently exploring moving forward with a subsample of roughly 3,000 Uber drivers and data for the past two years, with initial analyses focusing on use cases for particular areas of the city for benchmarking transit impacts and first and last mile connectivity.

The results of a 2015 Make My Trip Count commuter survey offer a glance at the complexity of the Pittsburgh commuter patterns (Figure 6). The survey asked where commuters travel from and to, and which modes they

All Destinations

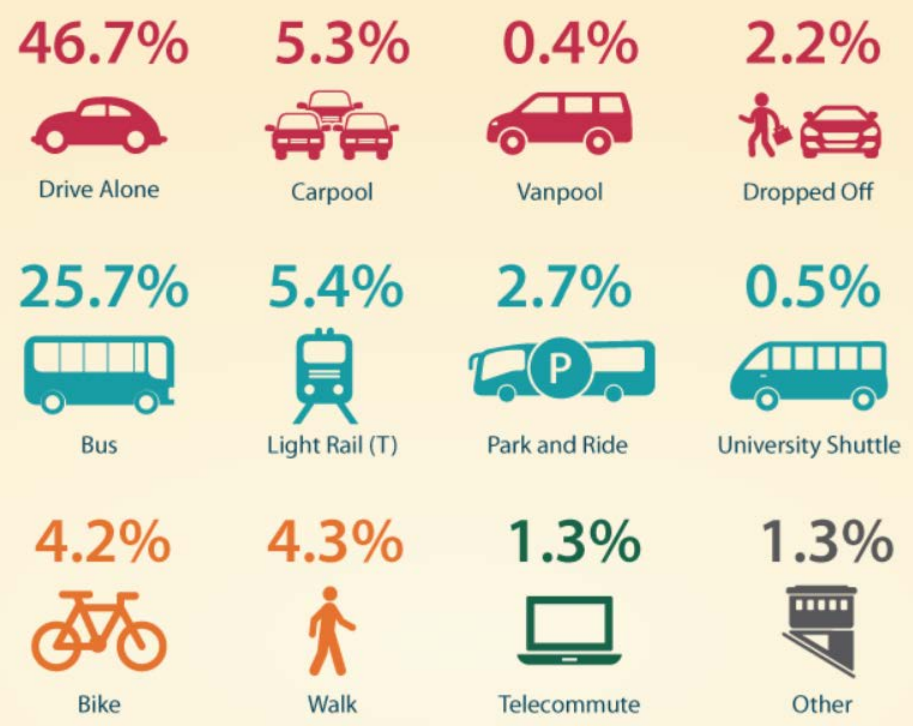

Figure 6. Mode split results from 2015 commuter survey regularly use. Compiled from 20,710 responses, the results reveal that less than half of respondents drive to work alone and that many commuters use multiple modes.

The City of Pittsburgh also actively engages multiple members of the Traffic 21 Research Institute and the Technologies for Safe and Efficient Transportation University Transportation Center, hosted at CMU. One new data analytics effort housed at the CMU Mobility Data Analytics Center focuses on transportation network modeling, emerging data from intelligent transportation systems (ITS), urban systems integration, transportation economics and traveler choices, and the various sources of data for multimodal transportation systems in Pittsburgh. A significant emphasis of the data being collected focuses on a regional Smart Mobility challenge on how innovative technology can improve mobility. CMU also has a parking data effort funded by the National Science Foundation's cyber-physical systems program, titled "Matching Parking Supply to Travel Demand Towards Sustainability: A Cyber Physical Social System for Sensing Driven Parking."

\section{Pittsburgh Transportation Modeling Capacity}

The Southern Pennsylvania Commission (SPC) oversees the long-term transportation planning and the travel demand modeling for the region. The SPC TDM is a four-step TDM belonging to the class of "legacy/traditional" travel models, and not the advanced "activity-based" travel models. Traditional travel models consider a person's travel itinerary as individual, disconnected trips without explicit consideration of the characteristics of the trip maker. The SPC model 
provides aggregated trip matrices to a static-assignment program, which simulates the trips on the network. The demand generation and network assignment processes happen in a sequential fashion, with feedback iteration across the entire peak period, hindering the model's ability to model real-time traveler behavior. The SPC model is built using CityLab's TP+ software and covers a geography of $\sim 1,200$ traffic analysis zones. The model considers auto, transit, walk, bike, and freight modes and is currently being run to inform various scenarios related to infrastructure, land use, and economic development of the region; scenarios that are quite traditional with respect to roadway infrastructure planning. The region conducted its last comprehensive travel survey in 2007, and the most recent upgrade to several components in the travel model took place in 2015. The SPC travel model provides the data and analysis that help shape the region's long-term transportation plans, manage congestion, and meet air quality requirements. Key future scenarios in the MPO's (as well as the City's) focus with respect to transportation are vehicle electrification, mode shift and transit use. Key drawbacks of the SPC travel model include 1) lack of advancement in a city-relevant modeling framework (although joint city-MPO modeling efforts are being made on a new bus rapid transit corridor), 2) inability to accurately reflect real-time travel behavior, and 3) lack of consideration to energy impacts.

The SPC covers a large area of Pennsylvania - 10 counties, including Allegheny County with Pittsburgh as the county seat. In contrast to other Smart City finalists, the relationship between the City of the Pittsburgh and its MPO (the SPC) is not as tightly coupled as observed in other cities such as Columbus, Denver, Kansas City, and others. In other urban areas, the primary city and its suburbs dominate the planning region with respect to land and population. In Pittsburgh, due to the vast coverage of the SPC and encompassing other population centers within the MPO region, this relationship is not as dominant. The SPC is seen more as a regional partner and a broader metropolitan regional actor. The SPC does publish regional data sets on its websites as an additional source for transportation and other planning data, but it is not considered as city- or urban-specific as the MPOs in other SCFs. (San Francisco is also an exception, due largely to two other major population centers within its MPO planning boundaries.)

[See the appendix for the Pittsburgh Modeling summary template.]

\section{Pittsburgh Takeaways}

- Energy interests are well represented in Pittsburgh's Smart City vision (the City expressed its desire to have the DOE at the table from the very beginning for the Smart City challenge); the intersections between the information and communication technologies, energy, and transportation themes all came up in the Smart City application.

- The Smart City Challenge helped the City to build new partnerships and think about existing partnerships. The intent and purpose of the Smart Pittsburgh consortium were all relevant to the infrastructure decision-makers, including Duquesne Light Company (as the electric utility). The City is also engaged in other activities via the 100 Resilient Cities initiative, in terms of how to build "resilience" into the Smart City proposal.

- Pittsburgh's strong partnerships with local universities, namely the University of Pittsburgh and CMU in the Smart City space, differentiates it from the other SCFs. 
Although other SCFs have university collaborations, in Pittsburgh these relations are integral to assisting in both the vision and execution of Smart City goals.

- Pittsburgh identified that it was important to define key concerns/goals (energy, mobility, and other) and then scrutinize if the technology offered by vendors matches the need. This was viewed as more efficient than simply receiving technology vendor pitches without a clear mapping into the City's goals and objectives.

- Pittsburgh has a unique interest and relationship with TNC service providers, particularly Uber due to its close ties to CMU and being the focal point of Uber's AV initiative. However, to date, access to TNC data or close collaboration with any TNC company, namely Uber, has not materialized as a result.

- With respect to travel modeling capabilities, Pittsburgh lags in that the City uses a traditional trip-based travel model lacking behavioral realism. The SPC model (in its current state) lacks the ability to model the mobility/energy impacts of CAV technologies or mobility as a service. 


\section{San Francisco: Smart City Challenge Finalist}

\section{Energy-Efficient Mobility Goals and Metrics (as stated in Sustainable \& Smart City Plans)}

- De-carbonization of the region's electricity supply

- One-hundred percent renewable electricity by 2030

- Sustainable Travel Choices

- Fifty percent Sustainable Trips: aim to reduce solo car trips and make at least half of trips by public transit, ridesharing, biking, or walking

- Low-energy and emissions "eco-zones"

- Reduce congestion and emissions via low-energy and limited entry zones or roadways (where hazardous levels of emissions and high energy use are reduced)

- Urban Sensors Deployment

- Emphasis on energy, transport, buildings data to be added to open data platform

- Alternative Fuels

$\circ$ Electrification and $100 \%$ renewable electricity (including large hydro) by 2030

- Smart Grids

- District energy, microgrids, roadway electrification and electric vehicles

- Parking Supply and Demand

- Manage and reduce energy use and emissions through SF-Park pilot initiatives

\section{Introduction to the San Francisco Smart City}

"In 2012, the SFMTA [San Francisco Municipal Transportation Agency] Strategic Plan targeted a goal of 50\% non-driving trips and 50\% sustainable trips (walking, transit, bicycling, shared rides) by 2018. The City has achieved a remarkable 50\% non-driving mode share 3 years early even while seeing quick growth in its population and employment." - City of San Francisco Smart City Challenge Proposal

Improving upon shared mobility with CAVs as a community-driven approach was an overarching goal for San Francisco. Reducing energy use, promoting non-single-occupancy driving trips, and expanding city efforts towards CAVs to shape the future of mobility continue to be an emphasis for the City. However, in the more immediate future, the City of San Francisco is concerned about the impacts of the proliferation of the use of TNCs such as Uber and Lyft on its streets, but there is a real lack of comprehensive data to help the public and decision makers determine how best to harness TNCs for reducing congestion, enhancing transit ridership, and attaining other system performance goals. For example, TNC trips are not all new trips to the city, some simply replace otherwise single-occupancy commutes. However, there is insufficient data to determine the percentage of TNC trips that are simple mode substitutions or net new travel.

Another consideration for the City has been accommodating the more than 45,000 TNC drivers operating in San Francisco from a prior system of only approximately 1,800 taxi drivers (Castiglione et al. 2017; San Francisco Municipal Transportation Agency 2016). The region also welcomes 50,000 regional visitors daily, noting that without adequate information on mobility 
choices, many may choose auto-based modes over transit, thereby adding to congestion, parking, and other related impacts.

In addition to the concern around TNC observability (as noted by Castiglione et al. [2017] and City staff), challenges due to rapid growth leading to lack of affordable housing and longer commutes for lower-income populations (from areas with more limited transport options) have also been noted.

With the surrounding region already seeing AV testing, the San Francisco proposal attempted to extend efforts and synergies among shared mobility, CAVs, and transit in ways that might reduce costs and time for travel, as well as the need to own a vehicle. This approach aligned with prior City goals of a 50\% non-driving mode share by 2018, which had already been met by 2015 .

The City of San Francisco not only viewed the Smart City competition as an opportunity to advance transportation partnerships and innovation in its region, it has continued to make significant progress since. While 16 pilot programs were proposed responding to neighborhood, city, and regional transportation challenges, the City has since received an advanced transportation grant that is funding four pilot programs from its Smart City application; with San Francisco County Transportation Authority (SFCTA) adding in Treasure Island pilot projects that include electronic tolling and automated shuttles. The U.S. DOT invested \$11 million in the City to help advance driverless shuttles, ride sharing (as connected carpool and public transit lanes), dedicated curb space, etc., and smart traffic management. In all, since the competition, the City has moved from proposing to develop 16 pilot programs in three years to developing six pilot programs in five years. One major emphasis has also been pursuing a grant from the California Air Resources Board to electrify portions of the TNC fleet. Another major emphasis is to streamline public-private partnerships, as catalyzed by Gillian Gillett, the mayor's Director of Transportation Policy.

As to the relationship of departmental roles and responsibilities to energy-efficient mobility systems, the Department of Environment oversees analyzing all the particulate matter and VMT, taking emission factors for fleet averages, and determining how to clean the electric power grid as relevant to emissions. Shipping, bus, and ferry planning, investment, and operations are led by the San Francisco Municipal Transportation Agency (SFMTA). The San Francisco Public Utilities Commission is responsible for the Community Choice aggregation initiative and focuses on power supply/grid side. City energy accounting is also under the Department of Environment (both fuel/electricity together). Pacific Gas and Electric Company and Hetch Hetchy Water and Power are the sources of electricity for city buildings and EV fleets. City staff are also working on an emerging mobility report, addressing mobility providers and their operations, and prioritizing key challenges and alignment of agencies and their respective goals. For example, the SFMTA with SFCTA most often have aligning goals, yet there are times where publicprivate partnerships affect relationships due to different governing structures (e.g., SFCTA has a board of supervisors, while SFMTA has a separate board, with some members appointed by the mayor).

\section{San Francisco Transportation Data Infrastructure}

At the time of its Smart City Challenge submittal, San Francisco had one of the most mature open data programs of the SCFs. This included an open data policy, open data platform, and 
central clearinghouse (called SFOpenData), which includes over 350 data sets (of which 30 were transportation related). Since then, new data sets have been added as open, machine-readable data, with increased interest in hosting data on shared, connected, and automated vehicles (once relevant policies are in place) for the City to help enable data-driven smart cities and energyefficient mobility entrepreneurship and innovation. Figure 7 shows an example of the TNCs Today Data Explorer - Fridays Summary Statistics.
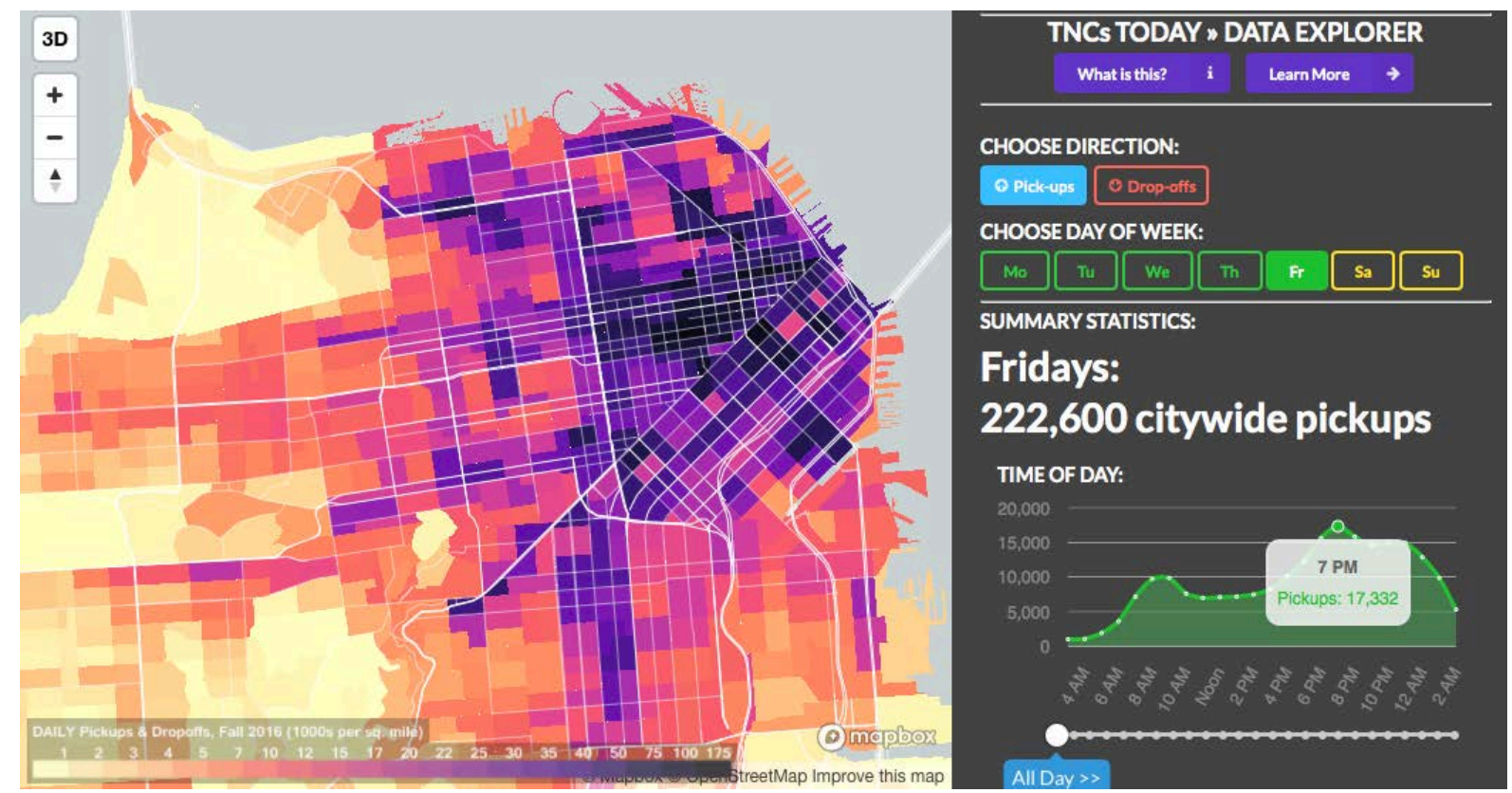

Figure 7. Sample of the TNCs Today Data Explorer - Fridays Summary Statistics

(Castiglione et al. 2017)

San Francisco's OpenData initiative, launched in 2009, continues to support the San Francisco Smart Cities initiatives that aim to meet GHG reduction goals and improve and increase public transportation service. The City is also very focused on TNC data. Access to data on TNCs, from a planning perspective, was identified as a near-term priority challenge and opportunity. Through initial collaborations with Northwestern University, a report titled TNCs Today: A Profile of San Francisco Transportation Network Company Activity was issued that characterized San Francisco TNC traffic using data skimmed from the API interfaces of TNC companies in November and December of 2016 (SCFTA 2017). The report was complemented by an initial TNC data web platform with data available for download (www.sfcta.org/tncstoday) and a visualization platform (http://tncstoday.sfcta.org) for exploring available San Francisco TNC data spatially and temporally. The study estimated that TNCs accounted for $15 \%$ of all intra-city

"The success of TNCs in attracting rides in San Francisco and other cities reflects the high unmet demand for premium services and the extensive benefits they provide. Initially TNCs offered some distinct advantages over taxis, including the ability to easily reserve a ride, the ability for both driver and passenger to contact each other and to know the location of the other using GPS, ease of payment, cheaper fares, shorter wait times, and more availability at all times of day due to a larger supply of vehicles. Taxis now offer some of these features, although the supply of taxis is still significantly smaller than TNCs, and taxi fares are higher." - SFCTA (2017) 
trips, where previously the City estimated TNCs accounted for $7 \%$ to $9 \%$ of all trips; however, neither estimate can be corroborated from other data sources.

\section{San Francisco Transportation Modeling Capacity}

The City and SFCTA interface on their larger model for the purposes of analysis of energy and transportation: the SF-CHAMP model produces all the relevant VMT data, and the City Department of the Environment is in charge of the GHG data. Currently VMT estimates for performance measure reporting are taken from the SF-CHAMP model, yet this model does not have vehicle fleet composition data (e.g., percentage of EVs or average fuel economy of internal combustion engine vehicles) as revealed from state registration data bases. On the modeling side, energy/GHG impact assessment is also done using the SF-CHAMP model as the primary city model. There is also a regional Metropolitan Transportation Commission/Association of Bay Area Governments as the MPO model that City staff were less familiar with. An observation from the City was that the regional model was ill-equipped and often lagging in terms of directly helping to understand city energy, VMT, and GHG emissions. This included the identified challenge of having over 45,000 new (Uber/Lyft) vehicles on the city's streets not being factored into the model. Figure 8 shows TNC activity as part of the modal split for an average weekday.

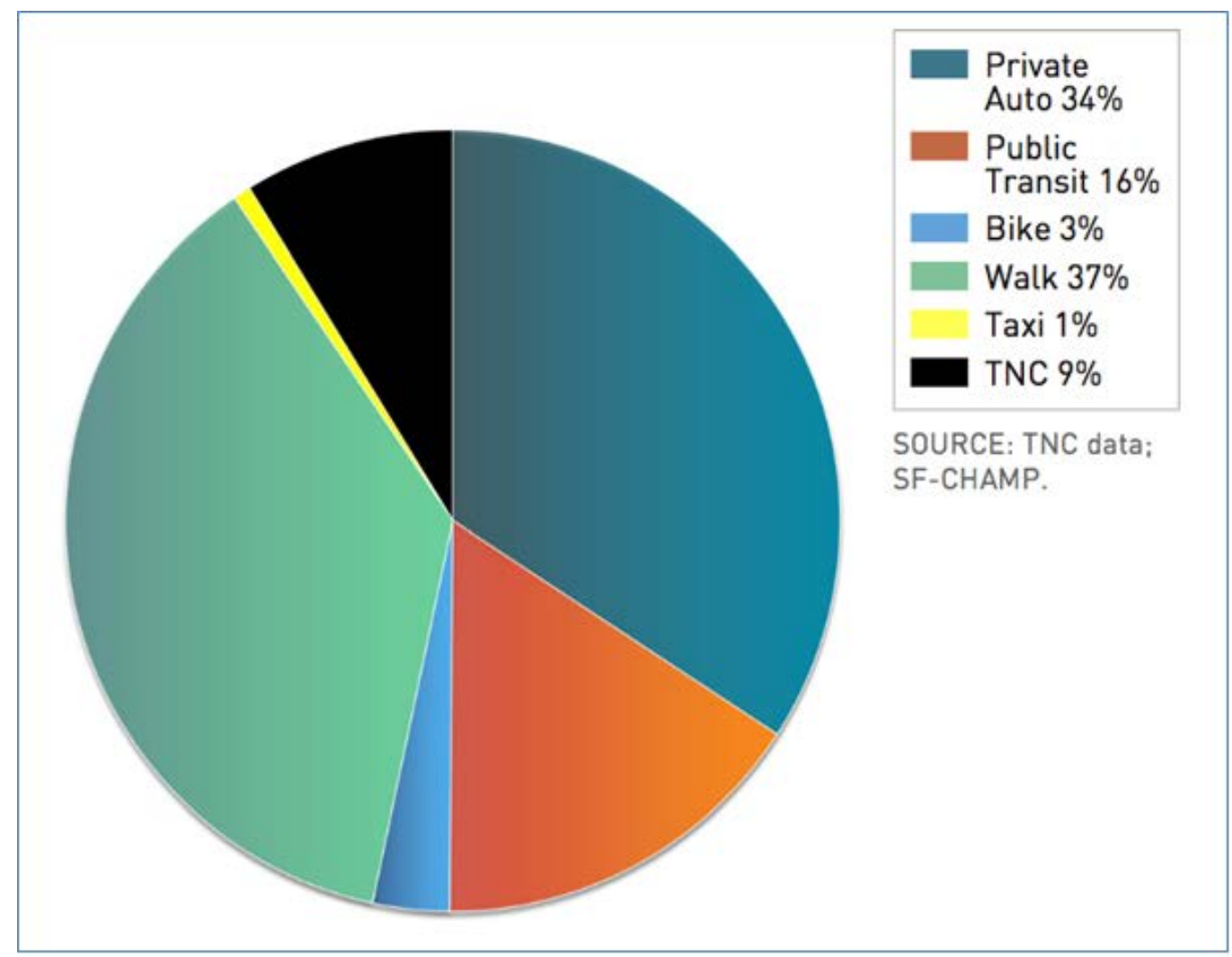

Figure 8. Profile of TNC activity as part of the modal split (average weekday)

Areas of interest identified by the City of San Francisco for improving the SF-CHAMP model capacity included:

- Learning what has been done or can be done to make the models accurately reflect new modes of transportation that were not foreseen when the models were built 
- Taking advantage of new technology (sensors, "big data," machine learning for validated predictive analytics) to build entirely new models that go beyond anything developed so far

- A better understanding of the "why?" of data collection and travel demand modeling, e.g., the types of questions models are currently unable to answer, the problems and limitations as well as the questions that — in theory - could be answered by implementing new data models.

[See the appendix for the San Francisco Modeling summary template.]

San Francisco Takeaways

Highlights:

- SFCTA is the main agency for city-regional modeling on energy and transportation, where VMT data are extracted by the San Francisco Department of Environment for cityscale energy and GHG accounting. However, the current model is limited with respect to the impact of TNCs as well as EV inventory.

- There is a concern over the approximately 50,000 new vehicles on city streets from TNC activity that are not being factored into the model. The model is ill-equipped to understand the VMT and GHG emissions of TNC vehicles.

- Fast changes are underway, with multimodal surveys indicating that TNCs went up from $2 \%$ in previous years to an estimate of $7 \%$ in 2017 .

- Remaining questions for the City: TNCs are likely taking some share of public transitbut how much? The TNC vehicles are likely also taking some share from private carsbut how much? Understanding these questions (and having available data on this) is critical to reducing congestion and pollution and shaping a TNC system that reduces private car trips.

- An opportunity was identified to have more targeted data collection with trips to and from the airport (as a City-owned asset). Today, San Francisco Airport charges $\$ 3.50$ for every TNC trip, generating upwards of $\$ 30$ million in revenue per year. Methods to collect financial data across cities via public disclosure reports can provide an early critical understanding of TNC trends/impacts. 


\section{Austin: Smart City Challenge Finalist}

\section{Energy-Efficient Mobility Goals and Metrics (as stated in Sustainable \& Smart City Plans)}

- Electrification

$\circ$ Public and fleet EV charging stations powered by $100 \%$ green-e certified renewable energy

- Deploy large numbers of electric TNC and taxi vehicles

- Travel Demand Management

- Reduce VMT and transport-related energy use and emissions

- Match employee origins of top employers to increase "pooling" matches for commuting

- Affordability

$\curvearrowleft$ Pncitivelv addrece the linkane hetwesen trancennrtation land uce and affordahility

\section{Introduction to the Austin Smart City}

Austin has noted it is among the top four cities in the nation for the number of EV charging stations and is leading the path towards accelerating and incentivizing the adoption of EVs into its consumer fleet by making charging opportunities abundant and at a reasonable cost. The city also is already home to one of the major Waymo self-driving car test and development sites and shared-use mobility services that are vibrant and growing. At the same time, like several other SCFs, Austin is experiencing rapid growth and is searching for methods to handle the increased congestion and strain on its transportation system because of that growth. Austin, like Columbus, has not invested in fixed-guideway transit such as light rail (although it has some commuter rail service). The pace of growth, relatively young population, and need for solutions to its growing mobility issues - in responding to shared, electric, and autonomous vehicle technologies - have led them to explore roadmaps and experimenting with new mobility options (City of Austin 2017).

Harnessing affordable, shared mobility is identified in Austin's smart mobility roadmap report as a top priority in response to growing congestion, and with early energy savings achievable in the near term relative to EVs and AVs. Shared mobility touches strongly on energy, affordability, congestion, travel time, and achieving social benefits. The City is asking the question of how quickly a 50\% reduction in energy use from transportation could be achieved for "shared" versus "electric" versus "automated" vehicles, and their interaction in the near term.

Austin's key stakeholders actively engaged in the Smart City Austin ecosystem, with emphasis on mobility and energy, including the Texas Transportation Institute (TTI), University of TexasAustin Center for Transportation Research, Austin Energy, Rocky Mountain Institute, Texas DOT, CapMetro, Capital Area Metropolitan Planning Organization (CAMPO), Central Health, and the City staff in the Transportation and Mobility Department. A key priority with respect to data among these organizations was ensuring interoperability and being able to easily interface with other departments that might be tangentially involved. A key gap identified by the Smart City partners was human behavioral components as they relate to the factors impacting the degree and pace of adoption of emerging mobility options. The Austin Smart City team has started a process to identify its top five to ten data needs, including TNC and AV data. In 
addition to mobility behavior, the team is also interested in identifying, benchmarking, and comparing mobility and critical transportation metrics across cities and across transportation sectors.

Austin's efforts towards accelerated EV adoption include various initiatives both to accelerate consumer adoption of EVs as well as to enable the electric power grid for significant vehicle electrification in the future. Austin Energy, the city's sole provider of electricity, stated that each new EV represents additional revenue generation of appropriately $\$ 400 /$ year for the utility. In addition to EV purchasing incentives (such as the $\$ 4.17 /$ month rate for accessing public chargers to address range anxiety), there is also an EV360 residential time-of-use rate pilot program to encourage residential customers to charge during off-peak hours (e.g., 7 p.m. to 2 a.m. on weekdays or weekends) by offering a flat fee of $\$ 30 /$ month. This begins to address not only the adoption of EVs, but management of the load on the grid.

On the automation front, in addition as serving as one of Waymo's testing grounds, the DOE announced in August of 2017 that Pecan Street Inc., in Austin, Texas, will receive \$1 million to pilot last-mile electric shuttle bus services. The project includes a feasibility assessment of new technologies such as autonomous and semi-autonomous vehicles and dynamic app-driven rerouting. This DOE living lab grant, which tests new ideas, collects data, and informs research on energy efficient transportation technologies and systems, will further Austin's track record for forward thinking mobility experimentation and create data and lessons learned for other Smart Cities.

At the state level, in 2016 the Texas Innovation Alliance (www.txinnovationalliance.org) was formed as "... an action network of local, regional, and state agencies and research institutions who are committed to addressing community mobility challenges by creating a platform for innovation." As a partnership containing eight of the most populous cities in Texas, the pooled approach emphasizes (1) procurement reform, (2) a comprehensive data strategy, (3) industry and stakeholder engagement meetings, (4) strategic and financial planning, (5) knowledge base, and (6) research-as-a-service. Austin and this alliance of cities in Texas were unique in the SCF approach to enacting Smart City plans in a collaborative fashion.

\section{Austin Transportation Data Infrastructure}

The Austin collaborative data infrastructure that has emerged to help respond to the Smart City initiative is called the Data Rodeo (www.datarodeo.org). The Data Rodeo focuses on creating a data management system that enables travelers, public agencies, and Smart City partners to archive, analyze, and access meaningful data and decision-making tools. Hosted by the University of Texas Center for Transportation Research at Austin, in conjunction with the Advanced Computing Center and regional partners such as CAMPO, the Data Rodeo provides a dynamic data-sharing ecosystem available to the broader transportation community. The Data Rodeo aims to provide a two-way open data portal and data exchange, allowing regional partners to contribute local data and access regional data. The Data Rodeo functions on an open platform that allows for the widest, most cost-effective way of sharing of data with partners, the public, research institutions, and third parties.

Some of the tools on the web site are shown in Figure 9. Of note is a re-identification data explorer (Bluetooth) that will allow users to view and directly download highly granular sampled 
travel time data from Austin's signalized corridors and a visualization tool for TNC data donated by the local Ride Austin company. More traditional data sources from CAMPO (the regional MPO) and sensor data from local jurisdictions are also made available.

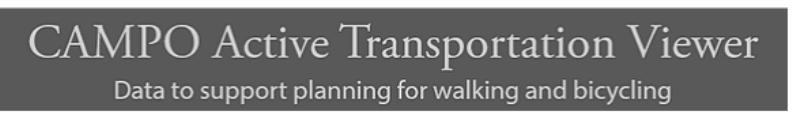

Data Location Explorer
Collected data, traffic signal locations, and Bluetooth sensor locations
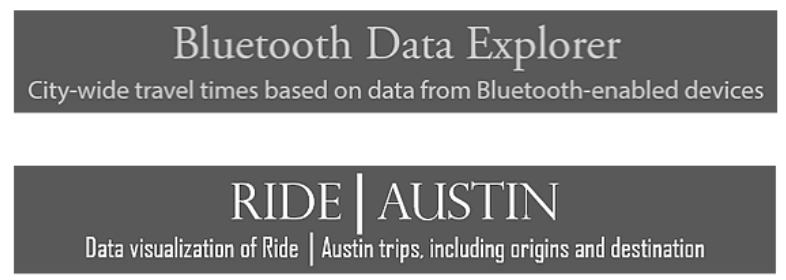

\section{Figure 9. Sample view of new transportation data portals in Austin}

Ride Austin (www.rideaustin.com) is a local TNC that was introduced to fill the void after Uber and Lyft left the Austin market in response to policy changes enacted by the City (but which were later rescinded at the state level). Ride Austin data are a useful source of TNC activity patterns, as it attracted up to 50\% market share at its peak. In contrast to Uber and Lyft, Ride Austin maintains an open data policy, making detailed data available to researchers, which allows for a better understanding of TNC activity patterns in Austin than is otherwise available. Data exploration and analyses of Ride Austin data are underway through collaboration among SMLC researchers.

A DOE Advanced Research Projects Agency for Energy project entitled "Traveler Response Architecture using Novel Signaling for Network Efficiency in Transportation (TRANSNET): The Connected Traveler" collects travel data in the Austin area from several thousand participants of the Metropia mobility app. The project, led by the National Renewable Energy Laboratory with collaborative partners from Metropia Inc., TTI, the University of California Davis, the University of Washington, and Kansas University, is testing the extent to which human behavior can be incentivized toward more sustainable travel behavior. The smartphone app developed and enhanced through the project is designed to influence travel behavior toward sustainability practice. It incorporates incentives to nudge users toward more energy-efficient travel options. Use of the app generates revealed behavior data to compare with stated preference data. The Metropia data set is being used to inform development of modeling capabilities undertaken by TTI.

\section{Austin Transportation Modeling Capacity}

The CAMPO regional transportation model is a combination of planning and modeling tools, including the TDM, utilities, and other functions. The CAMPO TDM is an aggregate, four-step model built using the TransCAD software. The current 2010/2040 model is calibrated to a 2010 household survey and 2010 census data. Modeled networks include 2010, 2015, 2020, 2025, 2030, 2035, and 2040. Of these, 2010, 2020, and 2040 are kept up to date. Trip generation is run for multiple trip purposes, including home-based work, home-based retail, home-based other, primary/secondary/university trips, non-home-based work, and other trips. An airport trip purpose, external auto and trucks, and a general service/truck generation purpose based on transportation analysis zone employment are also included in trip generation. Trip distribution is performed using a TransCAD-provided gravity model for each trip purpose. Trips are distributed between production and attraction transportation analysis zones based on travel times, with 
iterative feedback of network speeds from the traffic assignment step. Mode choice supports modeling for high-occupancy vehicle (HOV) lanes, for HOV2 (two or more passengers) and HOV3+ (three or more passengers), and several transit modes with walk access, drive access, and park-and-ride lots. Households are further disaggregated by auto availability classes-zerocar households and classes based on household auto ownership in relation to workers per household. Output of the mode choice component serves as input to a planning-level static user equilibrium traffic assignment model, which can be run for different time periods (AM Peak, Mid-day, PM Peak, and Night).

Austin is home to the University of Texas at Austin and is near the TTI, both of which offer world-class research and development programs in transportation. Austin has benefitted from several research initiatives using the CAMPO model as a base, and enhancing and expanding it for various research objectives, several of which are associated with ACES technology. In one such initiative, researchers at TTI developed a simulation-based DTA model of the entire modeled CAMPO region. The current benefits of the DTA model include:

- Addressing both short- and long-term impacts of new facilities or operational practices at the integrated systems level

- Capturing a dynamic range of congestion conditions over time

- Reflecting interactions of travel demand and management strategies in integrated systems, including congestion pricing

- Modelling reactions of travelers adapting to dynamic congestion conditions

- Allowing for consideration of a range of operational conditions, including incident patterns, weather, and variation in travel demand.

More recently, the Austin DTA model (developed by TTI) has been linked to Metropia - a mobile-based platform that employs gamification and behavioral strategies to influence travelers to make more informed personal mobility decisions that include mode shift, off-peak travel, and route choices to under-utilized corridors. The DTA platform is also linked to MOVES to analyze multiple GHG pollutants. The CAMPO model as it stands now includes:

- Separate classification of detailed trip purposes, such as home-based retail trips and education trips

- Several stratifications of households by size, income, and number of workers

- Specific treatment of auto availability in the mode choice step

- Aggregate treatment of time periods (four)

- A generalized cost impedance static user equilibrium traffic assignment that accounts for the cost of tolls in addition to operating cost, along with travel speeds, in route assignment

- An adjustment of trip distribution and mode choice based on estimated average congestion from peak and off-peak period static traffic assignment. 
The CAMPO model experiences the same limitations as any other aggregate trip-based model. Many of these limitations could be overcome using an ABM structure. However, building an $\mathrm{ABM}$ for the CAMPO region would require extensive regional effort, funding, time, and coordination among multiple agencies. Still, ABMs face the issue of a lack of data upon which future transportation choices could be calibrated. Also, ABMs face the same issue of feedback of system performance (supply modeling from precision DTA) to demand estimation and adjustment. Therefore, the most that can be done with the CAMPO model to reflect future transportation choices is to treat the CAMPO model prima facie. Subjective engineering judgement combined with reasonable estimation of scenarios and time frames will need to be used.

Subsequent discussion with the City of Austin indicated that the ability of and confidence in the CAMPO model to provide timely input into the current decision process of the City with respect to its visions and goals as reflected in the Smart Mobility Roadmap 2017 centered on ACES technologies are lacking. This is due partly to many of the concerns previously addressed, in that TDMs generally lag, being primarily a rearward facing modeling construct. Without a history of the impacts of ACES technology, they are hard-pressed to reflect future impacts. Also, as just one of several jurisdictions (although the most populous), the City of Austin has limited influence to direct the MPO with respect to the urban-centric data, and modeling required by the City, while not a priority of the less populous jurisdictions composing the planning regions served by CAMPO. Such a dynamic between the principal city and numerous other, less populous jurisdictions represented by an MPO is not uncommon. As such, Austin is exploring data and non-traditional TDMs and analysis to inform its Smart City process.

[See the appendix for the Austin data and model summary templates.]

\section{Austin Takeaways:}

Research questions and primary concerns that surfaced in discussion with the Austin Smart City players included:

- What are the elemental components to developing a shared/electric/autonomous vehicle plan and roadmap? Who will be involved in implementing Austin's Smart Mobility roadmap?

- What are the urban modeling capabilities to study impacts of TNCs? What data are available and what can Austin do with the TNC data?

- What is the impact on energy production if there is a $25 \%$ increase in EVs in the city? What will be the sources for electricity?

- What kind of policy, regulations, and human behavior issues need to be changed across Austin to accept and embrace Smart City deployments? What are the motivations and incentives for urban travelers to migrate to smart mobility technology deployments and new services?

- How is Smart Austin going to acquire data to integrate across all platforms and technologies?

- What can be learned from EV pilot programs with Austin Energy? Where will existing 
and new EV charging stations need to be located?

- When and how will an AV proving grounds be formulated and deployed? What are the best funding mechanisms/financing options?

- What are return on investment results and economic benefits for smart investments? What resources will TNCs need to grow a larger participation rate?

- How does Austin encourage or incentivize TNCs fleets to adopt EVs and provide sustainable economic models for its drivers?

- What will be the key land use, infrastructure, and parking changes and their energy impacts?

Many of the Smart City goals and initiatives predate the Austin Smart City Challenge application, and Austin is actively proceeding with electrification and automation initiatives. As a sprawling, high-growth city, many are watching Austin to see if any of the emerging ACES technologies can address the stresses (particularly congestion) that are plaguing its current mobility system, threatening continued economic expansion. 


\section{Denver: Smart City Challenge Finalist}

\section{Energy-Efficient Mobility Goals and Metrics (as stated in Sustainable \& Smart City Plans)}

- More "Pooling" and Less Single-Occupancy Vehicle Commuting

- Reduce trips in single-occupant vehicles to less than $50 \%$ of commutes (today, $73 \%$ of Denver commuters drive alone)

- Increase bike/pedestrian commutes to $15 \%$ and transit commuters to $15 \%$

- High-Occupancy, High-Mileage, On-Demand EV Fleets

- Interest in synergy between (increasingly electric) transit and TNCs

- Business models for publicly owned, high-mileage, on-demand EV fleets

- Partner with Xcel Energy and others to rapidly expand EV infrastructure

- Lead by example by adding 200 EVs to the Denver city fleet by 2020

- Partner with car share, taxi, and TNCs to deploy EVs in ride-sharing applications

- Managing Population Growth and Preparing for CAVs

- Energy- and resource-efficient infrastructure and multi-modal mobility systems development for increased accessibility/freedom for all, within a context of rapid population growth, and rising congestion/pollution levels (e.g., one in ten Denver residents is living with asthma)

- Work with the Colorado DOT, Panasonic, and others on electric CAV technology

\section{Introduction to the Denver Smart City}

Denver Smart City is leveraging new mobility technologies and services innovation, tapping into real-time data and insights to address the key community problems. As a multi-agency program, Denver is focused on better health and wellness, more convenient and equitable access to city services, cleaner air and environment, safer streets, and more affordable mobility options. Supported through industry and community partnerships and federal funding, Denver Smart City is working to improve the quality of life for residents and visitors. Key emphasis areas for Denver have been on connected vehicles, TNC electrification, a first-mile/last-mile pilot program, EV adoption, an overall enterprise data management (EDM) system, an integrated mobility app (including for mobility choices and payment), air quality sensors, equity and affordability, and mobility systems designed for population growth and economic development.

Today, Denver is ranked third among U.S. cities whose population was over 250,000 in 2010 for population growth, with growth of $15.5 \%$ from 2010 to 2016 . This is just behind the $16.9 \%$ growth rate of Austin (as shown in Table 1). In addition, as one of the fastest-growing U.S. cities, Denver is experiencing significant increases in construction and traffic congestion.

In response to problems such as increased fatalities on Denver streets, increased congestion, and its impact on air quality, the City has developed the Denver Smart City initiative, which builds on greater Denver efforts, including a mobility action plan that includes strategic goals for mode choice diversity (walk, bike, drive, transit or shared); safety (improving safety through a Vision Zero initiative); climate and health (by expanding use of EVs and charging stations); and accessibility (leveraging technology to make individual trips easier and faster). Other related efforts within Denver include: Vision Zero, Safe Routes to School, 80 x 50 Climate Goal, and 2020 Air Quality goals. 
Table 1. Denver is Ranked Third Respectively in Population Growth among 39 Cities over 250,000 Population, including Four Other Smart City Finalists

(Source: U.S. Census Bureau, 2012)

\begin{tabular}{llllll}
\hline Ranking & City Name & $\begin{array}{l}\text { Population in } \\
\mathbf{2 0 1 0}\end{array}$ & $\begin{array}{l}\text { Population in } \\
\mathbf{2 0 1 6}\end{array}$ & Pop. Growth & $\begin{array}{l}\text { \% Growth } \\
\mathbf{( 2 0 1 0 - 2 0 1 6 )}\end{array}$ \\
\hline $\mathbf{3}$ & Denver, Colorado & 599,864 & 693,060 & 93,196 & 15.5 \\
\hline \multicolumn{2}{l}{ Other DOT Smart City Competition Finalists with Population over } & $\mathbf{2 5 0 , 0 0 0}$ & \\
\hline $\mathbf{1}$ & Austin, Texas & 811,045 & 947,890 & 136,845 & 16.9 \\
$\mathbf{2 2}$ & Portland, Oregon & 583,799 & 639,863 & 56,064 & 9.6 \\
$\mathbf{2 4}$ & Columbus, Ohio & 788,866 & 860,090 & 71,224 & 9 \\
$\mathbf{2 9}$ & $\begin{array}{l}\text { San Francisco, } \\
\text { California }\end{array}$ & 805,193 & 870,887 & 65,694 & 8.2 \\
\hline
\end{tabular}

To address air quality issues, Denver is exploring real-time, hyper-local air quality data and programming empowering communities, families, and schools to limit exposure and reduce pollution through behavior change, advocacy, and community engagement. With respect to Denver's mobility ecosystem:

- Denver is a leader in emerging modes: B-Cycle with 87 bike-share stations is the first city-wide bike-share system in the country. The concept has now expanded to more than 60 U.S. cities since 2010. Five car-share operators (e.g., ZipCar, Car2Go, eGo CarShare, Uber, and Lyft-as indicated in Denver's Smart City Vision Narrative [City and County of Denver 2016]) operate within the city. Uber and Enterprise are piloting a system to rent or lease vehicles to ride-hailing drivers.

- With respect to electrification, there are 34 city-owned EV charging stations (at the time of the proposal), strong state-level incentives for EV purchasing, wireless charging for downtown electric buses, electric AV mobility-on-demand planned for the Peña Station Next development, and additional EV infrastructure expansion.

- The City is working collaboratively with internal and external partners on a \$12M congestion mitigation effort to develop and deploy a connected ecosystem focusing on Vehicle to Everything (V2X), with a specific focus on Vehicle to Infrastructure (V2I), Infrastructure to Vehicles (I2V), and Pedestrians to Infrastructure (P2I) technologies. The three use cases that inform these key communication channels are: connected freight, connected fleet, and pedestrian safety. In particular, connected freight is being deployed in an "environmental justice" community to respond to the desire to minimize the negative effects of freight traffic on children, whether crossing the streets or getting to school safely.

- The Denver area is served by a growing light right system managed by the Regional Transit District (RTD), recently opening lines that connect the bustling downtown to Denver International Airport. Maximizing the return on investment in this light rail system is a common objective in many Smart City projects. 
- As part of the focus on CAVs, Denver has partnered with Panasonic and EasyMile (along with RTD) at $61^{\text {st }}$ Avenue and Peña Boulevard to pilot automated electric shuttles connecting the Peña Station Next light rail station with the $61^{\text {st }}$ Avenue bus stop, closing a last-mile gap of about one mile.

Colorado, with its Taxpayer Bill of Rights (TABOR), a constitutional measure that limits the annual growth in state revenues or spending to the sum of the annual inflation rate and the annual percentage change in the state's population, restricts revenues for all levels of government (state, local, and schools). Under TABOR, Colorado and local jurisdictions cannot raise tax rates without voter approval and cannot spend revenues collected under existing tax rates without voter approval if revenues grow faster than the rate of inflation plus population growth. As a byproduct of TABOR, Colorado, by necessity, has used public-private partnerships for financing and other capital improvements. This has resulted in the expansion of the system of toll roads in Colorado to increase highway capacity. It will likely continue to largely influence mobility planning and decision choices in Colorado as well as Denver, encouraging public-private partnerships to create revenue-neutral solutions to solve mobility challenges.

Denver as the largest metropolitan area in Colorado and lead city of the Front Range population centers, has several supporting partners, including the regional MPO, a strong relationship with the Colorado DOT (CDOT), several local and regional universities and research laboratories, and other civic institutions. This also includes the Mobility Choice Blueprint Initiative (MCBI), a partnership among public, private, and nonprofit organizations focused on changing how Denver moves and making the Denver metro area a better place to work and live as a result. An initiative with the nonprofit Denver Metro Chamber Leadership Foundation, the MCBI (www.mobilitychoiceblueprint.com) mission is to create a mobility vision for metro Denver driven by public and private sectors by developing key strategies to leverage current assets using new technologies, defining clear roles, and providing an integrated system of the future for all.

The objectives of MCBI include:

- Targeting options for connected mobility such as transit, personal vehicles, for-profit mobility services, car-sharing, ridesharing, bicycling, and walking; creating choice; and moving the region to a convenient, integrated system

- Maximizing the investment in the region's light rail transit system

- Identifying public-private pilot projects, and joint-funding partnership opportunities

- Improving roadway reliability by using new technology to support active traffic management, including express toll lanes, signal coordination, ramp metering, variable speed limits, and lane control

- Ensure clear roles for implementation and evaluation of identified strategies by transportation agencies, mobility service providers, and research partners.

\section{Denver Regional Transportation Data Infrastructure}

At the city level, Denver has begun to focus on aspects related to an overall EDM solution, integrating Smart City strategies into ITS work, and integration with other important sensors such as air quality devices. The EDM builds off Denver's Open Data Catalog 
(https://www.denvergov.org/opendata), which was created in partnership with Open Colorado to create a data-sharing platform to make public data available and accessible to all Colorado constituents. Currently, there are 210 data sets, from traffic accidents to crime information. All the data are made available with a dashboard that allows for quickly analyzing the data. Denver is also extending the EDM and smart mobility technology testing through its living labs approach, where tests, demonstrations, and pilot programs for collecting new real-time and ongoing data streams in a controlled environment occur. The objective of the living lab is to leverage knowledge toward improvements on a larger scale in ways that may improve safety and reduce congestion and energy use.

At the metropolitan scale, the MPO, Denver Regional Council of Governments (DRCOG), serves up regional data, mining data from local, state, federal, and private sources annually to create the data set list that follows. Most are made available for public download through its Regional Data Catalog (http://gis.drcog.org/datacatalog/). Those that are marked as restricted are not available to the public but may be shareable with partners with the appropriate written permissions. This is not an exhaustive list.

- Regional Open Space

- Regional Zoning

- Regional Bike Facility Inventory

- Nursing Homes and Assisted Living Facilities

- Transportation Improvement Projects

- Crashes

- Building Roofprints

- Sidewalks, Trails, and Ramps

- Parking Lots

- Census

- Regional Housing and Employment Data Summary - restricted

- Development Type Classification (Urban, SemiUrban, SemiRural, Rural) - restricted

- Regional Parcels and Subdivisions - restricted

- High-resolution aerial imagery - restricted.

DRCOG also serves highly granular and detailed data sets (referred to as raw data). DRCOG uses these data sets as inputs into regional data development efforts and can share them with partners.

- Quarterly Census Employment and Wages Q2, Department of Labor and Employment

- Business data, InfoGroup

- Residential data, InfoGroup

- Local open space, local governments

- Local zoning, local governments

- Local bike/trail, local governments

- Commercially available origin-destination data, via CDOT. 
DRCOG has several original data sets that are not available elsewhere. Some of these data are the product of land use and travel models, which take information about current conditions in the region and estimate forecasts for future conditions. Other data sets in this list are mined from our services and ride-share programs and are available by request only, and access is granted on a case by case basis.

- Travel Forecasts

- Regional origin-destination matrices by vehicle occupancy (drive alone, shared ride 2 , and shared ride $3+$ ) for 10 different times of day

- Average daily/by time period traffic volumes for specific "links"

- Zonal statistics (mode share, average trip length, and percent of trips less than $\mathrm{x}$ miles)

- Regional VMT

- VMT per household

- Total number of tours/trips per household

- Total number of tours/trips by purpose

- Travel times by mode for specific origin-destination pairs

○ Household mode share statistics

- Population Forecasts

- Employment Forecasts

- Land Use Forecasts

- Way to Go - Schoolpool/Vanpool/Carpool ride-share statistics: http://www.waytogo.org/

- Bike to Work Day statistics: https://biketoworkday.us/

- Go-Tober statistics: http://www.waytogotober.org/

- Health care service utilization data (Meals on Wheels, paratransit etc.).

CDOT has also been a strong data partner of the City, recently hiring a chief data officer who had experience leading the New York City open data efforts under Mayor Bloomberg, and at New York State DOT under Governor Cuomo, where data were made available publicly on EVs registered by county in the state. As Denver and the Front Range region is the dominant metropolitan region in the state, much of the CDOT operations and planning functions focus heavily in this area. The remaining portions of the state are primarily rural. CDOT is investing in data systems for ITS, connected vehicle, and its internal operations. This includes a multi-year project with Panasonic for deployment of over 300 miles on the central I-70 corridor in the state, serving the Denver area as well as the popular ski destinations to its immediate west. The CDOT data for operations, including over 3,000 sensors, are being brought together under a new Data Analytics Intelligence SYstem (DAISY) that will not only bridge the internal data silos within CDOT, but also provide the API-based sharing mechanism to allow third parties to access CDOT data for value-added applications. The DAISY effort in many ways is analogous to the citybased IDE efforts and will complement the City of Denver's EDM and DRCOG's data-sharing platforms. The major highways around Denver (including portions of I-70 and C-470) are also undergoing major capital improvements, including the addition of toll lanes, as a significant investment in ITS. CDOT's Road-X program is one of the leading state initiatives in the ACES space, creating many opportunities for collaboration and partnership between CDOT and 
Denver. This includes the Peña Station Next automated electric shuttle projects as well as an MCBI focused on the transformative capacity of new technology in the transportation field.

\section{Denver Transportation Modeling Capacity}

DRCOG developed an ABM (labelled FOCUS) using the 1997 travel behavior inventory survey and updated it recently with the 2008 transit survey data and 2010 household travel survey conducted in the region. CDOT is gearing up for its next state-wide travel survey (to be deployed by the end of 2020), and DRCOG plans to use the data for another update to the FOCUS model. It hopes to capture the much needed TNC "travel" behavior with the travel survey that is soon to be deployed. The operational schematic of the FOCUS model is similar to that of the other ABMs (such as the METRO model or the $3 \mathrm{C}$ model) in that it receives land use inputs from a land use model developed in UrbanSim. The FOCUS model couples this information with sociodemographic and network data to generate travel patterns at the individual level in the model region. The trips are then sent for loading on the network to a static-assignment model (as opposed to a DTA in the METRO model). Travel times for network segments are output to the EPA MOVES model for energy and emission calculations. In addition to modeling travel patterns at the disaggregate level of an individual, the FOCUS model houses a variety of submodels to explicitly model travel to airports and universities in the region, and other special generators.

Scenarios related to infrastructure, land use, energy, and economy are being developed by DRCOG to be tested using the FOCUS model. A key feature of the FOCUS model is that it only takes a few hours to run (many ABMs take much longer), while a key shortcoming is that it is linked with a static-assignment model, which limits the model's capability in depicting traveler's real-time responses to network incidents (e.g., crashes, lane closures etc.).

[See the appendix for the Denver data and modeling summary template.]

\section{Denver Takeaways}

The Denver Smart City program seeks to address its mobility issues using a variety of technologies, partnerships, and approaches, with emphasis on both electrification of transportation (including transit) and shared mobility.

- The City and State have a strong emphasis on EV adoption predating the Smart City Challenge. This includes EV charging infrastructure as well as state tax credits for EV adoption that rival that of any state. Denver has instituted wireless charging for downtown electric buses $\left(18^{\text {th }}\right.$ Street corridor).

- Denver cooperates heavily with the CDOT RoadX program with respect to ITS and AV interests. This includes a demonstration of automated electric shuttles at the Peña Next Station, a joint collaboration of Denver, RTD, Panasonic, and Easy Mile.

- The City, RTD, and the larger metro area are interested in further stimulating early-stage shared, connected, and automated mobility business models by creating an enabling policy environment, enhancing infrastructure and operations through its MCBI (2017). The transit agency, with the City, is also in the process of creating a First and Last Mile 
Strategic Plan that builds on initial pilots in the nearby city of Centennial with Lyft and the Uber app used for Lone Tree Transit vehicles (RTD 2018).

- The light rail system, with recent buildout and connections including Denver International Airport, provides a dedicated guideway transit system to optimize intraurban travel. Investments in emerging modes are balanced against this infrastructure and the over-taxed roadway system.

- Denver's efforts with respect to ACES technologies are set against a backdrop of strong local and state partners including CDOT, DRCOG, RTD, MCBI, and regional universities (University of Denver, University of Colorado at Denver, and others), and research laboratories (National Renewable Energy Laboratory).

- Being the leading city within the Front Range region of major population centers, operating under the Colorado TABOR law, enjoying a fast-growing urban economy and population, and having close operational ties with the progressive CDOT provide Denver with unique constraints, motivations, and opportunities to experiment with ACES mobility solutions as well as their accompanying business models. 


\section{Kansas City: Smart City Challenge Finalist}

\section{Energy-Efficient Mobility Goals and Metrics (as stated in Sustainable and Smart City Plans)}

- Energy Efficient Traffic Signals and Street Lights

$\circ$ All streetlights and $\sim 40 \%$ of traffic signals already had energy-efficient retrofits

- Alternative Fuels

- Build on \#3 ranking of 50 largest U.S. cities for percent of fleet vehicles (50\%) that operate on alternative fuels_-all diesel vehicles use biodiesel and 250 vehicles (including shuttle buses at the Kansas City airport) operate on compressed natural gas.

- Managing Ozone Levels

- During summer, action plans to reduce unnecessary travel, use of transit for

\section{Introduction to the Kansas City-Smart City}

The Kansas City metropolitan area straddles the Kansas-Missouri state line, with the city sitting at the border along the Missouri River. The Kansas City metropolitan area, like Austin, has few geographical features to constrain continued metropolitan development. Even so, the city has experienced renewed growth in the downtown and surrounding core areas. The Kansas City Smart City initiative, termed the Living Lab, is a public-private partnership designed to develop and deploy Smart City-based internet-of-things and Smart Connected Cities technologies. The premise of the Kansas City Living Lab is to seek out the best emerging technology solutions whenever a problem or challenge presents itself, and to test and validate the technology with the goal of fullscale commercial deployment. The scope of foreseeable projects includes connected platforms (vehicles, intersections, and back-office systems); public Wi-Fi; community kiosks; video as sensors; and smart lighting technology deployments. Reliable, high-speed, wired, and wireless networks and communication are at the heart of Kansas City Living Lab objectives, as evidenced by the graphic from the Kansas City Living Lab website (Figure 10) with the common symbol for wireless communications at the center of the image.

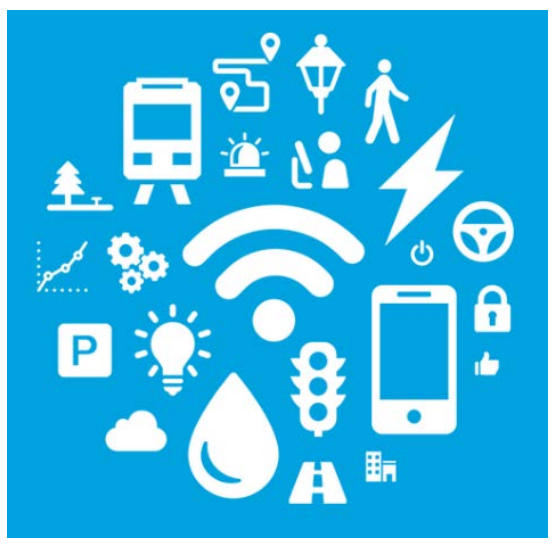

Figure 10. Kansas City Living Lab graphic

A major partner in the Kansas City Living Lab is Cisco Systems. In May 2014, Kansas City signed a letter of intent with Cisco Systems, Inc., to explore the feasibility of developing a Smart City network, predating the U.S. DOT Smart City Challenge. Many of the Kansas City Smart City objectives are based on increasing communities' access to the internet through municipalbased Wi-Fi, leveraging wireless communications for the benefit of its citizens, as well as to more easily communicate city-specific information to the community.

Kansas City is heavily involved in the Gigabit City Summit, which takes the perspective of not simply how to build new infrastructure and deploy new technology (particularly in the 
communications and networking realm), but how to apply those assets in the right way, that takes the needs of the individual citizen into account. Through strategic partnerships with Cisco Systems and Google Fiber, Kansas City is a leader in emerging gigabit cities, a necessary step to have the infrastructure to support the smart data bandwidth across all smart initiatives, programs, and projects, especially in energy-savings technologies within the transportation arena.

Kansas City has also been progressing in EV adoption with a primary partner of Kansas City Power and Light. Through Kansas City Power and Light's Clean Charge network, over 1,000 EV charging stations have been deployed throughout the Kansas City metropolitan area, and EV charging usage is tracked. Kansas City has also offered free charging on the network (Kansas City Power and Light 2017).

Kansas City has an area of 319 square miles, with over 93,000 streetlights. Kansas City is examining streetlights as a platform for low-latency wireless sensor networks while providing Wi-Fi access to citizens and public servants. Through the use of newer light-emitting diode technology, the City has the opportunity to reduce streetlight operating and maintenance costs while saving energy. Advanced lighting controls can provide spatially balanced illumination that reduces crime while saving energy through presence-based dimming. Self-monitoring features can send fault alerts to a centralized control system, even detecting (and thus deterring) copper theft and preventing costly unscheduled maintenance.

With respect to automation, the Kansas City Regional Transit Authority plans to field an autonomous transit vehicle in a limited geographical area. In the spirit of testing and validating the technology, the transit authority has a staged plan to run the autonomous shuttles on different routes over various distances and different levels of separation from regular traffic.

\section{Kansas City Transportation Data Infrastructure}

The Kansas City Living Lab has deployed various sensors along a recently constructed two-mile streetcar route, termed the Smart Corridor. As of August 2017, the data are available to researchers by application at http://kclivinglab.org/. The application process at the Living Lab specifically queries applicants on ideas and projected use of the data. In addition to the new mobility data, the available data span Smart Parking infrastructure (availability, type, occupancy, violations, and reservations); Smart Lighting (streetlight state - on or off, brightness, energy use, and strobe capability); environmental sensors (temperature, humidity, pollution levels, noise, barometric pressure); and Smart Waste (container type, level, last emptied). This data system is a developmental data sandbox, offering partners with ideas that align with Kansas City's vision and objectives the ability to quickly experiment and prototype.

Kansas City has implemented an open data standard and has various data sets, reports, and charts available for public use. OPENDATA KC (https://data.kcmo.org/) is the web-based data repository for Kansas City, including 61 transportation-specific data sets. The site also serves data across the entire spectrum of city operations and business. Similarly, KCStat (https://kcstat.kcmo.org) is a data-driven approach to improve city services. KCStat focuses on monitoring the City's progress toward its Five-Year Citywide Business Plan, which is organized around six goal statements adopted by the Mayor and City Council. This site provides an "at-aglance" analytics view of these goals and objectives, along with narrative and visualizations that automatically update to reflect the most recent data. 
XAQT, Cisco Systems, and Kansas City have developed the first Kansas City-specific Smart City real-time application based upon the Living Labs open data sets. Accessible via http://smartkc.xaqt.com (password protected), this OPENDATA KC application provides a realtime view of traffic speed, streetcar location, and parking along a 2.2-mile designated roadway in downtown Kansas City.

The Mid-America Regional Council (MARC), the MPO that serves the Kansas City metropolitan area, hosts a regional data center (http://www.marc.org/Data-Economy) for data sets typically associated with state/regional/city planning and has developed a data architecture to support sensor deployment, data acquisition, and system development as part of its ITS efforts.

\section{Kansas City Transportation Modeling Capacity}

MARC maintains the regional TDM for the bi-state, eight-county planning area (Leavenworth, Johnson, Wyandotte, and Miami Counties on the Kansas side and Cass, Clay, Platte, and Jackson Counties on the Missouri side). The current MARC model is an enhanced four-step, trip-based model that focuses on daily travel patterns. Over the last few years, MARC has improved and augmented the model to include many enhancements, such as an auto availability model with household income and household size sub-models, improved trip distribution procedures to include destination choice formulations, enhanced the time-of-day component to model 24-hour daily slices, and Kansas City International Airport as a special generator. The modeled area is 3,849 square miles comprising 2,477 traffic analysis zones and 33 external stations. The model is implemented using the EMME transportation modeling software package and contains approximately 35,964 links and 17,471 nodes. The model has been calibrated to reflect a base year of 2015 and contains future year data reflecting forecast 2040 conditions.

Scenarios pertaining to infrastructure, land use, and economy are currently being tested using the MARC travel model. The mode choice module has been converted from FORTRAN to Python scripts. In addition, demographic data and roadway and transit networks have all been updated to a 2015 base year. Furthermore, in addition to the regional TDM, a dynamic DTA model is under development for a portion of the Kansas City region. It is being developed for the Beyond the Loop planning and environmental linkage study, which is considering a range of alternatives for the Buck O’Neil (Broadway) bridge and north portion of the downtown Interstate loop.

[See the appendix for the Kansas City data and modeling summary template.]

\section{Kansas City Takeaways}

The Kansas City Smart City initiative is characterized by an emphasis on enhanced communications and networking as the backbone for advancing its goals, followed by rapid experimentation with technology as solutions to Kansas City problems and challenges. Termed the Kansas City Living Lab, the program is a test and deployment laboratory, providing a unique public-private partnership that is designed to accelerate city and industrial IOT innovation. Key investments with strategic partners, like Cisco Systems and Google Fiber, are providing core networking and communications technologies necessary to make Kansas City a leader in the Smart City movement. This initiative is against a backdrop of strong local support, particularly from Kansas City Power and Light, for adoption of EV and other energy-efficient transitions in the mobility space. Notable project level take-aways include: 
- Kansas City has a successful initial deployment in open data with the OPENDATA KC portal with XAQT application, allowing sharing of real-time parking, traffic speed, and streetcar status updates.

- Kansas City Power and Light has deployed a clean charge network consisting of over 1,000 EV charging stations throughout the Kansas City area, with charging use data being analyzed for impact on energy use within a Smart City.

- TDMs for Kansas City and the surrounding geographical areas are supported by MARC using traditional methodologies.

- MARC developed and uses an integrated Kansas City regional ITS architecture to provide an overarching framework that spans all the region's transportation organizations and individual transportation projects, including smart-oriented mobility deployments. 


\section{Discussion: Cross-City Key Findings and Initial Comparative City Assessments}

This section synthesizes the challenges, data gaps, and research opportunities common to all cities that emerged from the curation process with the objective to identify opportunities where the DOE's SMART Mobility initiative and supporting SMLC can contribute consonant with the its abilities and mission to further the objectives of the Energy Efficient Mobility Systems (EEMS) research program. Research areas are identified that complement SMLC expertise in data and modeling, can enable and accelerate the SCFs toward their goals and objectives within their mobility plans, and where key data assets and city goals align with, and may contribute to, SMART research task objectives, all influencing minimum energy mobility solutions approaches.

\section{Energy and Mobility Goals, Model Capacities, and Data-Driven Performance Indicators by City}

With respect to the top-level motivations and overall objectives, although the SCFs share some common themes and objectives, at the top level, Smart City priorities and motivations are unique and distinct to each city. The common element across all cities is the need to bring data collection, management, analysis, visualization, and modeling to the core of the Smart City operations and decision-making process. Data-driven decisions, data-informed policy, and objective data-validated performance measures are all strong elements of each city's platform, both in the mobility/energy space as well as water resources, pollution, air quality, equity, health care and other areas vital to the quality of life of its citizens. While mobility plays a large role in the Smart City objectives, it remains balanced with (or seen as a key enabler of) other concerns of health, equity, economic vitality, and jobs. Mobility is unique in that it is seen as a tool to address concerns over a wide variety of issues. This is best illustrated in the Columbus Smart City portfolio where some of the mobility-based pilot programs are undertaken with the primary objectives of improving healthcare, access to jobs, and improve overall sustainability of the city, particularly for the underserved communities such as the Linden neighborhood. In short, whereas mobility is seen as a cornerstone to Smart City initiatives, at the motivational and objective level, simply "improving mobility" is rarely directly stated, but rather it is a derived objective, or a means to an end of the more fundamental needs of the citizens in the community.

Likewise, the data movement within cities is not limited to transportation or energy in transportation, but, similar to base objectives and motivations of Smart Cities, transportation data, metrics, and analysis play a substantial role in assessing the quality of several motivational concerns such as access to health care, employment, basic resources such as food and services, social equity, and the ability to support an economically vibrant community. As an opportunity to fill an identified gap, a "quality of mobility" metric is needed-not one that is based on vehicle speed or number of transit routes, but one that reflects the ability of the transportation system to connect inhabitants with the basic goods, services, and employment which define a quality urban environment, or as was stated concerning the Smart City Challenge:

"Transportation is not just about concrete and steel. It's about how people want to live." 
Engagement with any city requires knowledge of the elements that shape its primary motivators in the Smart City arena, and to then identify how mobility and energy goals may align. Although there are commonalities between different cities, each is unique in its objectives, shaped by the current economic condition, history of the city, and specific geographic/climate-based context. For example:

- The Columbus Smart City program is deeply rooted in supporting a continually growing and vibrant economy that will provide benefit to all its citizens, with specific emphasis on how to address the underserved communities effectively as the city grows. Having experienced going from the world capital of buggy production in the early 1900s to a nearly extinct industry in less than ten years, Columbus is determined to capitalize on the emerging paradigm shifts in mobility, harnessing it as a growth engine, and not be left behind.

- Portland, with a history of air quality issues stemming from its industrial heritage, keeps emissions and air quality at the forefront of its objectives in its Smart City objectives, emphasizing mobility options that not only connect its citizens but provide a long-term air quality / emission benefit while complementing its existing transit infrastructure.

- Austin, like Columbus and most of the SCFs, is growing rapidly. The potential to outgrow its existing road and transit capacity is seen as a threat to continued economic prosperity. Austin is experimenting with emerging technologies to not only decrease energy use (EVs), but equally to keep congestion at bay to sustain the growth of the city.

- Denver, having invested in light-rail and its expansion (most recently to the airport) is emerging as the focal point city of the Rocky Mountain Front Range population centers. Due to Taxpayer's Bill of Rights (TABOR) legislation as well as the state Transportation Commission policy, any significant roadway capacity infrastructure investment is likely to be tolled-facilities moving forward. As the Denver metropolitan region continues to grow and develop, methods to leverage emerging ACES technology, in concert with its newly enhanced light rail system, are at the forefront to ease congestion, and also to continue to improve air quality and sustainability.

- San Francisco with its Bay Area Rapid Transit (BART) and street cars, is motivated by its sustainability goals as part of the larger California state initiative. As the originator of the TNC movement, the growth of TNC service and its secondary issues (street and curbside congestions), which could potentially threaten progress toward its climate sustainability goals, are at the top of their agenda.

- Pittsburgh, a legacy industrial city in rugged western Pennsylvania, is experiencing growth after decades of decline and is faced with how to best leverage its aging infrastructure assets in combination with ACES technology to capitalize on growth opportunities as fiscally efficiently as possible.

- The Kansas City metro region, located in two states and straddling the Missouri River, possesses few geographical impediments to continued urban sprawl in any direction, yet core city growth continues. Technology options to encourage continued, efficient urban 
development and economic growth is at the core of the region's motives to invest in Smart City technology.

Although the motivating factors are varied, each of the SCFs is rapidly experimenting in the emerging mobility options and associated data space as funding resources allow.

\section{Data Infrastructure}

Collaborative data sharing initiatives are a common theme across all cities. These approaches range from establishing the Smart Columbus Operating System (SCOS) and "data sandbox" in Columbus, "data utility" in Pittsburgh, the data PORTAL in Portland, an enterprise data management system in Denver, a "one data system" and "data rodeo" in Austin, an awardwinning "XAQT" platform in Kansas City, to "DataSF" in San Francisco. Existing data sharing and exchange within the cities are currently enabled by collaborative efforts in and among the city, surrounding jurisdictions, and transit agencies, with primary partnerships with the local and regional entities such as the MPOs, universities, philanthropic institutions, and economic development interests. In most instances, these organic data-sharing efforts pre-date the Smart City Challenge with regional data warehouses and geographic information system data set sharing from the city, MPO, and/or university partner. However, these initiatives share a common goal of supporting a sophisticated, dynamic data exchange capacity (not just warehousing and sharing) with the goal of enabling API-based data access to third parties. This dynamic data exchange capacity is at the heart of the Columbus SCOS development and is also prominent in the objectives in all the other SCFs. However there exists no clear common path across all these cities to obtaining this dynamic information exchange, nor are there standards, nor a common framework. Each city approaches this independently based on the resources and expertise within its data infrastructure partner collaborative, which is substantial in many cases.

The development of city data infrastructure for Smart Mobility is paralleled by a data infrastructure initiative by the U.S. DOT to create a Roadway Transportation Data Business Plan for state DOTs and local agencies (U.S. DOT 2013). The Federal Highway Administration Office of Operations began this effort in 2013 to help state DOTs and local agency staff charged with mobility data-related responsibilities, develop, implement, and maintain a tailored plan for "Roadway Travel Mobility Data." This was in response to increasing data reporting requirements from MAP-21, the Moving Ahead for Progress in the 21st Century Act (P.L. 112-141), and the increasing amount of base data being collected by each agency as part of its ITS programs. Base data collection technologies for traffic and road infrastructure are undergoing a technological revolution such that vast amounts of disaggregated electronic data from sources such as industry probe data, imagery, and new sensors are created, which need to be controlled for quality, aggregated, archived, and reduced to summary information. The goals, motivating pressures, and framework encompassed in this Federal Highway Administration effort to assist DOTs are analogous to the current need within Smart Cities to create dynamic data/information exchanges. While the DOT effort is motivated by making data-driven decisions to maximize the effectiveness of limited federal and state highway funds for developing, maintaining, and operating highway transportation infrastructure, the data initiative for cities is motivated by the need to advise and guide investments of limited resources at the local level to the greatest effectiveness for Smart City objectives and provide continuous feedback on the performance of those investments. The U.S. DOT Roadway Transportation Data Business Plan addresses both 
technical (integration, sources, tools, and technology) as well as institutional (costs, roles and responsibilities, and data governance) aspects.

The SMLC's data expertise and subject matter expertise within the energy spectrum provide a basis to be a major contributor to the Smart Cities data infrastructure program. These new data exchange platforms that rely on agile development, distributed computing, federated data assets, and sophisticated rights tracking are all areas that the DOE Laboratories have had to navigate in their data systems (for example, the Transportation Secure Data Center, Alternative Fuels Data Center, Fleet DNA, and others). The inclusion of energy and emissions data and metrics, particularly as they intersect the mobility network, is challenging for nearly all cities. This provides the DOE with an opportunity to influence and encourage the integration of energy metrics into urban mobility performance measures and inform the collection of key data.

As the data infrastructure and exchanges within cities continue to evolve and mature, standardized APIs across a variety of core data areas would enable outside parties to efficiently access and leverage public data sources for analysis/visualization/data products. For example, as DOE analysis programs mature in this space (such as the Electric Vehicle Infrastructure Projection [EVI-Pro] model to estimate the number, type, and location of electric vehicle supply equipment to support EV adoption goals), developing protocols in these tools to operate off emerging Smart City data platforms will accelerate the data exchange infrastructure and provide motivation to standardize protocols and APIs. Until standards emerge, transportation and mobility data at the urban level will continue to be ad hoc, enabled by collaborative efforts within cities, and will appear somewhat chaotic when viewed at the national level. Partnerships and collaboration with local entities (universities, non-profits, business community, MPOs, Clean Cities coalitions, transit agencies, and other jurisdictions) will remain a viable path to open data exchange enabling research and data-driven Smart Cities.

These emerging open data exchanges at the city level would benefit from new data collection methodologies, techniques, and sources. For example, speed data collected through road-side sensors were the norm for state DOTs until about ten years ago. The cost and ability to deploy and maintain traffic sensors limited its wide-spread proliferation (particularly on lower road classes such as minor arterials and local streets). About ten years ago, data from vehicles selfreporting their location and speed based on onboard global positioning system equipment as well as personal data from smart phone travel applications began revolutionizing traffic speed and travel time reporting. Thanks to these technological advancements, traffic conditions are known with confidence across the entire network (and not just a handful of locations with installed sensors). These same data are also being mined to identify incidents, predict travel times, and provide performance metrics across the national highway system. Such data are the basis for the National Performance Management Research Data Set for the reporting requirements in the most recent MAP-21 legislation.

Similarly, new technology is providing cities with data sets for arterial roadway performance, bike and pedestrian activity, infrastructure inventory and utilization, parking operations, and many other areas at price points, performance, and scalability that far exceed traditional data collection methods. As these capabilities come on line, the Smart City networks benefit from communicating best practices and lessons learned from early adopters to other Smart Cities (while communicating the data through the data exchanges) to quickly leverage the benefits of 
these advances. Similarly, the emerging Smart City data exchanges provide opportunities to the SMLC to access new data sources critical for SMART research tasks, which in turn contribute to the progress of Smart Cities. Many of these new technology service-driven initiatives create "Big Data" sets that DOE laboratories can navigate and explore more readily (through their highperformance computing capabilities) than the computing resources in a typical mid-size city. The procurement of statewide trip data by the Ohio DOT through an industry source (INRIX) is one such example. The beginning and ending locations and intervening waypoints (between one second and one minute apart) of approximately $1 \%$ to $2 \%$ of all trips in Ohio represent tremendous opportunities for cities to understand existing travel patterns for numerous applications. However, the data management and processing to deal with giga-byte data sets are not yet readily prevalent in Columbus or other Ohio jurisdictions.

One last shared theme that emerged among many (though not all) SCFs was the need for better TNC data to understand the extent of market penetration (what percent of travel is being taken by TNCs), impacts to congestion, influence on car ownership, propensity to use transit, contribution (positive or negative) to a city's sustainability goals with respect to VMT, impact on land use (parking and curbside requirements for new developments), and impacts on revenue (due to parking demand declines or increases due to access fees). Although many cities are posing such questions about TNCs, San Francisco stands at the forefront with respect to its concerns about the influence of TNCs to its overall sustainability goals, citizen mobility, and energy footprint. However, the dominant TNC companies, Uber and Lyft, are inhibited from sharing data over concerns of commercial competitiveness. With the critical shortage of base data, data collection and analysis centered about major inter-modal mobility hubs, such as airports, that collect access fees (and thus data) for TNC as well as other ground modes (parking, car rental, car-sharing) offer a prime opportunity to observe mode choice and travel behavior shifts. Such data collection and analysis activities were undertaken within the DOE EEMS initiative in 2018 as part of the overall effort to address the larger research question of whether mobility-as-a-service (with TNCs being the leading edge) will have a positive or negative energy impact, as well as the factors that impact this determination.

Establishing methods to estimate key impact parameters from available data is critical for Smart Cities to monitor performance as well as augment data assets for modeling long-term impacts of ACES technology in the energy and mobility domains.

\section{Modeling Capacity}

Since the Federal-Aid Highway Act of 1962, standard planning processes managed by MPOs have been required in the United States for urbanized areas with a population greater than 50,000. As a result, a large majority of the travel modeling practice (and subsequent expertise) is concentrated at the MPOs that serve the major cities in the United States, with a few notable exceptions. For the SCFs, this pattern holds true for all cities except San Francisco where three large population centers in the Bay Area (San Francisco, Oakland, and San Jose) have prompted the county of San Francisco to maintain a separate transportation model specific to San Francisco interests. Typically, TDMs developed and operated by the MPOs inform the long-range transportation plans for the region. These models are also used on a regular basis to study and estimate the impact of proposed infrastructural improvements in a city/region, such as adding a new lane to an existing roadway. Over the years, more and more have been required from these 
models. Initially planned for highway capacity concerns, their scope has been increased over the decade for emissions (planning air quality), transit and transit-oriented development, and ITS operations, and now they are being called upon for Smart City operations and assisting with exploring the anticipated influences brought upon by emerging ACES technologies.

As with previous challenges to transportation modeling, the ability for TDMs to reflect the impact of emerging ACES technologies lags in capability but is quickly evolving. Over the past decade and a half, TDMs have evolved more sophisticated methods to reflect travel behavior choices at the individual traveler level. This new methodology, referred to as ABM, models the decision process of each member of a representative population for all activities through a typical day, then combines all the individually generated trips into an overall aggregate representation of travel demand, referred as the trip table. Previous methods (referred to herein as a four-step approach) use more homogenous assumptions about the population and its travel needs to directly estimate a trip table, concentrating mainly on journey to work periods (and other peak periods) of the population. Similarly, the assignment of these trips onto the network model (encompassing roadways, transit, pedestrian, cycling, etc.) has also evolved. Modern methodologies, referred to as DTAs, assign the trips to the network in small time increments (such as 5-minute, 15-minute or 1-hour intervals) rather than the general peak hour assignment of older methods (referred to as static assignment). While the previous generation of TDMs had the travel demand and network assignment components work in a sequential fashion (demand is first generated for the peak period and supplied to the assignment module for simulation on the network), the more advanced methods currently being adopted by the MPOs have the demand (ABM) and network assignment (DTA) components communicate on a more regular basis. The $\mathrm{ABM} \Leftrightarrow \mathrm{DTA}$ interaction at regular intervals allows for accommodating realistic representation of real-time travel behavior as well as responses to recurring and non-recurring network congestion. For instance, as the travel time increases in response to congestion, trips may be assigned to different routes. If the DTA and ABM are tightly coupled with feedback loops, congestion or incidents on the road network may prompt a traveler to change the mode to transit and thus alter the trip table.

The TDM capacity and capability within the SCFs range from the most modern methodology implemented (an ABM with a DTA) to more traditional approaches (four-step with a static assignment). The pace at which an urban area adopts the newer methodology varies based on needs, resources, and the cyclic nature of model development, which tends to be on an 8- to 10year cycle. The ABM with DTA framework is the most modern and is anticipated to be sufficient to support ACES modeling. However, as revealed by the interaction with the SCFs, as well as supported by the feedback from the modeling and data workshops, current TDMs do not have the capacity to provide information to all (or even some) of its research questions with respect to emerging ACES technology, and rightfully so. This is not surprising as modeling is generally reactive to needs. Without sufficient data upon which to base the behavioral and traffic expectations, any attempt to build predictive capacity into a TDM would not yield results with any level of confidence. Although the current TDM frameworks (ABM and DTA) are anticipated to be sufficient to reflect the impact of ACES technology, base-level knowledge to build the human and traffic behavioral responses remains lacking.

As an example, if a "taxi mode" were to be incorporated in a TDM, it would have facilitated (or begun to facilitate) the modeling of TNCs in cities. However, none of the models reviewed has a 
"taxi" option in them because the market share of this mode has historically been negligible (below 2\%) in most cities. The prevalence of taxi trips in cities was so small with respect to other, more-dominant modes that no need was apparent for inclusion of taxis in TDMs. Roughly five years ago, expectations that TNCs would gain rapid market share, much less thinking about incorporating TNCs as a new modal option, was not a consideration. Now that TNC trips are increasing in number, many cities are considering including this as a separate mode in their mode choice models. However, the available base data to understand consumer behavior is currently insufficient to build the models. The case for building capabilities to model AVs will be similar, as it is not possible to understand the impact of AVs on travel until people experience them and their observations and preferences are recorded.

A cross-city comparison of the model capability is provided in Table 2 . A review of model maturity across different cities reveals that many cities are building up their modeling capabilities, be it moving from trip-based modeling approaches to more advanced (and behaviorally realistic) ABMs or incorporating DTA to depict real-time travel behavior more accurately across several modes. As evidenced in the table, no two TDM profiles are the same, with each model being customized to the needs of a city/region.

- Of the cities fully characterized in Table 2, four incorporated ABMs while the other three rely on the four-step method. (Note that even within ABMs there are different levels of fidelity, but such characterization is beyond the scope of this review.)

- Three of the cities use DTAs, while three use a more traditional static assignment approach. The Austin official model is static, though it has been extended by TTI to a DTA.

- The dates of the existing and planned upgrades (when known) indicate a period for model development ranging from 5, 7, and 13 years for Columbus, San Francisco, and Denver, respectively.

- As noted, none of the models reviewed has a specific TNC mode (or even a taxi mode) incorporated in its mode choice models.

- Some models had a multitude of sub-models to capture travel from special generators (airports, universities, etc.), while others had limited sub-models (and thus run more rapidly.)

- Scenarios of interest varied. While some focused on developing and testing scenarios related to technology, others focused on changes in land use patterns in the short- and long-term futures.

- Model capacity and capability were estimated based on review of the framework (ABM/DTA) and level of coupling. Such an approach provides a common platform/rubric to initiate a dialogue among cities.

The TDM model characterizations in Table 2 are for the most commonly used model in each city. It is not unusual for different models, or even model variants, to be active within a city, particularly in cities where universities are active in urban modeling research. Austin, for 
example, with the University of Texas at Austin and Texas A\&M's TTI nearby, has been the subject of various research experimentations leveraging various aspects of the TDM developed by the local MPO (CAMPO). A 2017 research study by the University of Texas at Austin (Liu et al. 2017) leveraged the base CAMPO model and supporting data using open-source ABM software, MATSIM, to explore the anticipated effect of fully automated demand responsive service ("Automated Uber") based on socio-economic behavioral estimations derived from a literature review. Likewise, TTI augmented the CAMPO model with better traffic response (in essence, a DTA) to assess the impact of consumers' change in vehicle routing in response to external (smart phone app) stimuli.

The discussion of the Austin CAMPO model touches on another theme and identified a research gap emerging from the data and model curation task. Model capability is also correlated to model complexity. As TDM models progress from four-step to ABM and from static to dynamic assignment, the data, computing, and personnel resources to build, maintain, calibrate, and exercise the model also escalate. As a result, the choice to advance the model from traditional to a more modern framework and methodology is also a fiscal commitment that falls on the urban area. The gap or research question that emerged from the model capability assessment exercise is whether cities with a traditional framework (four-step and static assignment) can use or leverage their existing model to elicit the impacts of ACES technologies or whether a new model development investment required. In other words, can more traditional (less expensive) modeling tools be leveraged with less fiscal investment to estimate the impacts of ACES and plan appropriately for the urban area?

As a corollary to the observation above, the modeling and analysis needs of the primary city within the region typically differed from those of other less populous and less-dense jurisdictions. TDMs originated and continue to evolve from a regional metropolitan trip context, emphasizing journey-to-work (peak hour) concerns that impact the volume to capacity ratios on the principal highway transportation network. While peak-hour highway congestion is a problem for jurisdictions across the board, new mobility technologies present an additional layer of complexity in the context of central city and other jurisdictions with significant population and job densities. This is experimental ground for new mobility technologies that unclog city streets, address parking availability and efficiency, and link commuters the last mile between employment and other opportunities with regional transit and other mobility-as-a-service offerings. Such areas are struggling with a host of complex mobility issues induced by density that most other suburban localities are not. Although existing TDMs acknowledge a portion of this diversity by using varying sizes of Traffic Analysis Zones, current modeling frameworks do not accommodate the need for high density areas to model the transportation network in corresponding "micro-resolution" needed to reflect the impact of ACES technology such as ridehailing, shared scooters, shared bicycles, and the curb congestion and parking impacts that they induce (particularly in the context of identifying terminal access/egress times and simulating them on the network). The central cities and some sub-jurisdictions in poly-centric cities require such capacity whereas the greater metro region does not. This points to a need for TDM frameworks to provide a "multi-resolution" approach, adapting higher resolution in the mobility network where and as needed.

Not listed in Table 2 are the types of energy and emissions outputs from the models. The TDMs were all similar in that they incorporated the EPA MOVES model, not unsurprising since air- 
quality analysis is mandated in the transportation planning processes. Whereas the modeling by MPOs was consistent with federal planning requirements, additional energy analysis was typically conducted at the jurisdiction-specific level. Motivation for doing so was either organic to the city's goals (such as Denver) or mandated at the state level (such as San Francisco). Columbus is pursuing similar objectives to provide performance metrics in the reduction of petroleum-based emissions as part of the electrification program. Although there may be some similarity in approaches due either to prevailing literature or state regulations, there is no common methodology widely linked to TDMs for estimation of energy usage. (Note, California regulations enforce uniformity for California jurisdictions.) The EPA MOVES model, which provides link-specific emissions, remains the current standard. Evolving methods that reflect the mixture of the actual consumer fleet of vehicles (based on vehicle registration records) and project alternative fuel vehicle adoption rates remains a gap in TDM methodology.

Table 2. Cross-City Model Capability Comparison Matrix

\begin{tabular}{|c|c|c|c|c|c|c|c|}
\hline $\begin{array}{l}\text { Cross-City Comparison and } \\
\text { Summary of Model Details }\end{array}$ & Columbus & Portland & Pittsburgh & Austin & $\begin{array}{l}\text { San } \\
\text { Francisco }\end{array}$ & Denver & $\begin{array}{l}\text { Kansas } \\
\text { City }\end{array}$ \\
\hline Model Name & MORPC & Metro & SPC & CAMPO & $\begin{array}{l}\text { SF- } \\
\text { CHAMP }\end{array}$ & FOCUS & MARC \\
\hline $\begin{array}{l}\text { 4-Step (4S)/Advanced 4-Step } \\
\text { (A4S)/Activity-Based (AB) }\end{array}$ & $A B$ & $A B$ & $4 S$ & A4S & $A B$ & $A B$ & $4 S$ \\
\hline $\begin{array}{l}\text { Static Assignment (SA) } \\
\text { Dynamic Assignment (DA) }\end{array}$ & DA & DA & SA & SA/DA & DA & SA & SA \\
\hline Last Upgraded & 2004 & 2010 & 2015 & 2010 & 2012 & 2010 & 2015 \\
\hline Next Upgrade & 2017 & ?? & $? ?$ & $? ?$ & 2017 & 2017 & $? ?$ \\
\hline TNC Mode Included? (Y/N) & $\mathrm{N}$ & $\mathrm{N}$ & $\mathrm{N}$ & $\mathrm{N}$ & $\mathrm{N}$ & $\mathrm{N}$ & $\mathrm{N}$ \\
\hline $\begin{array}{l}\text { Special Generator } \\
\text { A - Airport, F - Freight, } \\
\text { IE - Internal/External Trips } \\
\text { U - University, O - Other }\end{array}$ & $F, I E$ & $A, F, I E$ & A, IE & $\begin{array}{l}\text { A, F, IE, } \\
\text { U, O } \\
\text { (Hospital, } \\
\text { Prison) }\end{array}$ & $A, F, I E$ & $\begin{array}{l}\text { A, F, IE, } \\
\text { U, O } \\
\text { (Mountain } \\
\text { / Casino) }\end{array}$ & A, IE \\
\hline $\begin{array}{l}\text { Scenarios Considered/Tested } \\
\text { I - Infrastructure } \\
\text { D - Demographic } \\
\text { L - Land Use } \\
\text { EN - Energy } \\
\text { EC - Economy } \\
\text { T - Technology }\end{array}$ & $\mathrm{I}, \mathrm{D}, \mathrm{T}$ & $\begin{array}{l}\text { I, D, L, } \\
\text { EN, EC, T }\end{array}$ & $\begin{array}{l}\text { I, L, EN, } \\
\text { EC }\end{array}$ & $\begin{array}{l}\text { I, D, L } \\
\text { EC }\end{array}$ & $\begin{array}{l}\mathrm{I}, \mathrm{L}, \mathrm{EN} \\
\mathrm{EC}, \mathrm{T}\end{array}$ & $\begin{array}{l}\text { I, L, EN, } \\
\text { EC }\end{array}$ & $\begin{array}{l}\text { I, L, EN, } \\
\text { EC }\end{array}$ \\
\hline $\begin{array}{l}\text { Model Capacity/Capability } \\
\text { Level } \\
\text { A - Advanced } \\
\text { H - High } \\
\text { M - Medium } \\
\text { L - Low }\end{array}$ & $\mathrm{H}$ & $\mathrm{H}$ & $\mathrm{L}$ & M & $\mathrm{H}$ & M & L \\
\hline
\end{tabular}




\section{Conclusions}

This review assessed the dynamically evolving state of urban mobility data and models, along with Smart City goals and priorities in the mobility and energy space. City data infrastructure and mobility modeling capabilities were characterized for the seven U.S. DOT SCFs according to their ability to support ongoing evolutions with emerging mobility technology related to vehicle automation, connectivity, electrification/efficiency, and sharing, frequently referred to as ACES. This baseline assessment of Smart City data and modeling capacity was created to explore how these systems, emerging services, and analysis capabilities are evolving, so to best identify gaps in data, practices, modeling and analysis, and to map any gaps to collaboration opportunities with the ongoing DOE research initiatives in the EEMS program. This research initiative is part of a portfolio of research projects pertaining to Urban Science whose overall objectives include:

- Providing cross-city and high value data sets that are more widely available across networks of cities, private and public mobility providers, and research communities

- Harnessing the power of emerging city data and observability to enable upgraded modeling platforms to help visualize, conduct analyses, and advance urban mobility model environments as these systems transition and transform in response to multiple disruptive changes that impact energy productivity of mobility, urban infrastructure systems (e.g., physical, natural, societal, and cyber) as well as associated travel behaviors and choices.

- Harmonizing approaches in data and modeling by developing common methods to observe transitions in urban mobility and the energy impacts from emerging mobility technology

- Addressing specific knowledge and data gaps as critical early-stage research. Exploring the impacts of, preparing for, and shaping transitions in cities at the intersection of mobility and energy is particularly needed (to inform performance in enhancing mobility energy productivity, infrastructure modernization, revenue diversification, and choices).

The knowledge and information gained from this assessment of smart city data and models are conveyed in the preceding detailed report. On a broad scale, these seven cities, as a result of being successful SCFs, are representative of the most progressive and proactive jurisdictions with respect to informing responses to emerging mobility technology, as well as balancing that with energy and emissions concerns. The lessons learned, take-aways, data and modeling gaps as well as opportunities for DOE collaboration are summarized below into three sections corresponding to upgrading data infrastructure, modeling and analysis capability, and overall Smart City gaps and opportunities.

\section{With respect to Smart City data initiatives ...}

Each SCF prioritizes a robust and continuously upgraded data infrastructure to monitor and inform decisions and to provide performance-based measures to assess progress toward its goals. 
- The need for robust data sharing and exchange platforms is a common theme and initiative within all seven SCFs. Most cities are pursuing this through collaborative efforts led by local partners (universities, MPOs, non-profits). As a reference example of implementation, the U.S. DOT Smart City awardee, Columbus, Ohio, is developing the Smart City Operating System as the core enabler of its portfolio of projects in the transportation and energy space moving forward.

- Most data infrastructure efforts are based on data warehouse and/or legacy geographical information system architectures. Such approaches offer the capacity to store data sets but are less adept at real-time transaction interfaces such as APIs. Legacy approaches are also challenged by complex user access rights needed to protect personal privacy as well as navigate licensing of commercial data sets. Newer approaches based on modern internet and smartphone application infrastructures involving agile programming are more adept at enabling robust data sharing.

- Most urban data initiatives incorporate existing mobility data gathered using legacy approaches, such as deployed sensors or data from existing services such as public transit or parking revenues. New technology-driven, commercial, crowd-sourced, and/or internet-of-things-based methods have the potential to scale quickly; minimize cost; and provide timely, even real-time, data availability, but require big-data expertise and computing resources typically beyond that of most municipalities. This presents an opportunity to leverage core DOE data expertise while gaining access to modern, relevant Smart City research data.

\section{With respect to Smart City mobility modeling and analysis capacity ...}

The TDM capacity and capability within the SCFs range from the most modern methodologies such an ABM coupled with a DTA network model to more traditional approaches (four-step with static traffic assignment).

- The pace at which an urban area adopts the newer modeling methodologies varies based on needs, resources, and the cyclic nature of model development, which tends to be on an 8- to 10- year cycle. The ABM with DTA framework is the most modern and is anticipated to be sufficient to support most cases of ACES modeling. However, as revealed by the interaction with the SCFs and supported by the feedback from the modeling and data workshops,_current TDMs do not have the capacity to inform cities on emerging ACES mobility technology due mainly to a lack of research data on emerging modes. This is not surprising as modeling is generally reactive to needs. Without sufficient data upon which to base the behavioral and traffic expectations, any attempt to build predictive capacity into a TDM would not yield results with any level of confidence. This is the situation that TDM finds itself in at the present time.

- TDM modeling capacity within the seven DOT SCFs is typically housed within the corresponding MPOs, with some exceptions particularly when there are multiple principal cities within the MPO's region. At present, for example, Columbus, has adopted modern TDM methodologies and has implemented state-of-the-art models with the latest in ABM and DTA, while Austin relies on a more traditional four-step approach. In either case, cities see the TDM primarily as a rearward-facing tool, informing traditional 
mobility (vehicle and roadway based) and not dynamic enough to inform on quickly emerging mobility technologies such as deployment of automated shuttles or management of TNCs such as Uber and Lyft. Tools to address the latter are in critical demand. Current TDM practice is resource intensive, requires large amounts of data, and takes months if not years to construct and calibrate. Tool suites that are nimble and agile are required to assist in the decision space surrounding the rapidly evolving urban mobility landscape and would be a welcome advancement.

- The standard outputs from TDMs related to energy are aligned with the EPA MOVES module that provides emissions estimates based on the operating speed and volume of roadway segments, which can be adapted for viable energy estimates. More sophisticated energy tools that integrate with TDMs are needed to tailor energy estimates based on consumer fleet composition as revealed by vehicle registration data, amount of shared ridership, and projections of future vehicle mix and ridesharing. This will help align TDM practice with future energy-efficient mobility systems priorities.

- The needs of the primary city within an MPO region with respect to emerging mobility cumulate on top of that of less-populous, less-dense jurisdictions. The denser central city has become the experimental ground for new mobility technologies due to the concentration of people and activity and exhaustion of road and parking capacity. Traditional TDMs, although having varying size traffic analysis zones, do not accommodate the need for "micro-resolution" within dense urban development where parking availability and curb space congestion may govern mode choice. This points to a need for TDM frameworks to provide a "multi-resolution" approach, adapting higher resolution in the mobility network where and as needed as population and activity densities dictate.

\section{With respect to overall Smart City gaps and opportunities at the junction of mobility and energy ...}

Aspiring Smart Cities everywhere are seeking to harness new data, communication, and mobility technologies for the benefits of its citizens. Mobility is unique in that it is not perceived as an end goal or objective in itself, but a means to an end for improved economic productivity, equitable access to health care and employment for citizens, and as an overall enabler to a higher quality of life.

- The impacts of TNCs such as Uber and Lyft are within the spectrum of awareness for most cities with respect to the benefits provided to citizens as well as long-term sustainability (e.g., congestion, emissions, equity, and/or land use impacts). As TNCs are emerging as a rapidly growing urban mode of transport and represent the leading edge of mobility-as-a-service, TNC data availability has emerged as a critical data gap, and perhaps the most urgent. Addressing this gap will benefit Smart City analyses, and also provide the base data to extend urban travel behavioral models.

- As a corollary to the previous take-away, the airport has emerged as the "front door" to Smart Cities, being the primary transportation hub welcoming visitors or connecting its citizens both to national and international air travel. As the rate of air travel growth far outstrips that of VMT (by about 3 to 1), the airport is emerging as a primary indicator of 
mobility behavior shifts, a sort of "canary in the coal mine." Collection and monitoring of airport access data provide critical insights into the rate of alternative mobility technology adoption. Similar changes are then anticipated to follow in other parts of the metropolitan area.

- Lastly, and likely of greatest importance, a gap in practices that spans both the data infrastructure and travel modeling is the issue of appropriate metrics for smart city analysis. Mobility itself is typically not a smart city goal, but rather an enabler of improved quality of life. Metrics that quantify the ability of a city's various transportation networks to connect citizens with the goods, services, and employment to increase the city's productivity and improve citizens' lives are needed for Smart City performance assessment.

While new technologies are enabling new data collection, modeling, and planning considerations, the research and science that can inform the future of cities need to keep pace. Data/model integration, visualizations, and analytics will continue to emerge, and a goal of this initiative is to further enable data-driven decision making through exchange of best practices via cross-city smart analysis such as this. Overall, this curation activity is intended to enable efficient access to the knowledge generated from Smart City peer cities, share knowledge and lessons learned, and benchmark their progress. It will also aid in continuing to identify gaps in knowledge and practices, which in turn will expose opportunities for the DOE EEMS initiative to contribute to Smart City objectives while gaining insight and valuable data from Smart City programs. 


\section{References}

Castiglione, J., T. Chang, D. Cooper, J. Hobson, W. Logan, E. Young, et al. 2017. TNCs Today: A Profile of San Francisco Transportation Network Company Activity. Draft Report. San Francisco County Transportation Authority (SFCTA), June 2017.

Castiglione, Joe, Drew Cooper, Bhargava Sana, Dan Tischler, Tilly Chang, Greg Erhardt, Sneha Roy, Mei Chen, Alex Mucci. 2018. TNCs \& Congestion: Final Report. San Francisco County Transportation Authority. San Francisco, CA. https://www.sfcta.org/sites/default/files/201905/TNCs_Congestion_Report_181015_Finals.pdf

City and County of Denver. 2016. "Beyond Traffic: The Denver Smart City Challenge. Part 1.” U.S. DOT Submission.

City of Austin. 2017. Austin Community Climate Plan Summary. http://www.austintexas.gov/sites/default/files/files/Sustainability/Climate/ACCP_summary_final_012 717.pdf

City of Portland. 2017. "Connected and Autonomous Vehicles Policy: Discussion Draft Recommendations." Accessed December 2017. https://www.portlandoregon.gov/transportation/article/643814

City of Portland. 2017. "Electric Vehicle Strategy.” www.portlandoregon.gov/bps/article/619275

Geller, Roger. 2013. "What Does the Oregon Household Activity Survey Tell Us About the Path Ahead for Active Transportation in the City of Portland?" White Paper. City of Portland, Portland, OR; https://www.portlandoregon.gov/transportation/article/452524

Hillman, T., and A. Ramaswami. 2010. "Greenhouse Gas Emission Footprints and Energy Use Metrics for Eight US Cities.” Environmental Science and Technology 44(6): 1902-1910. http://pubs.acs.org/doi/abs/10.1021/es9024194

Kansas City Power and Light, 2017. "Kansas City Zooms Ahead in Electric Vehicle Growth.” Accessed: https://www.kcpl.com/about-kcpl/media-center/2017/june/kansas-city-zooms-ahead-in-electricvehicle-growth

Kennedy, C., J. Steinberger, B. Gasson, Y. Hansen, T. Hillman, M. Havránek, D. Pataki, A. Phdungsilp, A. Ramaswami, and G. Villalba Mendez. 2009. "Greenhouse Gas Emissions from Global Cities." Environmental Science and Technology 43(19): 7297-7302.

Liu, J., Kara M. Kockelman, Patrick M. Boesch, and Francesco Ciari. 2017. "Tracking a System of Shared Autonomous Vehicles across the Austin, Texas Network Using Agent-Based Simulation." Transportation 44: 1261. https://doi.org/10.1007/s11116-017-9811-1 .

Mehrotra, S., B. Lefevre, R. Zimmerman, H. Gerçek, K. Jacob, and S. Srinivasan. 2011b. Climate Change and Urban Transportation Systems. Climate Change and Cities: First Assessment Report of the Urban Climate Change Research Network. C. Rosenzweig, W. D. Solecki, S. A. Hammer, S. Mehrotra, Eds., Cambridge, UK: Cambridge University Press, 145-177.

Metro. 2012. 2011 Metro Travel Behavior Survey. Metro Research Center, Transportation Research and Modeling Services. Portland, OR. https://www.oregonmetro.gov/2011-metro-travel-behavior-survey.

Metro. 2016. You are here: A snapshot of how the Portland region gets around. www.oregonmetro.gov/news/you-are-here-snapshot-how-portland-region-gets-around 
Metro. 2018. "Chapter 4: Our Growing and Changing Region.” In 2018 Regional Transportation PlanPublic Review Draft. https://www.oregonmetro.gov/sites/default/files/2018/06/29/RTP_Ch4_OurGrowing_Changing_Regi onpublicreview.pdf

Mid-Ohio Regional Planning Commission, 2017. Franklin County Energy Study. Draft Report for Public Comment. http://www.morpc.org/program-service/energy-studies-and-technical-assistance/

Mobility Choice Blueprint. 2017. “Accelerating Mobility in Metro Denver.” Accessed: https://www.mobilitychoiceblueprint.com

Mohammadian, A., J. Auld, and S. Yagi. 2009. "Recent Progress on Activity-Based Microsimulation Models of Travel Demand and Future Prospects." Chapter 7, Transportation Statistics, Brian W. Sloboda, ed. J. Ross Publishing, 151-172.

Oak Ridge National Laboratory. "SMART Mobility, Modeling, and Simulation Tools: Practice, Challenges, and Future Directions." https://www.dropbox.com/s/22719dvbae8sx56/SMART\%20Mobility\%20Summary FINAL.pdf?dl=0

Ramaswami, A., and A. Chavez. 2013. "What Metrics Best Reflect the Energy and Carbon Intensity of Cities? Insights from Theory and Modeling of 20 US Cities.” Environ. Res. Lett. 8: 035011.

Regional Transportation District. 2018. First and Last Mile Strategic Plan. Accessed: www.rtddenver.com/firstmile-lastmile.shtml

San Francisco County Transportation Agency. 2017. TNCs Today: A Profile of San Francisco Transportation Network Company Activity.

San Francisco Municipal Transportation Agency. 2019. San Francisco Mobility Trends Report 2018. https://issuu.com/sfmta_marketing/docs/sfmta_mobility trends_report_2018

San Francisco Municipal Transportation Agency. 2019. TNCs and Disabled Access. SFMTA Taxis and Accessible Services Division. https://www.sfmta.com/sites/default/files/reports-anddocuments/2019/05/tnc_and_disable_access_whit_paper-rev11_2.pdf

Sarkar, R., and J. Ward. 2016. "DOE SMART Mobility: Systems and Modeling for Accelerated Research in Transportation.” In Road Vehicle Automation, Springer International Publishing. 3: 39-52.

Shaheen, S. 2017. "Theoretical Framework and Index of Transportation Innovation in Smart Cities: Early Understanding and Best Practices." Transportation Research Board - Transportation Research Database. Accessed 2017: https://trid.trb.org/Results?txtKeywords=smart+cities\#/View/1473802

Shared-Use Mobility Center. 2016. Los Angeles Shared Mobility Action Plan. Accessed: http://sharedusemobilitycenter.org/wp-content/uploads/2016/09/SUMC-Single-Page-Web-2.pdf

Sperling, J., S. Young, J. Beck, V. Garikapati, Y. Hou, and A. Duvall. 2017. “Exploring Energy-Efficient and Sustainable Urban Mobility Strategies: An Initial Framework to Curate Data/Models, Measure Performance, and Diffuse Innovation.” ITS World Congress Paper ID \# AM-SP133.

Terrien, C., R. Maniak, B. Chen, and S. Shaheen. 2016. "Good Practices for Advancing Urban Mobility Innovation: A Case Study of One-Way Carsharing." Research in Transportation Business \& Management, 20: 20-32.

Texas A\&M Transportation Institute. 2015. “Urban Mobility Scorecard.” Accessed June 2017: https:/mobility.tamu.edu/ums/ 
U.S. Census Bureau, 2012. "Growth in Urban Population Outpaces Rest of Nation." Census Bureau Reports. Accessed: https://www.census.gov/newsroom/releases/archives/2010 census/cb12-50.html

U.S. Department of Transportation. 2013. "U.S. DOT Roadway Transportation Data Business Plan (Phase 1). Final Report.” FHWA-JPO-13-084. www.its.dot.gov/index.htm

U.S. Energy Information Administration. 2018. Annual Energy Outlook 2018: Energy Consumption by Sector and Source. Accessed: https://www.eia.gov/outlooks/aeo/data/browser/\#/?id=2$\underline{\mathrm{AEO} 2018 \& \mathrm{cases}=\mathrm{ref} 2018 \& \text { sourcekey }=0}$. 


\section{Appendix. Smart City Data and Modeling Templates}

The data and modeling templates and profiles shared in this Appendix document the state of evolving data and model assets, and related Smart City strategies emerging in 2016 and 2017. It is intended to be a cross-city comparison for some of the who, what, where, why, when, and how of city mobility data and models. The templates contain model profiles for all seven U.S. DOT Smart City finalists (SCFs) and four regional data profiles.

Note that not all the data in templates shown have been quality assured by the city data and modeling leads; however, is accurate to the best of the authors' understanding of each city's modeling and data infrastructure supporting Smart City initiatives. This Appendix is expected to serve as a gateway for exploration of data and models via listed links and information (analogous to 'the back of a cereal box as to the key ingredients' for each city). Treat the content as characterization by an outside observer and contact the already listed people in each smart city data and regional modeling team for more context-specific information on the available and emerging data and models.

\section{SUMMARY OF PROFILE CONTENT}

\section{Model Profile Content}

- Model Owner; Sentence and Paragraph Summary Descriptions; Spatial Resolution; Model Architecture; Input Data;

- Region Covered; Model Process Flow Chart; Key Inputs and Outputs; Benefits and Limitations

- Related Projects; Contacts and Reviewers; Related Models; Links to Model Data and Related Data Resources

- Scenarios (as types and may soon include specific automated, connected, electric \& shared mobility scenarios for each city)

\section{Data Profile Content}

- Data Platform/s and Regional Data Sharing Efforts and Web-Based Tools for Data Integration, Visualization, and Analytics

- State of Data (\# of available datasets); Key Institutions Hosting Data; Institutional Mapping of Data; Data Maturity Levels

- City/Utility Open Data Resources and Mapping / Visualizations / Interactive Analytics for Featured Datasets

- City Priorities for Data, Smart City-Related Research Questions, and New Datasets Under Development 


\section{Columbus: Travel Demand Model}

The MORPC travel demand model belongs to the class of activity-based models, and is built with a similar structure as the San Francisco, and New York (NYMTC) travel demand models.

\begin{tabular}{|c|c|c|c|c|c|c|c|}
\hline \multicolumn{2}{|c|}{ Spatial Resolution of Model } & \multicolumn{3}{|c|}{ TAZs } & \multicolumn{3}{|c|}{ MAZs } \\
\hline \multirow{2}{*}{$\begin{array}{c}\text { Model } \\
\text { Architecture }\end{array}$} & 4-Step & Activity-Based & \multicolumn{2}{|c|}{ Input Data from Surveys } & 1999 HIS & & \\
\hline & $\begin{array}{c}\text { Static } \\
\text { Assignment }\end{array}$ & $\begin{array}{c}\text { Dynamic } \\
\text { Assignment } \checkmark\end{array}$ & \multicolumn{2}{|c|}{ Latest Upgrade Year } & 2004 & Next Upgrade & Ongoing (2017) \\
\hline Modes Covered & $\checkmark$ Auto & $\checkmark$ Transit & $\checkmark$ Walk & $\checkmark \quad$ Bike & Freight & Taxi & TNCs \\
\hline Special Generator & Airport & $\checkmark$ Freight & $\checkmark$ Externa & rip Generator & University & Other: & \\
\hline Scenarios & Infrastructure & Demographic & Land Use & Energy & Economy & Technology $\checkmark$ & Other \\
\hline
\end{tabular}

The MORPC modeling team expects to have the $3 \mathrm{C}$ activity-based model with dynamic traffic assignment available for use very soon. The current MORPC model has 1805 TAZs; with 72 TAZs in downtown area; and 3 transit accessibility zones. The model uses 9 computers to run; and uses Java code, CUBE platform/city lab software; and SQL used in the new model. Activities together with FHWA Transims Deployment have allowed for extracting all model results to run in TRANSIMS, including both the network and travel demands. The DynusT DTA is separable and can be provided as a separate file upon request. The model is also borrowing ideas from the Maricopa Association of Governments in Arizona (who also worked with PB) in terms of CAV scenarios: e.g. capacity changes on highway side; vehicle availability to new age demographics; new modes (e.g. walk, kiss-and-ride, park-and-ride, and another kiss-andride mode for AVs); and a focus on parking in new model. The model may not pursue updates based on the SMART Columbus project, as this was not part of the scope. This model label details the current MORPC model but not their latest $3 \mathrm{C}$ model as the latest one is not operational yet.

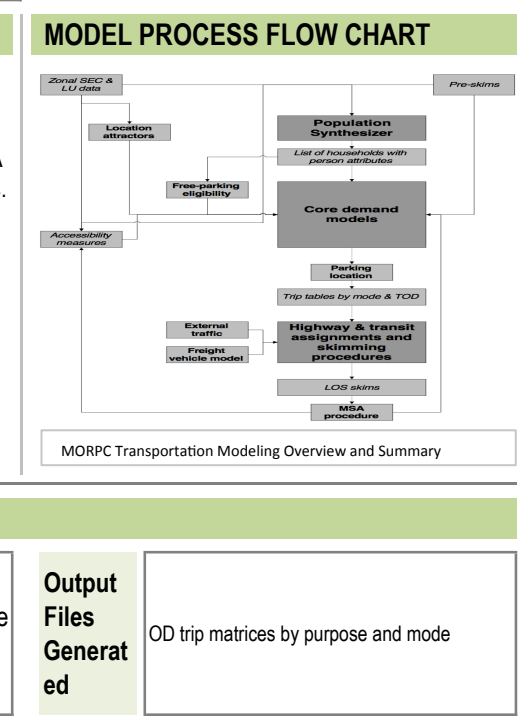

LIMITATIONS

Existing survey was very small sample size

Few raw records where transit was taken

No mention of links to energy/emissions models

\section{KEY DATA RESOURCES}

http://morpc.ms2soft.com/tcds/tsearch.asp ?loc=Morpc\&mod=
http://morpc.org/Assets/MORPC/files/MTP_Report_Chapter3.p df

\section{RELATED MODELS}

SFC Model / NYMTC Model / MAG Mode

DynusT (DTA Model) 


\section{Portland: 圈 Metro Travel Demand Model}

METRO has two sets of travel demand forecasting models for the Portland metro region, built using 19945 Household Activity Diary Survey and updated using the 2011 HHTS.

\begin{tabular}{|c|c|c|c|c|c|c|c|}
\hline \multicolumn{2}{|c|}{ Spatial Resolution of Model } & \multicolumn{3}{|c|}{ TAZs } & \multicolumn{3}{|c|}{ MAZs } \\
\hline \multirow{2}{*}{$\begin{array}{c}\text { Model } \\
\text { Architecture }\end{array}$} & 4-Step & Activity-Based & \multicolumn{2}{|c|}{ Input Data from Surveys } & 1994-1995 & 2XXX Transit Survey & 2011 HHTS \\
\hline & $\begin{array}{c}\text { Static } \\
\text { Assignment }\end{array}$ & $\checkmark \begin{array}{c}\text { Dynamic } \\
\text { Assignment }\end{array}$ & \multicolumn{2}{|c|}{ Latest Upgrade Year } & 2010 & Next Upgrade & Destination2030 \\
\hline Modes Covered & $\checkmark$ Auto & $\sqrt{ }$ Transit & Walk & $\checkmark \quad$ Bike & Freight & Taxi & TNCs \\
\hline Special Generator & $\checkmark$ Airport & $\sqrt{ } \quad$ Freight & \multicolumn{2}{|c|}{ Mnternal / External Trip Generator } & University & \multicolumn{2}{|c|}{ Other: Mountain / Casino } \\
\hline Scenarios & Infrastructure & Demographic & Land Use & Energy $\checkmark$ & Economy $\checkmark$ & Technology $\checkmark$ & Other \\
\hline
\end{tabular}

The Portland METRO uses both a trip-based and tour-based travel demand forecasting model (covered in this model label), based on data from a 1994-5 Household Survey. The survey work was conducted by Metropolitan Planning Organizations throughout Wilmette Valley and Medford, as an identical 2-day household activity diary survey concurrently in 1994-95 and was used to estimate, calibrate and validate the current version of the Portland trip-based and tour-based models. The MPOs and Oregon DOT have jointly specified and estimated joint travel demand models for metro regions throughout the state, and the region's primary transit operator, TriMet has started a new transit onboard survey and Metro is also considering a longitudinal survey that tracks respondents over time. While similar to the San Francisco modeling system, based on the 'full day pattern' modeling approach, there are slightly different modes, availability settings, and more detail for discretionary (recreation, civic, and social activities) and maintenance (shopping, errands) type activities; the model also uses a sample enumeration where one household is modeled and expanded to represent some target number from the population. The overall models/analytical tool suite (shown on the right) aims to integrate models and support local officials in evaluating transportation, growth management, environment, quality of life, equity, finance, and economic prosperity. The proposed new activity model, aims to also address health and distributional impact measures, to prioritize projects regionwide. The models are implemented using a combination of $\mathrm{R}$, EMME/2, and a 32 node Linux cluster (with 28 nodes dedicated to TRANSIMS).

\begin{tabular}{|c|c|c|c|}
\hline \multicolumn{4}{|l|}{ INPUTS } \\
\hline $\begin{array}{l}\text { Socio-Demographic } \\
\text { Data }(2010)\end{array}$ & $\begin{array}{l}\text { Road } \\
\text { Network } \\
\text { (xxxx) }\end{array}$ & 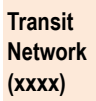 & $\begin{array}{l}\text { Land Use } \\
(2010)\end{array}$ \\
\hline
\end{tabular}

Jeff Frkonja, Research Center Director, Oregon Metro

Peter Bosa, Senior Researcher and Modeler, Oregon Metro

Robert Kirkman / Dick Walker (Travel Forecasting Mgr.)

\section{OUTPUTS}

\begin{tabular}{|c|c|c|c|}
\hline $\begin{array}{l}\text { Automobile } \\
\text { Operating } \\
\text { Costs (xxxx) }\end{array}$ & 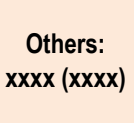 & $\begin{array}{l}\text { Temporal } \\
\text { Resolution }\end{array}$ & $\begin{array}{c}\text { Continuous } \\
\text { Simulation: } \\
\text { every } 6 \\
\text { seconds }\end{array}$ \\
\hline
\end{tabular}

\section{BENEFITS}

Models more discretionary and maintenance activities

Detailed bicycle model and benefit-cost analysis model

64 household categories; by size, income, age, employment
Metro

\section{Bicycle modeling tool}

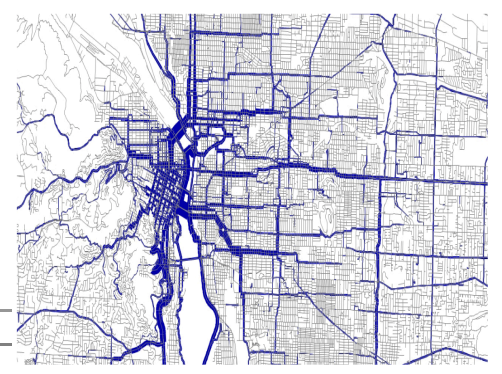

\section{MODEL PROCESS FLOW CHART}

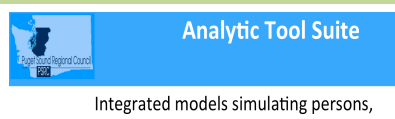

(n)

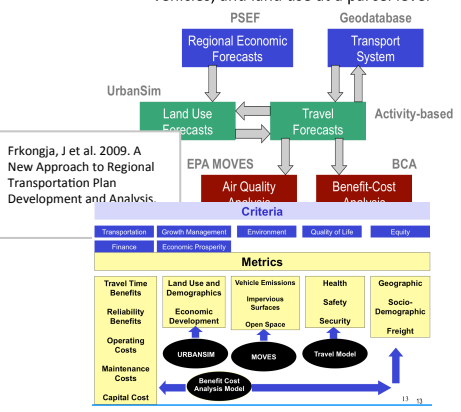

\section{RELATED PROJECTS}

Regional Transportation Plan (Destination 2030)/ 2040 Growth Concept Plan

http://www.oregonmetro.gov/public-projects/2018regional-transportation-plan

\section{RELATED MODELS}

Urban Sim and MetroScope (tests public policies and provides data for travel models)

MOVES emissions model
DynusT and Dynameq Models)

\section{Output 1. Person trip tables by district and by trip \\ Files 2. Highway, transit travel times and speeds \\ Generat 3. Link flows and transit assignment results by ed Time of day}

\section{LIMITATIONS}

Concerns on cross-sectional data collection

Low overall response rates to surveys

Income-specific non-response bias in surveys

\section{KEY DATA RESOURCES}

https://gis.oregonmetro.gov

https://www.portlandoregon.gov/28130 


\section{Pittsburgh: SPC Regional Travel Demand Model}

The SPC Regional Travel Model is a four-step travel demand model and is updated in 2015 using the 1997 Travel Survey.

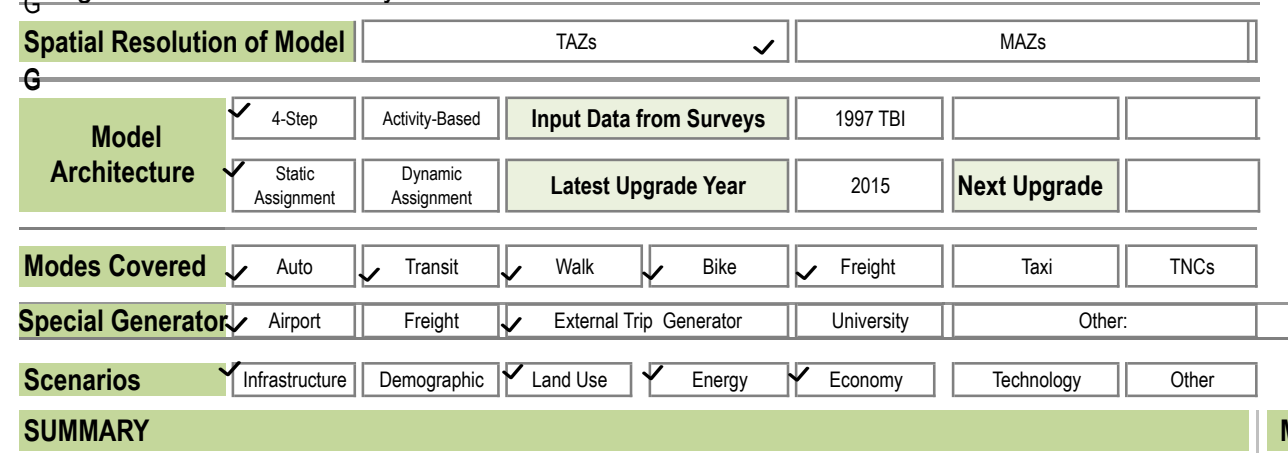

The Southern Pennsylvania Commission (SPC) [ ] model, was updated in 2015 and based on data from the 1997 Travel Behavior Inventory Survey. The model focuses on the 10-county region, with a highway network consisting of 1,150 Traffic Analysis Zones. The model is developed using TP+ software package.

\begin{tabular}{|c|c|c|c|c|c|c|c|c|c|}
\hline \multicolumn{6}{|l|}{ INPUTS } & \multicolumn{4}{|l|}{ OUTPUTS } \\
\hline $\begin{array}{l}\text { Socio- } \\
\text { Demographic Data } \\
(1997)\end{array}$ & 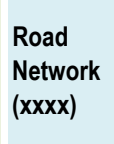 & $\begin{array}{l}\text { Transit } \\
\text { Network } \\
(\mathbf{x x x x )}\end{array}$ & $\begin{array}{l}\text { Land Use } \\
\text { (xxxx) }\end{array}$ & $\begin{array}{l}\text { Automobile } \\
\text { Operating } \\
\text { Costs (xxxx) }\end{array}$ & $\begin{array}{c}\text { Others: } \\
\mathbf{x x x x}(\mathbf{x x x x})\end{array}$ & $\begin{array}{l}\text { Temporal } \\
\text { Resolution }\end{array}$ & $\begin{array}{l}\text { Output } \\
\text { Files } \\
\text { Generat } \\
\text { ed }\end{array}$ & $\begin{array}{l}\text { 1) OD trip matrices by mode } \\
\text { Transit boardings }\end{array}$ & 2) \\
\hline \multicolumn{4}{|c|}{ MODEL KEY POINTS OF CONTACT \& REVIEWERS } & \multicolumn{3}{|l|}{ BENEFITS } & \multicolumn{3}{|c|}{ LIMITATIONS } \\
\hline \multicolumn{9}{|c|}{ Chuck Imbrogno (Models/Data Analysis Manager) } & \\
\hline \multicolumn{4}{|c|}{ RELATED PROJECTS } & \multicolumn{3}{|c|}{ RELATED MODELS } & \multicolumn{3}{|c|}{ KEY DATA RESOURCES } \\
\hline \multicolumn{4}{|c|}{$\begin{array}{l}\text { Analysis of propose service cuts to port authority of allegheny } \\
\text { county }\end{array}$} & \multicolumn{3}{|c|}{ MOVES 2014 emissions model } & \multicolumn{3}{|c|}{$\begin{array}{l}\text { Western Pennsylvania Regional Data Center } \\
\text { (http://www.wprdc.org/) }\end{array}$} \\
\hline
\end{tabular}




\section{SF: SFCTA 'SFChamp'- DTA Model}

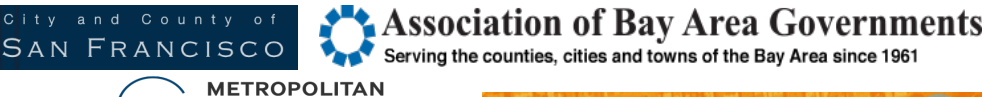

MT METROPOLITAN

M TRANSPORTATION

The SFCTA 'Chained Activity Modeling Process (known as SF-CHAMP) is a regional activity and tour-based, dynamic traffic assignment (DTA) travel demand model for the 9-county SF Bay area, initially built in 2001 using1999 State Preference Survey (calibrated using MTC's BATS 1990/1996 surveys; \& recalibrated in 2007+)

\begin{tabular}{|c|c|c|c|c|c|c|c|}
\hline \multicolumn{2}{|c|}{ Spatial Resolution of Model } & \multicolumn{3}{|c|}{ TAZs } & \multicolumn{3}{|c|}{ MAZs } \\
\hline \multirow{2}{*}{ Model Architecture } & 4-Step & Activity-Based & \multicolumn{2}{|c|}{ Input Data from Surveys } & $\begin{array}{c}2012 \text { CA HH } \\
\text { Travel Survey }\end{array}$ & 2013 Transit Survey & 2013 counts \\
\hline & \begin{tabular}{|c|} 
Static \\
Assianment \\
\end{tabular} & \begin{tabular}{|c|} 
Dynamic $\checkmark$ \\
Assianment \\
\end{tabular} & \multicolumn{2}{|c|}{ Latest Upgrade Year } & 2007 & Next Upgrade & 2017 \\
\hline Modes Covered & Auto & Transit & $\checkmark \quad$ Walk & $\checkmark \quad$ Bike & $\checkmark$ Freight & Taxi & TNCs \\
\hline Special Generator & Airport $\checkmark$ & Freight & $\checkmark$ Intern & $\begin{array}{l}\text { xternal Trip } \\
\text { erator }\end{array}$ & University & & \\
\hline
\end{tabular}

\begin{tabular}{|c|c|c|c|c|c|c|c|}
\hline Scenarios & Infrastructure & Demographic & Land Use' & Energy $\checkmark$ & Economy & Technology & Other \\
\hline
\end{tabular}

The SF CHAMP activity-based model, is the longest running activity based model in the world. It was developed in 2001 and based on data from a 1999 Stated Preferences Surveys coupled with the MTC's BATS 1990 and 1996 surveys (when no onboard transit survey data was avaialble). A 2004 recalibration was undertaken to account for a new transit onboard surveyin 2004 (with support from the FTA New Starts application). In 2006, comparisons were made with the MTC's BAYCAST model and SF-CHAMP model, to harmonize travel demand modeling efforts and address inconcensistencies in non-motorized trips and trip generation rates, especially in forecast years. The Model refresh and recalibration efforts began in 2006/7, using the MTC home-interview survey and 2004 onboard transit OD survey. Based on Atlanta (ARC) methods, using 2000/2010 Census/ACS Data, SFCTA and MTC did a joint update, with now over 981 zones in SF alone, and 350 new zones in non-SF Bay Area counties, with population synthesis going from 110 classes to almost 600 classes. With the current Bay Area model maintained by MTC not meeding local SFCTA needs, the latest version of SF Champ 5 aims to help local officials evaluate the SF transportation plan, fleet plans, waterfront trasnrpotation alaysis, transit core capacity, congestion pricing, climate action strategies and inventories, feasibility studies, alternatives analysis, EIS, and public health analysis. The SF Champ model has a model consistency report released every 2 years together with MTC/ABAG's BAYCAST model. Software used includes UrbanSim/OPUS (for land use), Citliabs Cube, 3.1 C++, Java, ESRI ArcMap for GIS mapping. When first created, the model ran on one PC in 26 hours; then 3 PCs in parallel running in less than 10 hours, with modeling speeds now at 1-2 hours to 1 day. Model upgrades are ongoing, with DTA starting in 2012.

\begin{tabular}{|c|c|c|c|c|c|c|c|}
\hline \multicolumn{6}{|l|}{ INPUTS } & \multicolumn{2}{|l|}{ OUTPUTS } \\
\hline $\begin{array}{l}\text { Socio-Economic Data } \\
\text { (2010 Census) }\end{array}$ & $\begin{array}{l}\text { Road } \\
\text { Network } \\
\text { (2013) }\end{array}$ & $\begin{array}{l}\text { Transit } \\
\text { Network } \\
\text { (2014) }\end{array}$ & $\begin{array}{l}\text { Land Use } \\
\text { (2010) }\end{array}$ & $\begin{array}{c}\text { Parking } \\
\text { Costs (2009) }\end{array}$ & $\begin{array}{l}\text { Others: } \\
\text { Household, } \\
\text { Job, School } \\
\text { Points }\end{array}$ & $\begin{array}{l}\text { Temporal } \\
\text { Resolution }\end{array}$ & $\begin{array}{c}5 \text { daily time } \\
\text { periods }\end{array}$ \\
\hline \multicolumn{4}{|c|}{ MODEL KEY POINTS OF CONTACT \& REVIEWERS } & \multicolumn{4}{|l|}{ BENEFITS } \\
\hline
\end{tabular}

SF Travel Model: Joe Castiglione / Dan Tischler / Billy Charlton

Urban Sim: Paul Waddell / Mike Reilly

UrbanSim \& SF-Champ synchronize every 5 years (since 2007)

\section{RELATED PROJECTS}

SF-Champ has been used to links with other Microsimulation tools (e.g. Syncho - for optimal signal timinas based on road volumes) \& VISSIM (for transit

http://www.sfcta.org/sites/default/files/content/Pla nning/DataMart/trb\%202007\%20-\%20sfchamp\%20in\%2015\%20minutes.pdf
Fine-grained spatial detail (every street in the city)

Run times: now takes just a few hours

Realistic tour purposes (work, work-based, scholo, other)

\section{RELATED MODELS}

Urban Sim (base development patters, future land use, zoning regulations, detailed employment forecasts)

MTC/ABAG Baycast Travel Demand Model:

http://www.sfcta.org/sites/default/files/conten t/Planning/CongestionManagementPlan/cha pter\%2010\%20-

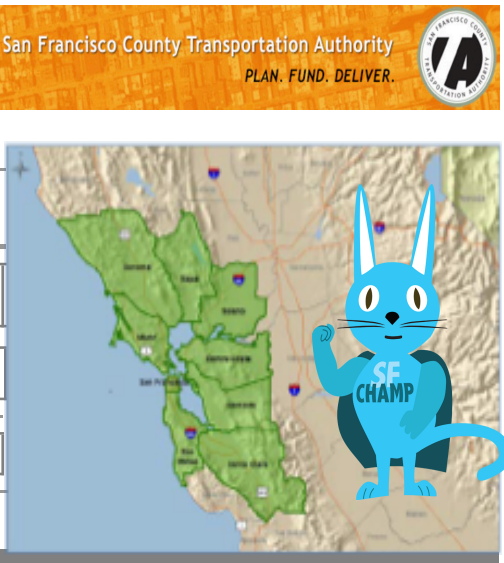

Fury, the SF-CHAMP Mascot

\section{MODEL PROCESS FLOW CHART}

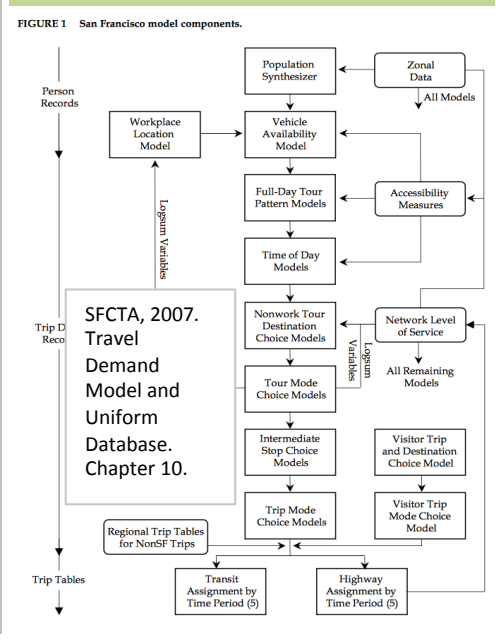

\section{Output 1. Trip Matrices; \\ Files 2. Link flows by time of day; \\ Generat 3. Boardings by transit route; \\ ed 4 . Highway, transit, walk and bike skims}

LIMITATIONS

Big models require significant maintenance/updates

TNC data still lacking in model VMT estimates

Doesn't model non-motorized assignment

\section{KEY OPEN DATA RESOURCES}

https://data.sfgov.org/Transportation/Vehicle. Miles-Traveled-Estimates-from-SF-CHAMP201/q4ve-s75w/data

https://datasf.org/opendata/

http://www.sfcta.org/tncstoday 


\section{Denver: DRCOG FOCUS, Travel Model}

The current DRCOG activity-based model for the Denver metropolitan region was built using the 1997 Travel Behavior Inventory (TBI) Survey and calibrated using 2005 input datasets.

\begin{tabular}{l|l|l|l|l|l|l|}
\hline Spatial Resolution of Model & \multicolumn{3}{|c|}{ TAZs } \\
\hline $\begin{array}{l}\text { Model } \\
\text { Architecture }\end{array}$
\end{tabular}

The Denver Regional Council of Governments (DRCOG) activity-based model, known as the Focus model, was developed after 2005 and based on data from the 1997 Travel Behavior Inventory Survey. The TBI survey work was conducted in 1997-1998, with data "cleaning" and summary conducted through 2001. Focus was calibrated using 2005 input datasets, including roadway/traffic counts, transit boardings, American Community Survey data, and Census data; a 2008 RTD transit survey and 2010 Household Travel Survey (HHTS). Based on Sacramento's activity-based model, the model forecasts typical weekday activity travel patterns of synthetic individuals. The model aims to help local officials, the Colorado Department of Transportation and Regional Transportation District (RTD) evaluate transportation improvements and provides data for tailpipe emission modeling for region conforming to federal air quality regulations. Focus incorporates information from various sources to estimate current and future roadway traffic volumes and transit ridership. The Focus model requires a free GitHub Account, powerful server/workstation, and three pieces of software: Microsoft SQL Server 2008 or later ; Microsoft Visual Studio 2012 or later; and TransCAD 6.0.

\section{INPUTS}

\begin{tabular}{|c|c|c|}
\hline $\begin{array}{l}\text { Socio-Demographic } \\
\text { Data (2010) }\end{array}$ & $\begin{array}{l}\text { Road } \\
\text { Network } \\
\text { (xxxx) }\end{array}$ & $\begin{array}{l}\text { Transit } \\
\text { Network } \\
(\mathbf{x x x x})\end{array}$ \\
\hline
\end{tabular}

\section{MODEL KEY POINTS OF CONTACT \& REVIEWERS}

DRCOG Travel Model: Yali Li, Scott Remming, Steve Cook

Urban Sim: Daniel Jerett

PopSyn: XX

\section{RELATED PROJECTS}

CDOT is developing an activity-based, statewide travel model, extending DRCOG Focus model to the entire State

https://www.codot.gov/programs/planning/documents/sta c-archives/2016-stac/may2016stac/statewide-travelmodel-stac-may2016

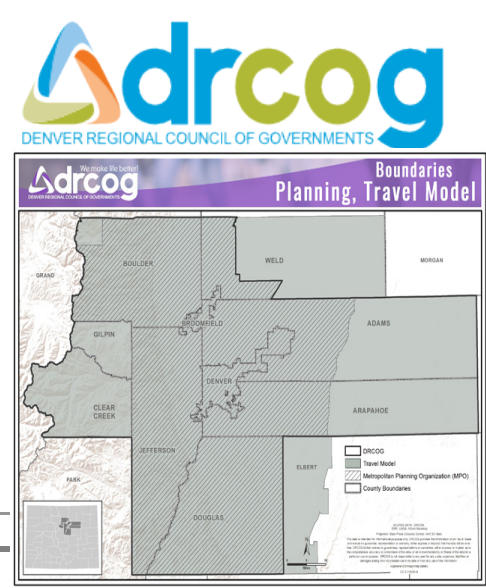

\section{MODEL PROCESS FLOW CHART}

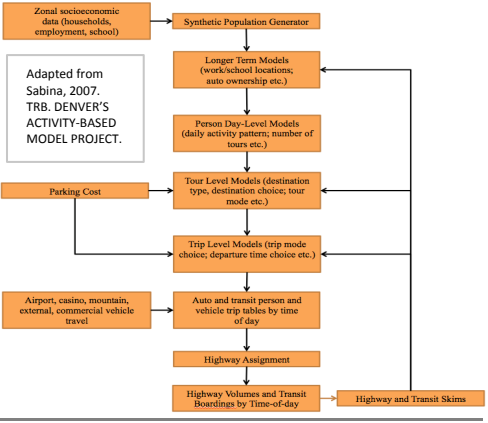

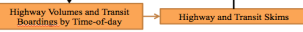

\section{OUTPUTS}

\begin{tabular}{c|c|l|c}
$\begin{array}{c}\text { Automobile } \\
\text { Operating }\end{array}$ & $\begin{array}{c}\text { Others: } \\
\text { Costs (xxxx) }\end{array}$ & $\begin{array}{l}\text { Temporal } \\
\text { xxxx (xxxx) }\end{array}$ & $\begin{array}{c}10 \\
\text { Resolution }\end{array}$ \\
& & time \\
periods
\end{tabular}

\section{BENEFITS}

Models more individual characteristics (vs. 4-Step Models)

Run times: from one week to run; now takes just a few hours

\section{KEY OPEN DATA RESOURCES}

www.drcog.org/services-and-resources/data-maps-

Urban Sim (base development patters, future land use, zoning regulations, detailed employment forecasts)

PopSyn (Population Synthesizer)

MOVES/MOBILE6.2 emissions models and the DRCOG Compass trip-based model
Doesn't model non-motorized assignment and-modeling/gis-maps

Output 1. Trip Matrices by time of day for auto

Files occupancy and transit mode;

Generat \begin{tabular}{l|l} 
2. Link flows by time of day; \\
3. Boardings by transit route;
\end{tabular}

ed $\quad$ 4. Highway, transit, walk and bike skims

\section{LIMITATIONS}

Doesn't model vehicle type choice and allocation

http://gis.drcog.org/datacatalog/ 


\section{Kansas City: Mid-America Regional Council (MARC) Travel Demand Model}

A four-step travel demand model developed (and recently enhanced) by MARC using a 2013 Travel Time Study conducted in the region.

\begin{tabular}{|c|c|c|c|c|c|}
\hline Spatial Resolution of Model & & TAZs & \multicolumn{3}{|c|}{ MAZs } \\
\hline \multirow{2}{*}{$\begin{array}{c}\text { Model } \\
\text { Architecture }\end{array}$} & Activity-Based & Input Data from Surveys & 2013 & 2005 Transit Sur. & 2009-13 ACS \\
\hline & $\begin{array}{c}\text { Dynamic } \\
\text { Assignment }\end{array}$ & Latest Upgrade Year & 2015 & Next Upgrade & $?$ \\
\hline Modes Covered & Transit & Walk & Freight & Taxi & TNCs \\
\hline Special Generator $Y$ Airport & Freight & External Trip Generator & University & \multicolumn{2}{|c|}{ Other: } \\
\hline Scenarios & Demographic & $\checkmark$ Energy & Economy & Technology & Other \\
\hline \multicolumn{6}{|l|}{ SUMMARY } \\
\hline
\end{tabular}

The MARC travel demand model is a population-level model used to assess future transportation needs in the Kansas City metropolitan area, implemented in the Emme transportation modeling framework from INRO Software. The model covers 3,849 square miles, encompasses 951 Transportation Analysis Zones (TAZs) and 30 external stations, and includes 30,438 transportation segments and 15,204 nodes. It includes major transit systems and roads from the minor collector street level up to freeways, but does not cover most local roads. The model generates trips using a cross-classification model based on income, household size, and auto availability. MARC predicts transportation mode choice using a separate nested logit model implemented in Fortran, which incorporates results of a 2005 onboard transit survey. Model inputs come from MARC forecasts of future land use at the parcel level, which are based on predicted population and economic growth and past patterns of land development. The overall model outputs travel times, delay times, volumes, and volume-capacity ratios for each transportation segment at one-hour intervals over a representative 24-hour period.

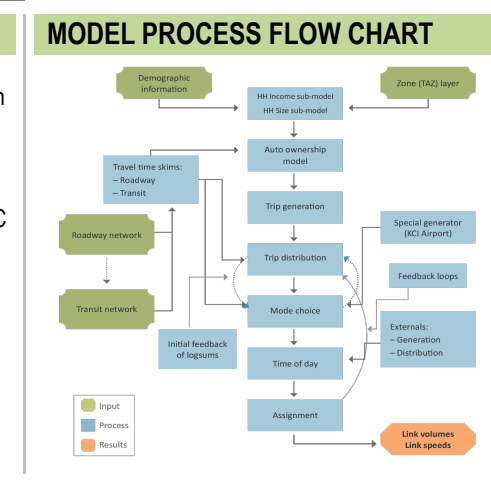

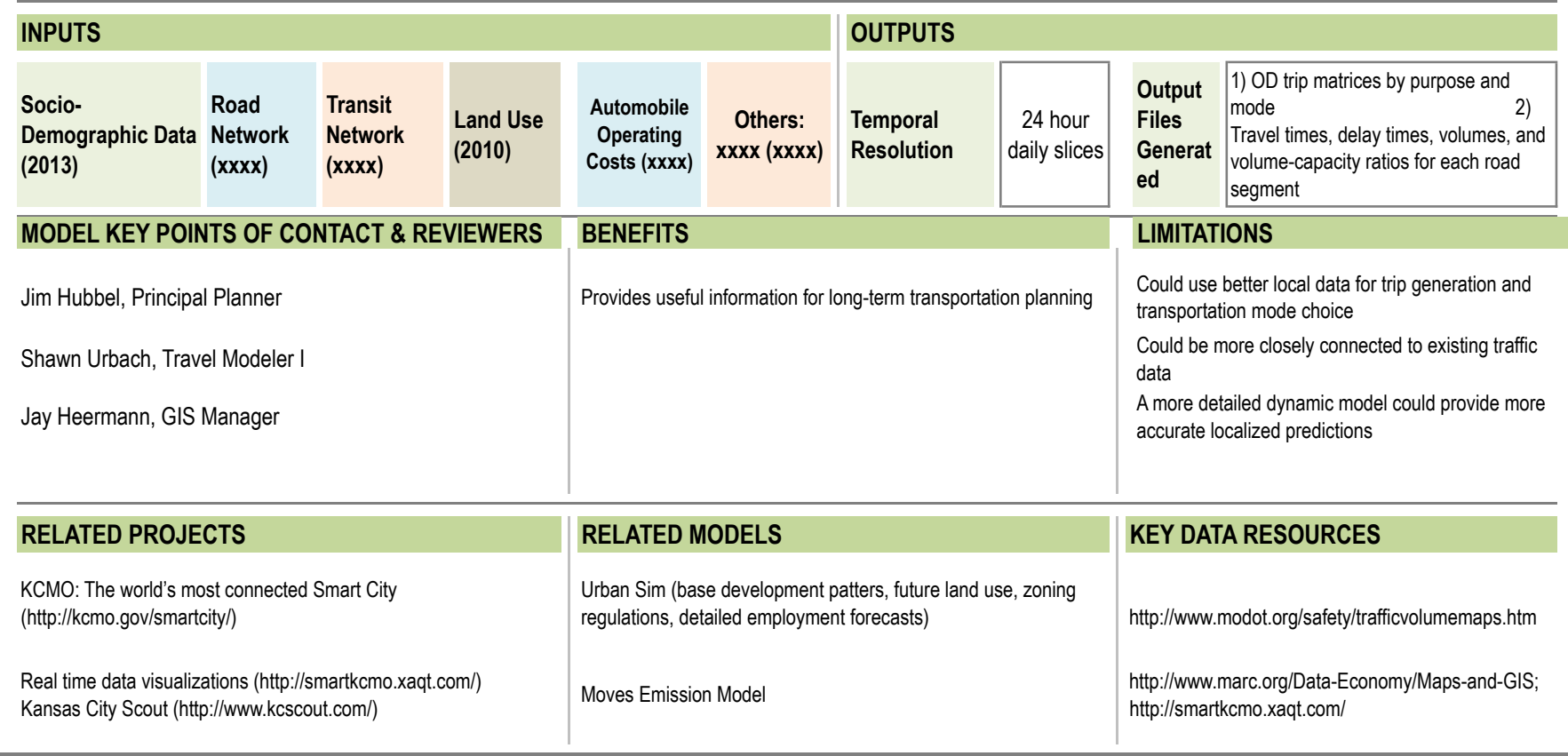




\section{Austin: Capital Area Metropolitan Planning Organization (CAMPO) Model}

The CAMPO regional transportation model is a combination of planning and modeling tools, including the travel demand model, utilities and other functions.

\begin{tabular}{|c|c|c|c|c|c|c|}
\hline Spatial Resolution of Model & & TAZs & $\checkmark$ & \multicolumn{3}{|c|}{ MAZs } \\
\hline \multirow{2}{*}{$\begin{array}{l}\text { Model } \\
\text { Architecture }\end{array}$} & Activity-Based & \multicolumn{2}{|c|}{ Input Data from Surveys } & \multicolumn{2}{|c|}{2010 Census Data } & 2010 HHTS \\
\hline & $\begin{array}{c}\text { Dynamic } \\
\text { Assignment }\end{array}$ & \multicolumn{2}{|c|}{ Latest Upgrade Year } & 2010 & Next Upgrade & $? ?$ \\
\hline Modes Covered $\sqrt{ }$ Auto & $\checkmark$ Transit & $\checkmark \quad$ Walk & $\checkmark \quad$ Bike & $\checkmark$ Freight & Taxi & TNCs \\
\hline Special Generator Airport & $\checkmark$ Freight & \multicolumn{2}{|c|}{ Mnternal / External Trip Generator } & $\checkmark$ University & \multicolumn{2}{|c|}{$\checkmark \quad$ Other: Hospital/Prison } \\
\hline Scenarios & Demographi & Land Use & Energy & Economy $\checkmark$ & Technology & Other \\
\hline
\end{tabular}

The Capital Area Metropolitan Planning Organization (CAMPO) regional transportation model is a combination of planning and modeling tools, including the travel demand model, utilities and other functions. The CAMPO travel demand model is an advanced, aggregate four-step model built using the TransCAD software. The Planning Model has 2,102 internal and 59 external stations for a total of 2,161 zones. The zone geography covers the full extent of Burnet, Bastrop, Caldwell, Hays, Travis, and Williamson Counties. The model is programmed $100 \%$ in the TransCAD scripting language-Geographic information systems Developer's Kit (GISDK). The current 2010/2040 model is calibrated to a 2010 household survey and 2010 census data. The CAMPO model includes a planning-level static user equilibrium traffic assignment that can be run for different time periods (AM Peak, Mid-day, PM Peak, and Night).
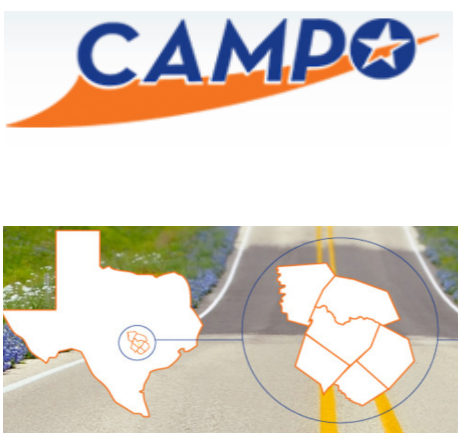

The CAMPO model region covers the full extent of Burnet, Bastrop, Caldwell, Hays, Travis, and Williamson Counties.

\section{MODEL PROCESS FLOW CHART}

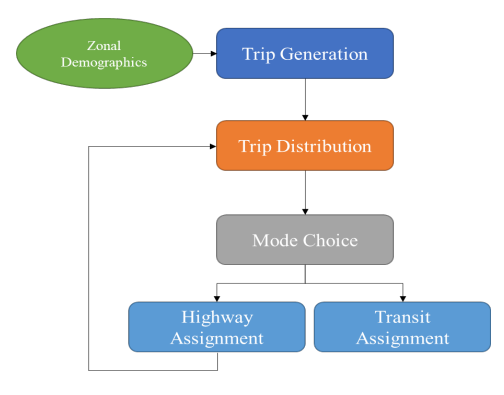

\section{INPUTS}

\begin{tabular}{l|l|l|l|}
\hline $\begin{array}{l}\text { Socio- } \\
\text { Demographic Data } \\
\text { (2010) }\end{array}$ & $\begin{array}{l}\text { Road } \\
\text { Network } \\
\text { (xxxx) }\end{array}$ & $\begin{array}{l}\text { Transit } \\
\text { Network } \\
\text { (xxxx) }\end{array}$ & $\begin{array}{l}\text { Land Use } \\
\text { (2010) }\end{array}$ \\
\hline
\end{tabular}

\section{MODEL KEY POINTS OF CONTACT \& REVIEWERS}

Jeff Shelton (TTI): J-Shelton@tti.tamu.edu

Thomas William (TTI) t-williams@tti.tamu.edu

\section{RELATED PROJECTS}

In addition to the travel demand model, researchers at TTI developed a simulation-based DTA model of the entire modeled CAMPO region.

Austin DTA model has been linked to Metropia-a mobile based platform which employs gamification and behavioral strategies to influence travelers to make more informed personal mobility decisions

\begin{tabular}{|c|c|c|c|}
\hline & & OUTPUTS & \\
\hline $\begin{array}{l}\text { Automobile } \\
\text { Operating } \\
\text { Costs (xxxx) }\end{array}$ & 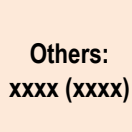 & $\begin{array}{l}\text { Temporal } \\
\text { Resolution }\end{array}$ & $\begin{array}{l}\text { AM Peak, } \\
\text { Mid-day, } \\
\text { PM Peak, } \\
\text { and Night }\end{array}$ \\
\hline
\end{tabular}

Detailed classification of trip purposes

Specific treatment of auto availability in the mode choice set

Accounting for the cost of tolls in route assignment

\section{RELATED MODELS}

MOVES: The DTA platform developed by TTI is linked to MOVES analyze multiple greenhouse gas pollutants

\begin{tabular}{l|lr|}
\cline { 2 - 2 } Output & 1. Trip Matrices by time of day for auto and \\
Files & transit modes; & 2. \\
Generat & Link flows by time of day; & 3. \\
ed & Boardings by transit route; \\
\hline
\end{tabular}

\section{LIMITATIONS}

Lack of linkage between non-home based trip making and other trip purposes

Aggregate treatment of time - four fixed periods

Aggregate treatment of trip making at the household level

\section{KEY OPEN DATA RESOURCES}

http://gis-txdot.opendata.arcgis.com/

https://www.datarodeo.org/ 


\section{AUSTIN

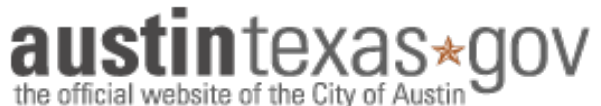

\begin{tabular}{l|l|l|l|}
\hline State of Open Data: & City: 2107 Datasets (28 on Mobility) & $\begin{array}{c}\text { CAMPO: traftic counts, population, employment, } \\
\text { safety, congestion, maps }\end{array}$ & TXDOT: 244 data sets \\
\hline
\end{tabular}

Data Profile

Existing Regional Data Sharing Efforts:

\section{CAMPE}

https://www.campotexas.org/

\section{data.austintexas *gov}

https://data.austintexas.gov/

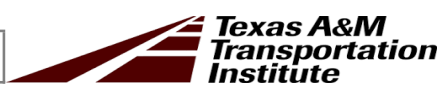

https://tti.tamu.edu/tti-austin/

Fit

http://gis-txdot.opendata.arcgis.com/ data.texas.gov 3

\section{Open Austin CapMetrics Sample}
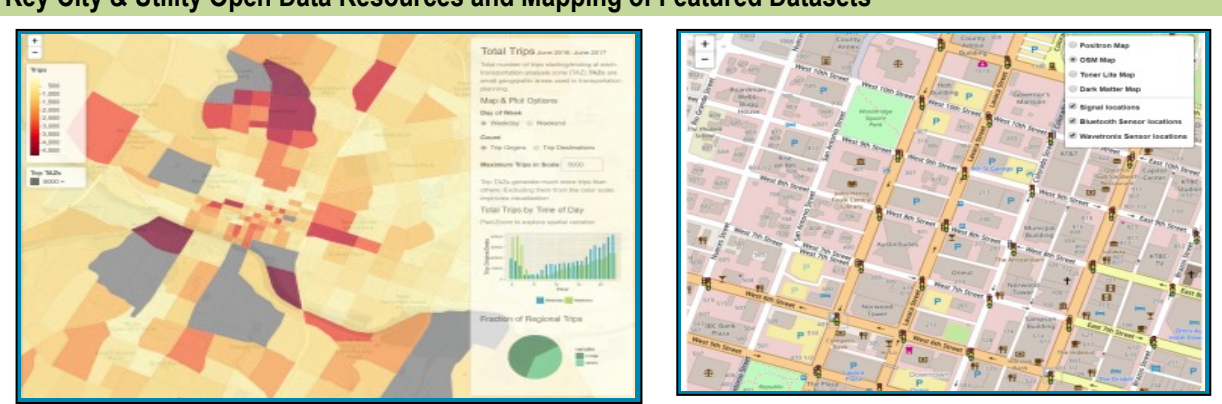

https://nmc-data.shinyapps.io/rideaustinapp/ \& http://shiny.utnmc.org/Data_Rodeo_Shiny_Sensor_Locations_App/

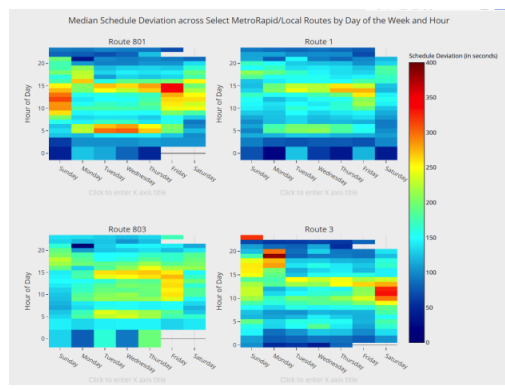

https://www.open-austin.org/projects/capmetrics.html

\section{City Profile}
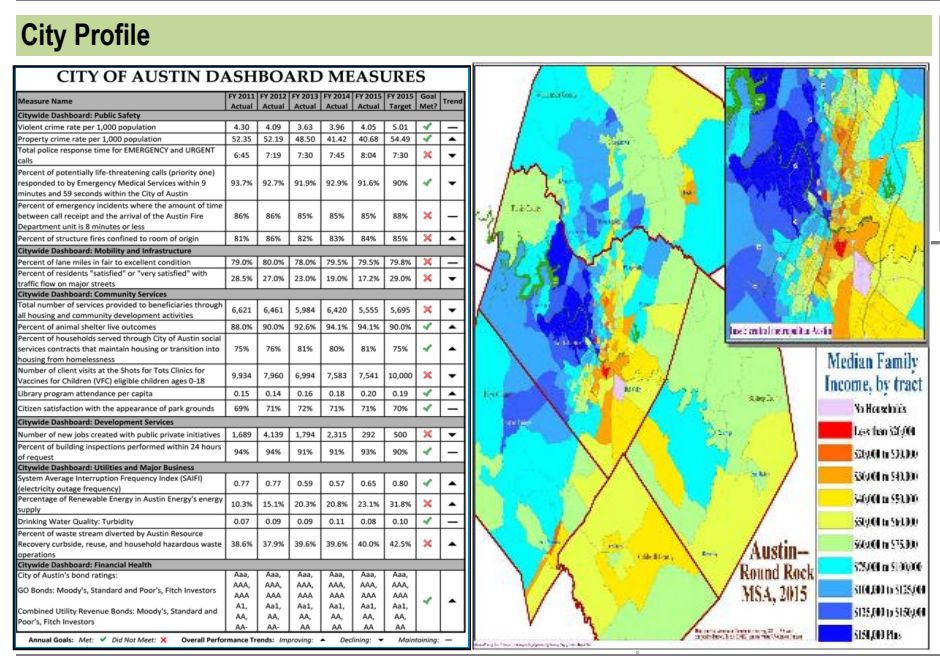

Smart City-Related Priorities for Moving Forward with Data Resources:

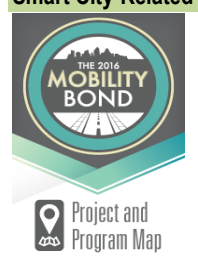

The 2016 Mobility Bond is putting Austin In Motion --Austin voters approved $\$ 720$ million in bond last year for transportation and mobility improvements throughout the city.

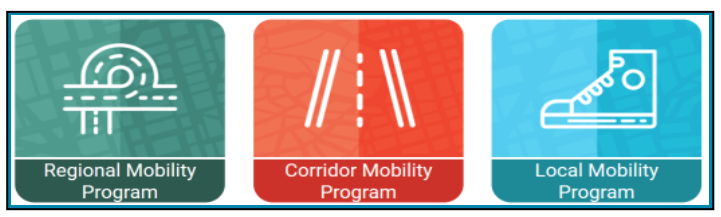

\section{Transportation-Specific}

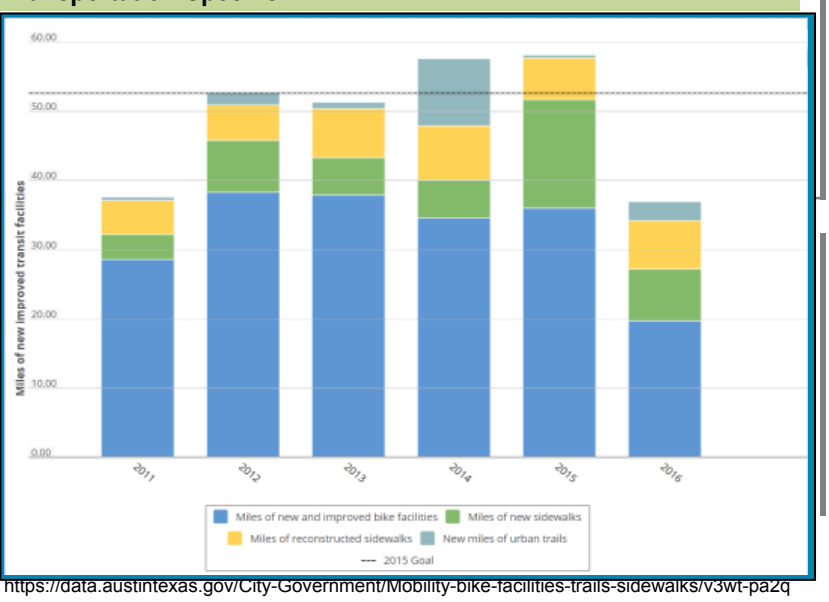

Smart City-Related Questions and New Datasets Under Development

The City of Austin has set its sights set on becoming a "Smart City" -- one that uses cutting-edge technology to address mobility, safety, equity and environmental challenges for all its residents. Austin's Smart City array of technology solutions and applications was developed by a regional partnership with Capital Metro, the Texas Department of Transportation (TXDOT), Austin Energy, the University of Texas, the Texas A\&M Transportation Institute, the Southwest Research Institute, the Central Texas Regional Mobility Authority (CTRMA) and the Rocky Mountain Institute. This team was augmented by numerous

community and private sector partners. https://austintexas.gov/department/smart-city 


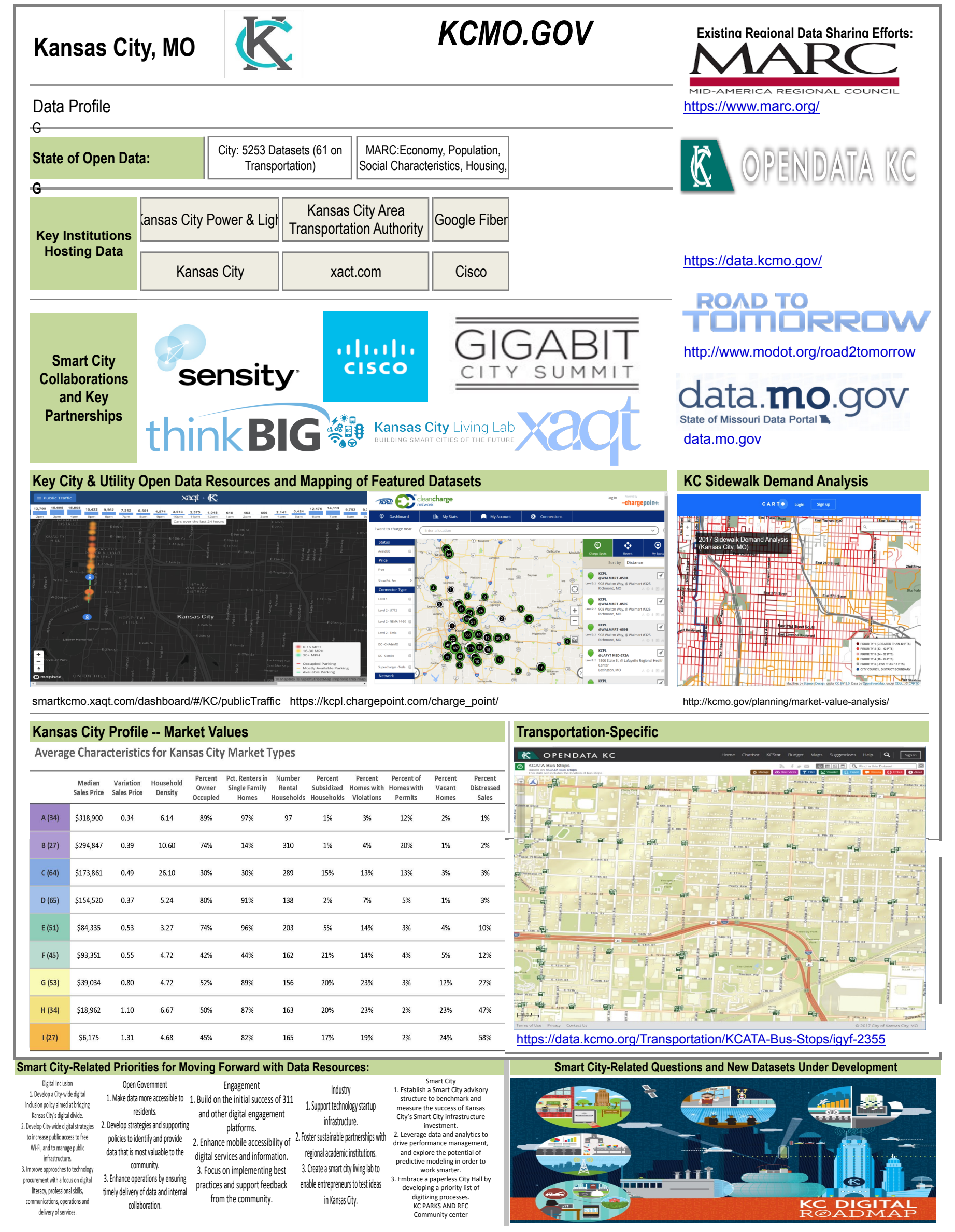




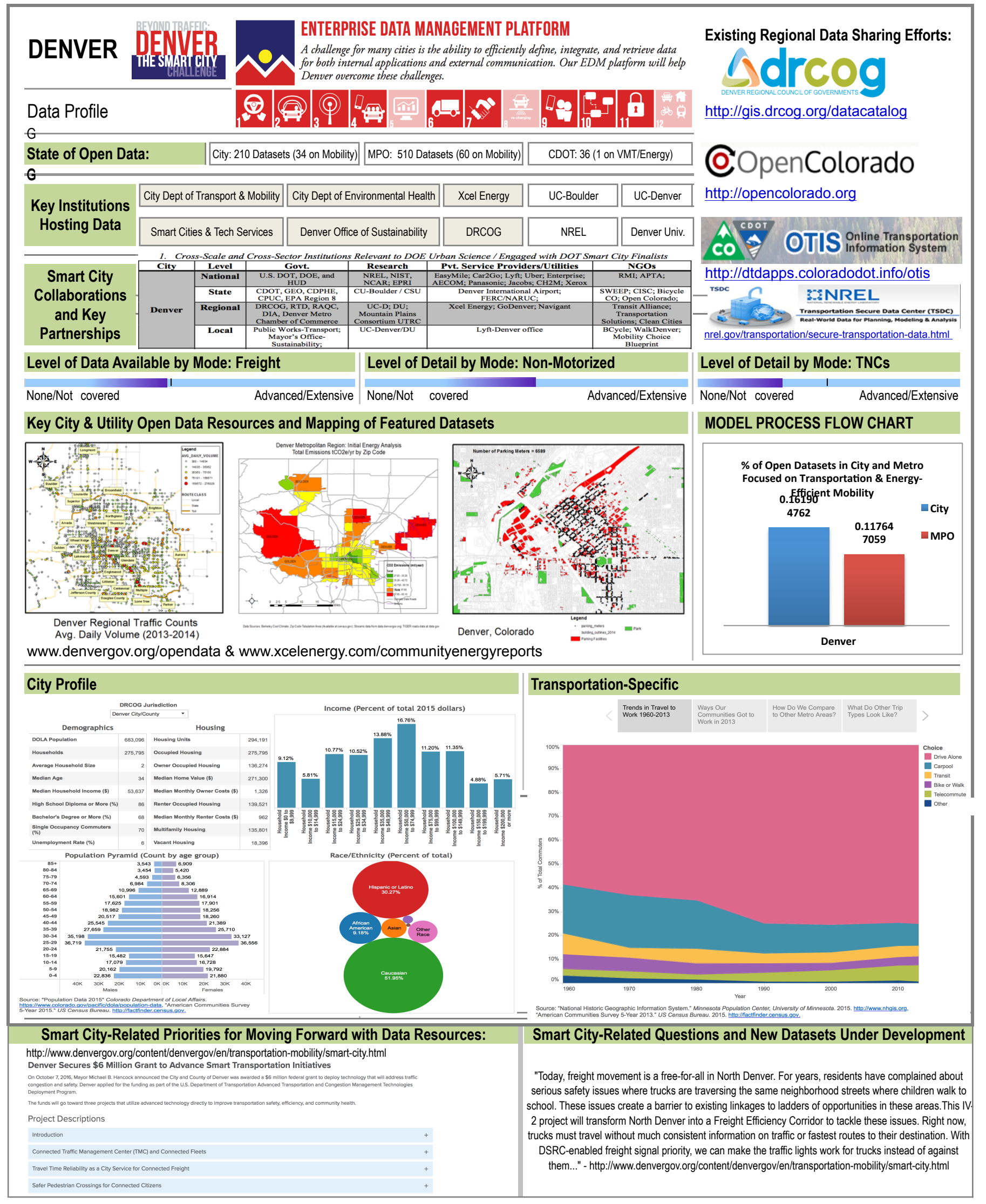



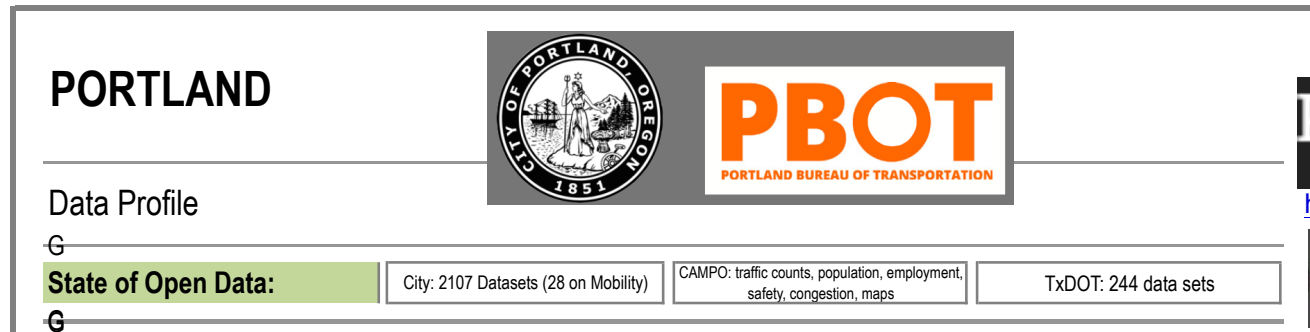

\begin{tabular}{l|c|c|c|c|}
\hline \multirow{3}{*}{$\begin{array}{l}\text { Key Institutions } \\
\text { Hosting Data }\end{array}$} & Austin Energy & City of Austin Mobility Department & TTI & State of Texas \\
\cline { 2 - 3 } & Rocky Mountain Institute & $\begin{array}{c}\text { Center for Transportation } \\
\text { Research, UT Austin }\end{array}$ & TxDOT & $\begin{array}{c}\text { City of Austin Transportation } \\
\text { Department }\end{array}$ \\
\hline
\end{tabular}

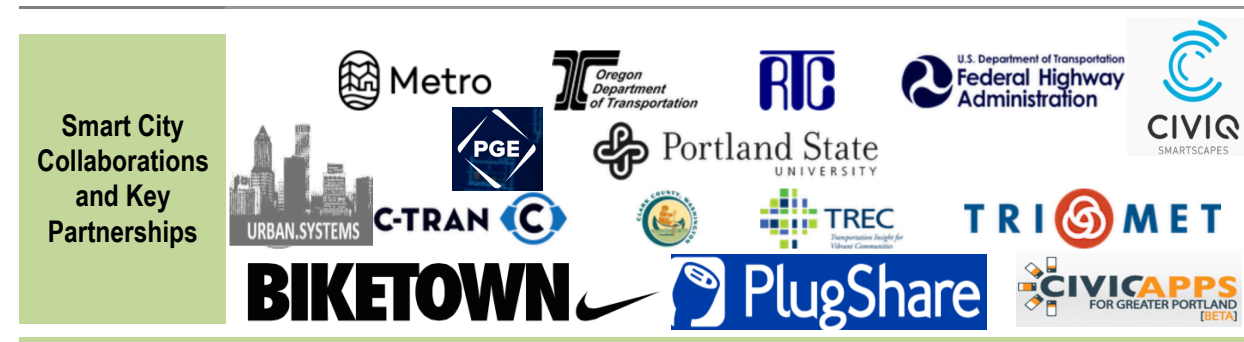

Key City \& Utility Open Data Resources and Mapping of Featured Datasets

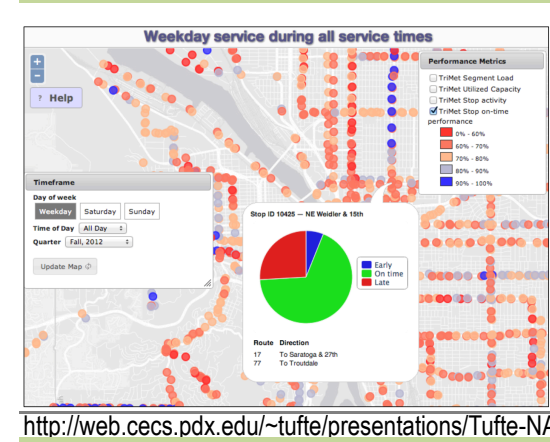

http://web.cecs.pdx.edu/
Table 7: Electric Mass Transit 2.0 Estimated Budget, $(\$, 000)$

\begin{tabular}{|c|c|c|c|c|c|c|c|c|}
\hline $\begin{array}{l}\text { Cost } \\
\text { Element }\end{array}$ & 2017 & 2018 & 2019 & 2020 & 2021 & 2022 & 2023 & 2024 \\
\hline Capital Carrying Costs & $\$ 141$ & $\$ 132$ & $\$ 121$ & $\$ 111$ & $\$ 103$ & $\$ 95$ & $\$ 88$ & $\$ 81$ \\
\hline O\&M Expenses & $\$ 79$ & $\$ 80$ & $\$ 82$ & $\$ 84$ & $\$ 85$ & $\$ 87$ & $\$ 89$ & $\$ 91$ \\
\hline Tax Credits & $|\$ 63|$ & $(\$ 63)$ & $(\$ 31)$ & (\$31) & $(\$ 31)$ & - & - & - \\
\hline Total Rev. Requirement & $\$ 157$ & $\$ 150$ & $\$ 172$ & $\$ 164$ & $\$ 157$ & $\$ 183$ & $\$ 177$ & $\$ 171$ \\
\hline Est. Customer Payments & $\$ 79$ & $\$ 80$ & $\$ 82$ & $\$ 84$ & $\$ 85$ & $\$ 87$ & $\$ 89$ & $\$ 91$ \\
\hline Net Costs & $\$ 78$ & $\$ 70$ & $\$ 89$ & $\$ 80$ & $\$ 72$ & $\$ 95$ & $\$ 88$ & $\$ 81$ \\
\hline
\end{tabular}

Existing Regional Data Sharing Efforts:

Portland Maps
Open Data
http://gis-pdx.opendata.arcgis.com

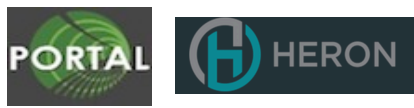

https://portal.its.pdx.edu/downloads

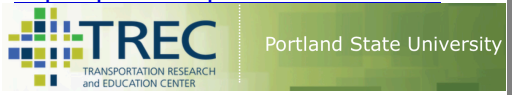

htth://trec.odx.edu

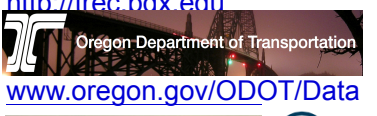

www.oregon.gov/ODOT/Data

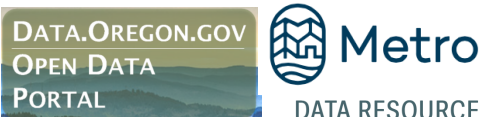
PORTAL

DATA RESOURCE

https://data.oregon.gov CENTER oregonmetro.gov/tools-partners/data-resource-center

UB Mobile Open Data Cloud Framework

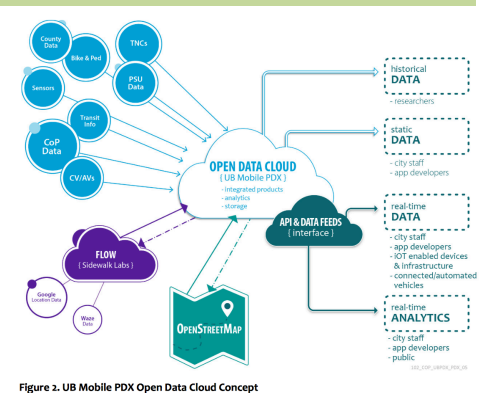

Figure 2. UB Mobile pox open Data cloud concept
WWW.portlandoregon. gov/transportation/article/579820

\section{PORTAL is the official transportation data archive for the Portland-Vancouver Metropolitan region.}

PORTAL provides a centralized, electronic database that facilitates the collection, archiving, and sharing of data and information for public agencies within the region. The data stored in Portal includes 20-second granularity loop detector data from freeways in the Portland-Vancouver metropolitan region, arterial signal data, travel time data, weather data, incident data, VAS/VMS message data, truck volumes, transit data, and arterial signal data. Many of these data feeds are received by PORTAL in real time or on a daily basis and for most, the retrieval and archiving process is fully automated.

PORTAL's multi-modal transportation data archive aims to support Metro's Regional Transportation Plan, the production of regional performance measures, support for regional transportation agencies and their consultants, and researchers at Portland State and elsewhere. Project objectives include producing tools and performance measures useful to local transportation professionals, exploring new and innovative uses of the data, and making the PORTAL data and system more accessible to agency personnel.

PORTAL is currently supported by funding from Metro, the Southwest Washington Regional Transportation Council (RTC), and the Transportation and Research Consortium (TREC) at Portland State. In addition, PORTAL has received funding from the Federal Highway Administration (FHWA) and the National Science Foundation (NSF).

https://portal.its.pdx.edu

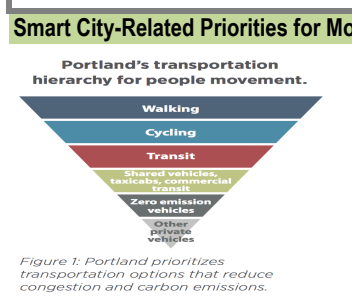

City \& PGE EV Strategy: www.portlandoregon.gov/bps/article/619275

Smart City-Related Questions and New Datasets Under Development

\section{Smart Charging and Time of Use (TOU) Rates}

Portland General Electric Transportation Electrification Plan, March 2017: "There is opportunity to engage our customers in the benefits of TOU rates as well as smart charging. Many EV drivers have the most to gain from a TOU rate, so we intend to make sure marketing collateral and technical assistance materials highlight these benefits. "Electric companies) need to offer well-formed TOU rates or other dynamic pricing to shift charging toward low-cost, off-peak hours; educate customers and vehicle dealers about the value proposition under these new rates; capture the potential value of EVs through controlled charging." http://www.rmi.org/Content/Files/RMI_Electric_Vehicles_as_DERs_Final_V2.pdf 